\title{
AVALIAÇÃO DO ÍNDICE DE PALMER PARA A CARACTERIZAÇÃo DE PERÍODOS DE SECA NO ESTADO DE SÃO PAULO
}

\section{ROSA MARIA NASCIMENTO DOS SANTOS}

Meteorologista

Orientador: Prof. Dr. ANTONIO ROBERTO PEREIRA

Dissertação apresentada à Escola Superior de Agricultura "Luiz de Queiroz", Universidade de São Paulo, para a obtenção do Título de Mestre em Agronomia, Área de Concentração: Agrometeorologia.

PIRACICABA

Estado de São Paulo - Brasil

Agosto, 1998 
(1) Na página 22, a equação 22 é escrita na forma: $X_{i}=\frac{n=1}{(3,420 i+2,317)}$

(2) Página 22, penúltima linha: leia-se "...n é o período (em meses), a partir do primeiro mês do intervalo seco avaliado."

(3) Na página 29 , Figura 5 , Gráfico $b$, no título do eixo das abcissas, onde se lê "MESES", leia-se "LOCALIDADES". 
Dados Internacionais de Catalogação na Publicação (CIP) DIVISÃO DE BIBLIOTECA E DOCUMENTAÇÃO - Campus "Luiz de Queiroz"/USP

Santos, Rosa Maria Nascimento dos

Avaliação do índice de Palmer para a caracterização de períodos de seca no

Estado de São Paulo / Rosa Maria Nascimento dos Santos. - - Piracicaba, 1998.

64 p. : il.

Dissertação (mestrado) - - Escola Superior de Agricultura Luiz de Queiroz, 1998.

Bibliografia.

1. Chuva 2. Climatologia 3. Condição seca 4. Efeito da seca 5. Estiagem 6. Meteorologia agrícola 7. Modelo matemático 8. São Paulo (Estado) 1. Titulo 
'No Final, tudo dá certo. Se ainda não está dando certo, é porque ainda não chegou o final!"

(Chico Adriano) 
À minha mãe, Vilma, e minha avó, Elza, por todo amor, carinho e compreensão, ao longo da minha vida, dando-me força e coragem para lutar por meus sonhos.

Ofereço.

Ao meu Amigo, Carlos Omena, pelo apoio e solidariedade, nos momentos difíceis, pela cumplicidade nos momentos de alegria e, pelo incentivo nos momentos de decisão. $\mathrm{E}$ ao amigo José Lima Filho, por ter me ensinado a "voar".

Dedico 


\section{AGRADECIMENTOS}

À Deus, por iluminar minha vida, mostrando-me sempre os melhores caminhos.

Ao Prof. Dr. Antonio Roberto Pereira, pela orientação, apoio e amizade, tão importantes durante o desenvolvimento deste trabalho.

Aos Professores do curso de Pós-graduação em Agrometeorologia da ESALQ/USP, Drs. Nilson Augusto Villa Nova, Valter Barbieri, Luiz Roberto Angelocci, Klaus Reichardt e Sérgio Morais, pelos ensinamentos que tanto contribuíram na minha formação profissional. E ao Prof. Dr. Paulo Libardi, chefe do Dep. de Física e Meteorologia, por prover as condições necessárias ao desenvolvimento deste trabalho.

Aos meus amigos, Juan Rojas e José Gabriel da Silva, pela amizade, carinho e companheirismo. E em especial, às minhas grandes amigas, irmãs, "Tias" e companheiras, Lucieta Martorano (Tia Luty) e Zilda Mariano (Tia Zilda), pela a amizade sincera, que as manteve sempre ao meu lado, nos bons e maus momentos.

As Amigas Ana Claudia Lira (My Love) e Cristina Lacerda (Lacerdinha), pela amizade sincera, carinho e apoio, que tornaram meus dias em Piracicaba mais felizes.

A todos os amigos e companheiros da Vila da Pós-graduação da ESALQ, em especial, a Norberto Cornejo (Nor), Jeane Portela (Jeane Morbidela), Betânia Lúcia (BB), Quelmo Novaes, Elton Lúcio, Rafael F. da Costa (Rafaelzinho) e Jailson Fagundes (Rato).

Aos meus amigos de sempre Sylvia Elaine M. de Farias e Ednaldo O. dos Santos, pelo incentivo para prosseguir na minha jornada. $\mathrm{E}$ a todos os amigos da Universidade Federal de Alagoas (UFAL), em especial aos amigos, Alailson Santiago e José Luiz Cabral Jr.

A Todos os professores do Curso de Meteorologia da UFAL, por tudo que me ensinaram durante a graduação.

Aos meus amigos da Escola Superior de Agricultura "Luiz de Queiroz" (ESALQ/USP), em especial, ao amigo Francisco A. Pereira (Chiquinho), pela ternura e cuidado para conosco, tendo sempre uma palavra de conforto nos momentos dificeis.

A todos os funcionários do Departamento de Física e Meteorologia da ESALQ/USP, por estarem sempre prontos a ajudar no que fosse preciso. Em especial, a Robinson Tuon e Ana Maria M. Michelon.

À Escola Superior de Agricultura "Luiz de Queiroz" pela oportunidade de realizar o Mestrado nesta instituição. 
Ao Departamento de Águas e Energia Elétrica do Estado de São Paulo (DAEE - SP), especialmente, ao $\mathrm{Eng}^{\mathrm{o}}$ Noboru Minei, do Centro Tecnológico de Hidráulica e Recursos Hídricos (CTH/DAEE), e também, ao Instituto Nacional de Meteorologia (INMET - $7^{\circ}$ DISME/SP), pela gentileza e atenção no fornecimento dos dados solicitados.

Ao Conselho Nacional de Desenvolvimento Científico e Tecnológico - CNPq - por conceder a bolsa de estudos para o Mestrado.

À todos aqueles que, de uma forma ou de outra, colaboraram para a realização deste trabalho. 


\section{S U M Á R I O}

Página

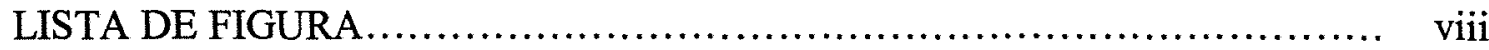

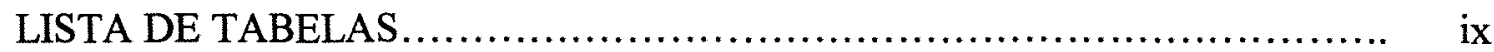

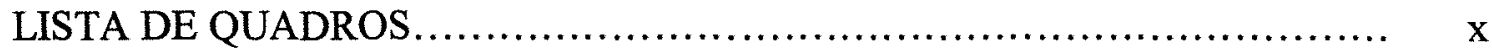

LISTA DE ANEXOS ............................................... xi

RESUMO ........................................................... xii

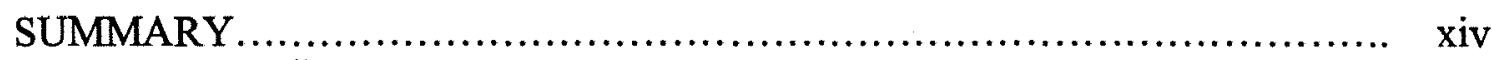

1 INTRODUÇÃ

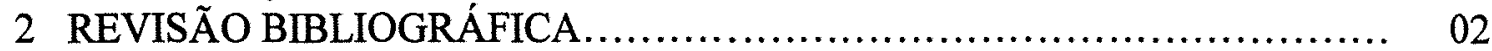

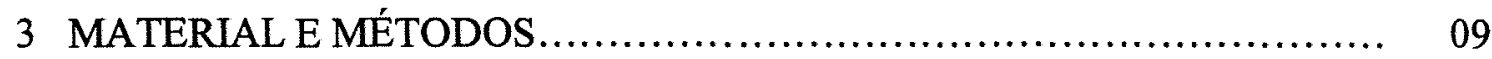

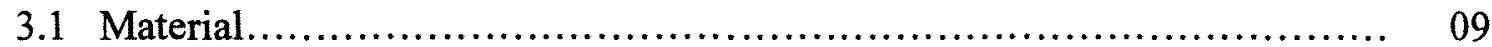

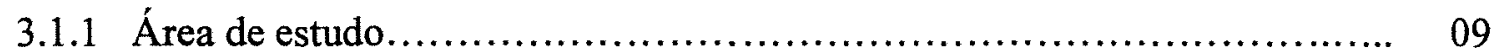

3.1.1.1 Clima............................................................ 11

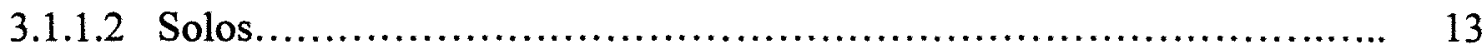

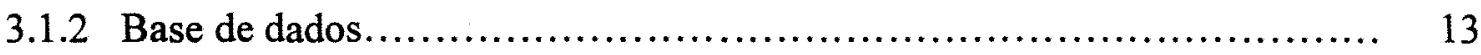

3.2 Métodos................................................................. 14

3.2.1 Tratamento preliminar dos dados...................................... 14

3.2.2 Índice de Palmer para severidade de seca (PDSI) - procedimentos preliminares....................................................... 15

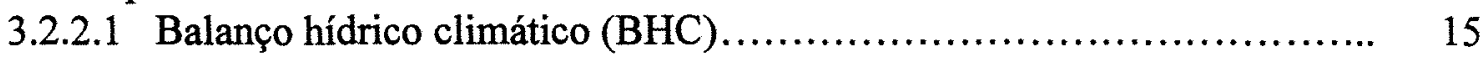

3.2.2.2 Procedimentos para o cálculo do índice de anomalia de umidade, z..... 17

3.2.3 Determinação do PDSI.............................................. 21

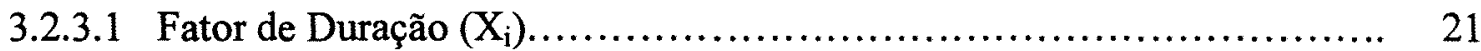

3.2.3.2 Coeficiente c......................................................... 24

3.2.3.3 Início e fim de um período seco.................................... 25

3.2.3.4 Classificação de um período de seca..................................... 25

4 RESULTADOS E DISCUSSÃO....................................... 26

4.1 Freqüência de meses secos.......................................... 26

4.2 Períodos de seca identificados............................................... 29

4.2.1 Secas em Auriflama/SP............................................. 31

4.2.2 Secas na região de Araçatuba/SP - Major Prado e Água Limpa............. 33

4.2.3 Secas na região de Adamantina/SP ................................. 35

4.2.4 Secas na região de Presidente Prudente/SP............................... 37

4.2.5 Secas na região de Salto Grande/SP..................................... 39

4.2.6 Eventos secos em Alfredo Marcondes/SP e Votuporanga/SP.............. 39

4.3 Análise geral para a região Oeste Paulista................................. 40

4.4 Considerações Finais................................................. 42

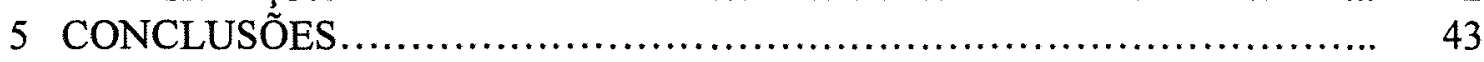

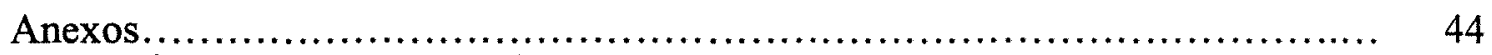

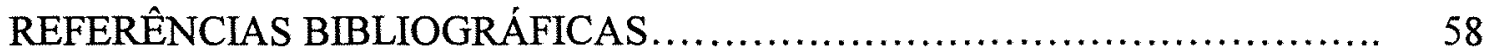




\section{LISTA DE FIGURAS}

1 Área de estudo (a) Região Oeste inserida no Estado de São Paulo; (b) Região Oeste Paulista, em detalhe.

2 Esquema representativo das feições climáticas individualizadas no território paulista dentro das células climáticas regionais e das articulações destas nas faixas zonais (Monteio, 1973)...

3 Fluxograma metodológico para os cálculos do índice de anomalia de

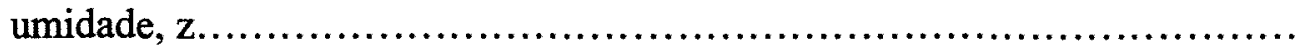

4 Gráfico de $\mathrm{z}$ acumulado, durante os períodos mais secos, de vários comprimentos.

5 (a) Freqüência média mensal de secas suave (ss) e moderada (sm), severa (sse) e extrema (se); (b) Freqüência média anual de meses com seca suave (ss), moderada (sm), severa (sse) e extrema (se), na região estudada.

6 Probabilidade (\%) e período de retorno $\mathrm{T}$ (anos), das secas na região...........

7 Representação gráfica de $\mathrm{P}(\mathrm{mm} / \mathrm{mês}), \mathrm{P}_{\text {cafec }}(\mathrm{mm} / \mathrm{mês}), \mathrm{d}(\mathrm{mm} / \mathrm{mês}), \mathrm{DEF}$ (mm/mês) e, $X_{i}$, em Auriflama - SP: (a) período - Jan/82 a Jul/82; (b) período - Fev/94 a Out/94.

8 Representação gráfica de $\mathrm{P}$ ( $\mathrm{mm} / \mathrm{mês}), \mathrm{P}_{\text {cafec }}(\mathrm{mm} / \mathrm{mês}), \mathrm{d}(\mathrm{mm} / \mathrm{mês}), \mathrm{DEF}$ $(\mathrm{mm} / \mathrm{mês})$, e $X_{i}$, em Major Prado - Araçatuba/SP (período - Jan $/ 96$ a Ago/96).

9 Representação gráfica de $P$ ( $\mathrm{mm} / \mathrm{mês}), \mathrm{P}_{\text {cafec }}(\mathrm{mm} / \mathrm{mês}), \mathrm{d}$ ( $\left.\mathrm{mm} / \mathrm{mês}\right)$, DEF (mm/mês) e, $X_{i}$, em Água Limpa - Araçatuba - SP: (a) período - Jan/79 a $\mathrm{Jul} / 79$; (b) período - Jan/96 a Ago/96).

10 Representação gráfica de $\mathrm{P}(\mathrm{mm} / \mathrm{mês}), \mathrm{P}_{\text {cafec }}(\mathrm{mm} / \mathrm{mês}), \mathrm{d}(\mathrm{mm} / \mathrm{mês})$, DEF (mm/mês) e, $X_{\mathrm{i}}$, em Adamantina/SP: (a) período - Jan/79 a Ago/79); (b) período - Fev/88 a Dez/88; (c) período - Jan/92 a Abr/92 .

11 Representação gráfica de $P(\mathrm{~mm} / \mathrm{mês}), \mathrm{P}_{\text {cafec }}(\mathrm{mm} / \mathrm{mês}), \mathrm{d}(\mathrm{mm} / \mathrm{mês})$, DEF (mm/mês), e $X_{i}$, em Pontal - Teodoro Sampaio/SP (período - Jan/79 a $\mathrm{Abr} / 79)$.

12 Representação gráfica de $\mathrm{P}(\mathrm{mm} / \mathrm{mês}), \mathrm{P}_{\text {cafec }}(\mathrm{mm} / \mathrm{mês}), \mathrm{d}(\mathrm{mm} / \mathrm{mês})$, DEF (mm/mês) e, $X_{i}$, em Presidente Prudente/SP: (a) período - Jan/64 a Set/64; (b) período - Jan/79 a Abr/79

13 Representação gráfica de $\mathrm{P}$ ( $\mathrm{mm} / \mathrm{mês})$, e $\mathrm{P}_{\text {cafec }}(\mathrm{mm} / \mathrm{mês}), \mathrm{d}$ ( $\left.\mathrm{mm} / \mathrm{mês}\right)$, DEF ( $\mathrm{mm} / \mathrm{mês}$ ), e $X_{i}$, em Salto Grande - SP (período - Jan/79 a $\mathrm{Abr} / 79)$.

14 Variação Média Mensal de $\mathrm{P}(\mathrm{mm} / \mathrm{mês}), \mathrm{P}_{\text {cafec }}(\mathrm{mm} / \mathrm{mês}), \mathrm{DEF}(\mathrm{mm} / \mathrm{mês})$ e $X_{i}$ (pol), para a região Oeste do Estado de São Paulo.

15 Variação Média Espacial de $\mathrm{P}(\mathrm{mm}), \mathrm{P}_{\text {cafec }}(\mathrm{mm}), \operatorname{DEF}(\mathrm{mm})$ e $\mathrm{X}_{\mathrm{i}}(\mathrm{pol})$, para a região Oeste do Estado de São Paulo.................................

16 Variação média anual do PDSI na região Oeste do Estado de São Paulo. 


\section{LISTA DE TABELAS}

1 Valores de $z, \Sigma z, X_{i}, X_{i-1}$ e $c$, nos meses em que $\Delta X_{i}=0$, na área de estudo.

2 Freqüência relativa $(\%)$ de meses com seca de qualquer intensidade $\left(\mathrm{X}_{\mathrm{i}}<-\right.$

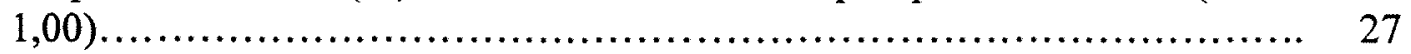

3 Freqüência relativa $(\%)$ de meses com Deficiência Hídrica (DEF) .......... 28 


\section{LISTA DE QUADROS}

1 Postos de observação na área de abrangência do trabalho..................... 14

2 Classificação de Palmer para períodos secos............................... 25

3 Sumário das secas ocorridas na região, durante as séries de anos estudadas, $\mathrm{d}$ acordo com seus períodos de duração (meses)......................... 30

4 Probabilidade (\%) de ocorrência de secas com, pelo menos, o número de meses indicado e, resumo dos períodos secos mais longos e de maior

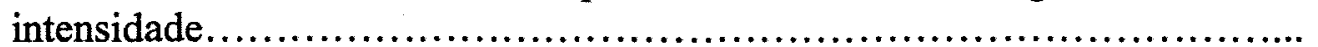




\section{LISTA DE ANEXOS}

A1. Períodos de seca identificados em Auriflama - SP, classificação e, respectivos valores de $\mathrm{z}(\mathrm{pol}), \mathrm{z}_{\mathrm{e}}(\mathrm{pol}), \mathrm{X}_{\mathrm{i}}(\mathrm{pol}), \mathrm{P}(\mathrm{mm}), \mathrm{P}_{\text {cafec }}(\mathrm{mm}), \mathrm{d}$ (mm) e DEF (mm)

A2. Períodos de seca identificados em Major Prado - Araçatuba/SP, classificação e, respectivos valores de $\mathrm{z}(\mathrm{pol}), \mathrm{z}_{\mathrm{e}}(\mathrm{pol}), \mathrm{X}_{\mathrm{i}}(\mathrm{pol}), \mathrm{P}(\mathrm{mm})$, $P_{\text {cafec }}(\mathrm{mm}), \mathrm{d}(\mathrm{mm})$ e DEF $(\mathrm{mm})$

A3. Períodos de seca identificados em Água Limpa - Araçatuba/SP, classificação e, respectivos valores de $\mathrm{z}(\mathrm{pol}), \mathrm{z}_{\mathrm{e}}(\mathrm{pol}), \mathrm{X}_{\mathrm{i}}(\mathrm{pol}), \mathrm{P}(\mathrm{mm})$, $\mathrm{P}_{\text {cafec }}(\mathrm{mm}), \mathrm{d}(\mathrm{mm})$ e DEF $(\mathrm{mm})$.

A4. Períodos de seca identificados em Alfredo Marcondes - SP, classificação e, respectivos valores de $\mathrm{z}(\mathrm{pol}), \mathrm{z}_{\mathrm{e}}(\mathrm{pol}), \mathrm{X}_{\mathrm{i}}(\mathrm{pol}), \mathrm{P}(\mathrm{mm}), \mathrm{P}_{\text {cafec }}(\mathrm{mm}), \mathrm{d}$ $(\mathrm{mm})$ e DEF (mm).

A5. Períodos de seca identificados em Adamantina - SP, classificação e, respectivos valores de $z(\mathrm{pol}), \mathrm{z}_{\mathrm{e}}(\mathrm{pol}), \mathrm{X}_{\mathrm{i}}(\mathrm{pol}), \mathrm{P}(\mathrm{mm}), \mathrm{P}_{\text {cafec }}(\mathrm{mm}), \mathrm{d}$ (mm) e DEF (mm).

A6. Períodos de seca identificados em Pontal - Teodoro Sampaio/SP, classificação e, respectivos valores de $\mathrm{z}(\mathrm{pol}), \mathrm{z}_{\mathrm{e}}(\mathrm{pol}), \mathrm{X}_{\mathrm{i}}(\mathrm{pol}), \mathrm{P}(\mathrm{mm})$, $P_{\text {cafec }}(\mathrm{mm}), \mathrm{d}(\mathrm{mm})$ e DEF $(\mathrm{mm})$

A7. Períodos de seca identificados em Presidente Prudente - SP, classificação e, respectivos valores de $z(p o l), z_{e}(p o l), X_{i}(p o l), P(m m)$, $P_{\text {cafec }}(\mathrm{mm}), \mathrm{d}(\mathrm{mm})$ e DEF $(\mathrm{mm})$

A8. Períodos de seca identificados em Salto Grande - SP, classificação e, respectivos valores de $\mathrm{z}(\mathrm{pol}), \mathrm{z}_{\mathrm{e}}(\mathrm{pol}), \mathrm{X}_{\mathrm{i}}(\mathrm{pol}), \mathrm{P}(\mathrm{mm}), \mathrm{P}_{\text {cafec }}(\mathrm{mm}), \mathrm{d}$ (mm) e DEF (mm)

A9. Períodos de seca identificados em Votuporanga - SP, classificação e, respectivos valores de $\mathrm{z}(\mathrm{pol}), \mathrm{z}_{\mathrm{e}}(\mathrm{pol}), \mathrm{X}_{\mathrm{i}}(\mathrm{pol}), \mathrm{P}(\mathrm{mm}), \mathrm{P}_{\text {cafec }}(\mathrm{mm}), \mathrm{d}$ (mm) e DEF (mm)

B1. Resumo de todas as secas ocorridas na região Oeste Paulista. 


\title{
AVALIAÇÃO DO ÍNDICE DE PALMER PARA A CARACTERIZAÇÃO dE PERÍODOS DE SECA NO ESTADO DE SÃO PAULO
}

\author{
Autora: ROSA MARIA NASCIMENTO DOS SANTOS \\ Orientador: Prof. Dr. ANTONIO ROBERTO PEREIRA
}

\section{RESUMO}

O presente trabalho teve por objetivo testar a metodologia desenvolvida por Palmer (1965), para a identificação e classificação de períodos de seca, adaptando-a às condições climáticas do Estado de São Paulo. Para tanto, foram utilizados, entre 24 e 31 anos de dados mensais de Temperatura do ar e chuva, de nove postos de coleta nas regiões oeste e sudoeste do Estado: Adamantina, Alfredo Marcondes, Major Prado (Araçatuba), Água Limpa (Araçatuba), Auriflama, Pontal (Teodoro Sampaio), Presidente Prudente, Salto Grande e, Votuporanga. O PDSI ( $\mathrm{X}_{\mathrm{i}}$ ) é baseado nos princípios do balanço entre o suprimento e a demanda hídrica, utilizando as séries de dados para identificar os períodos de seca, sua duração e intensidade. A partir dos resultados do balanço, estimou-se mensalmente os parâmetros necessários para o cálculo de $\mathrm{X}_{\mathrm{i}}$ : chuva climaticamente apropriada para as condições existentes $\left(\mathrm{P}_{\text {cafec }}, \mathrm{mm}\right)$, fator climático $(\mathrm{K})$, desvio da chuva $(\mathrm{d}=\mathrm{P}$ $\mathrm{P}_{\text {cafec }}$ ) e, índice de anomalia de umidade $(\mathrm{z})$. As secas foram classificadas de acordo com o valor obtido para $\mathrm{X}_{\mathrm{i}}$ : $-1 \leq \mathrm{X}_{\mathrm{i}}<-2$ - seca suave (ss), $-2 \leq \mathrm{X}_{\mathrm{i}}<-3$ - seca moderada 
(sm), $-3 \leq X_{\mathrm{i}}<-4$ - seca severa (sse), e $X_{i} \leq-4$ - seca extrema (se). Considerou-se uma seca estabelecida sempre que $X_{i}=-1$; e o período seco estava terminado quando $\mathrm{z} \leq$ $\mathrm{z}_{e}$ (umidade requerida para reduzir a severidade de uma seca a índices considerados normais, isto é, $\mathrm{Xi}=-0,50)$. Foram considerados secos os períodos que apresentaram duração igual, ou maior que 4 meses. O método identificou 69 eventos, dentre os quais, aqueles com 5 meses de duração, ocorreram com maior frequêencia. Os meses mais secos na região foram agosto e setembro, e os menos secos novembro e dezembro. As secas suaves e moderadas, concentraram-se entre os meses de abril e setembro, ocorrendo com maior frequiência em agosto. As secas severas e extremas ocorreram com menor frequiência e, estiveram concentradas em janeiro e fevereiro. A localidade que apresentou a maior frequiência de secas foi Adamantina, e a de menor freqüência foi Salto Grande. Os anos que apresentaram a maior incidência de secas severas e extremas foram 1979, 1992 e 1996, durante os quais, foram identificadas secas em quase todos os postos de observação. 


\title{
EVALUATION OF THE PALMER INDEX FOR THE CHARACTERIZATION OF DROUGHT PERIODS IN THE STATE OF SÃO PAULO
}

\author{
Author: ROSA MARIA NASCIMENTO DOS SANTOS \\ Adviser: Prof. Dr. ANTONIO ROBERTO PEREIRA
}

SUMMARY

The present study had for objective to test the methodology developed by Palmer (1965), for the identification and classification of drought periods, adapting it to climatic conditions of State of São Paulo. For this, one were used, among 24 and 31 years of air Temperature and rainfall monthly data, from nine sites in west and Southwest regions of the State: Adamantina, Alfredo Marcondes, Major Prado (Araçatuba), Água Limpa (Araçatuba), Auriflama, Pontal (Teodoro Sampaio), Presidente Prudente, Salto Grande and Votuporanga. The PDSI $\left(\mathrm{X}_{\mathfrak{i}}\right)$ is based on the buyget between the supply and the demand of water, using large series of data to identify the drought periods, its duration and intensity. From the water balance results, it was estimated the necessary parameters for the calculation of the monthly $\mathrm{X}_{\mathrm{i}}$ : the rainfall climaticaly adapted for the existent conditions (Pcafec, $\mathrm{mm}$ ), the climatic factor $(\mathrm{K})$, rainfall deviation $(\mathrm{d}=\mathrm{P}-\mathrm{Pcafec})$, and index of humidity anomaly $(\mathrm{z})$. The droughts were classified in agreement with the value obtained for 
$\mathrm{X}_{\mathrm{i}}$ : $-1 \leq \mathrm{X}_{\mathrm{i}}<-2-$ mild drought, $-2 \leq \mathrm{X}_{\mathrm{i}}<-3$ - moderate drought, $-3 \leq \mathrm{X}_{\mathrm{i}}<-4$ - severe drought, and $\mathrm{X}_{\mathfrak{i}} \leq-4$ - extreme drought. It was considered an established drought whenever $X_{i}=-1$; and the dry period was finished when $z \geq z_{e}$ (moisture requested to reduce the severity of drought spells to indices considered normal, so that, to Xi will be equal to -0.50 ). The periods with duration equal to or larger than 4 months were considered dry. The method identified 69 events, within them, those with 5 months of duration happened with larger frequency. The driest months in the region were August and September, and the less dry were November and December. The mild and moderate drought spells concentrated between April and September, happening with largest frequency in August. The severe and extreme droughts happened with smaller frequency and concentrated in January and February. The site that presented the largest drought frequency was Adamantina, and the one with the smaller frequency was Salto Grande. The years that presented the largest incidence of severe and extreme droughts were 1979, 1992 and 1996, with drought spells identified in almost all sites. 


\section{1 - INTRODUÇÃO}

Seca é característica normal e recorrente (cíclica) do clima, embora alguns a considerem um evento raro e casual. Ocorrem em todas as zonas climáticas, mas suas características variam de uma região para outra. É um evento temporário e diferente de aridez, visto que essa última está restrita a regiões de pouca chuva e se apresenta como uma característica climática permanente ${ }^{1}$.

Do ponto de vista sócio-econômico, a definição de seca diz respeito aos prejuízos financeiros e sociais causados pela falta prolongada de água em determinado local. A Organização Meteorológica Mundial (OMM) define seca como "deficiência contínua e extensa na precipitação" (Farago et al., 1989), ou seja, as secas estão relacionadas com deficiências de chuvas em períodos extensos, durante uma ou mais estações do ano. Sendo assim, um estudo sobre secas deve considerar vários aspectos, tais como: as condições médias normais do balanço entre chuva e evapotranspiração potencial; o período de ocorrência, atrasos no início da estação chuvosa e relação com os principais estádios de crescimento de uma cultura; e a efetividade das chuvas (intensidade e número de eventos).

De acordo com suas características, a seca pode ser: permanente, sazonal, contingente, e invisível (Ayoade, 1996). Seca permanente ocorre nas regiões áridas e semi-áridas, onde a estação de chuvas nunca é suficiente para atender às necessidades hídricas das plantas. Seca sazonal ocorre em áreas com estações seca e úmida bem definidas, como é o caso dos trópicos e subtrópicos, e pode ser prevista, pois depende

\footnotetext{
${ }^{1}$ NATIONAL DROUGHT MITIGATION CENTER. Understanding and Defining Drought. Home page do NDMC, 1995.
} 
das variações sazonais nos padrões da circulação atmosférica. A seca contingente é característica de regiões úmidas e subúmidas e ocorre quando deixa de chover num determinado período. E sempre que o suprimento de água do solo, ou a quantidade de água das chuvas, deixe de ser igual às necessidades hídricas diárias das plantas, impedindo seu crescimento em índices ótimos, ocorre a seca invisível.

Devido à sua grande extensão territorial e conseqüente diversidade climática, o Brasil é submetido a períodos de seca com características sazonais bastante complexas, em quase todas as suas regiões. Em algumas regiões, tais períodos apresentam efeitos de longa duração sobre a maior parte das atividades sócioeconômicas, como é o caso das secas no nordeste do País. No caso das regiões sul e sudeste, os efeitos das secas têm menor duração, apresentando, no entanto, períodos de recorrência razoavelmente constantes; isto é, costumam ocorrer todos os anos, normalmente, durante o inverno nessas regiões.

O Estado de São Paulo aparece como uma zona de transição climática, com diversos fatores influenciando seu clima, principalmente no que diz respeito à distribuição temporal e espacial das chuvas. A maior parte do Estado está sujeita a períodos secos bem definidos, que costumeiramente ocorrem durante o outono-inverno (estação fria e seca) e, dependendo da duração, podem causar sérios prejuízos às atividades agro-econômicas. Apesar disso, o número limitado de estudos sobre secas no Estado se apresenta como um obstáculo, especialmente no que se relaciona ao planejamento de atividades agrícolas.

Este trabalho de pesquisa foi proposto no intuito de testar uma metodologia que possa ser utilizada operacionalmente para identificar e classificar períodos de seca, adaptando-a às condições ambientais do território paulista. Pretendese, desta forma, fornecer subsídios técnico-científicos para eventuais programas de monitoramento de secas no Estado, servindo como instrumento de auxílio ao planejamento agro-ecológico regional. 


\section{2 - REVISÃO BIBLIOGRÁFICA}

A caracterização de períodos de seca, principalmente em escala regional, ainda se constitui em problema para estudos climatológicos. Numa tentativa de simplificação, tem-se optado por considerar apenas aspectos meteorológicos de uma seca, visto que a resposta biológica aos fatores do meio, é extremamente dificil de ser tratada, devido à quantidade de variáveis envolvidas, tais como: espécie de planta e sua fase de desenvolvimento, propriedades físico-químicas do solo, além dos fenômenos meteorológicos (Van Bavel, 1953; Thornthwaite \& Mather, 1955; Lawrence, 1957; Moretti Filho, 1965).

A maioria dos estudos de caracterização de secas esta baseada na demanda e suprimento de água do solo, por meio de métodos climatológicos de cálculo do balanço hídrico. Van Bavel (1953), utilizando o método do balanço hídrico estudou a probabilidade de ocorrência de dias secos para uma cultura de fumo, assumindo como dia seco aquele em que o excedente de água era nulo.

Utilizando séries temporais, Lawrence (1957) estimou a freqüência de ocorrência de dias secos, no sul e leste da Inglaterra, a partir de dados de precipitação. Ainda nessa linha de trabalho, Moretti Filho (1965) avaliou a incidência e probabilidade de ocorrência de dias secos, para a cultura da cana-de-açúcar, no Estado de São Paulo.

$\mathrm{O}$ balanço hídrico é um método de estimativa da disponibilidade de água no solo para as plantas, sendo indispensável em estudos sobre as relações hídricas entre as plantas e o ambiente. Sua aplicabilidade vai desde a avaliação e delimitação dos potenciais hídricos regionais, passando pela determinação e quantificação de períodos 
com excesso e escassez de água, e por estudos de bacias hidrográficas para o planejamento de reservatórios (Amorim Neto, 1989).

O método do Balanço Hídrico está fundamentado no princípio da conservação da massa, onde a transferência de água, em um volume de controle com uma capacidade finita de armazenamento (ARM), em um determinado intervalo de tempo $(\Delta t)$, pode ser descrita da seguinte forma:

$$
\mathbf{P}_{i}+\mathrm{DEF}_{\mathrm{i}}-\mathrm{ETp}_{\mathrm{i}}-\Delta \mathrm{ARM}_{\mathrm{i}}-\mathrm{EXC}_{\mathrm{i}}=0
$$

sendo, $\mathrm{P}_{\mathrm{i}}(\mathrm{mm})$ a chuva ocorrida no i-ésimo período (mensal, decendial, quinzenal, etc); $\mathrm{DEF}_{\mathrm{i}}(\mathrm{mm})$ a deficiência de água no i-ésimo período, segundo Thornthwaite (1948) $\mathrm{DEF}=\mathrm{ETp}-\mathrm{ETr} ; \mathrm{ARM}_{\mathrm{i}}(\mathrm{mm})$ a variação do armazenamento de água no solo e; EXC o excesso de água no solo (Bergamaschi et al., 1992).

Do ponto de vista da física do solo, o balanço hídrico é a somatória das quantidades de água que entram e saem de um elemento de volume de solo, num intervalo de tempo, resultando na variação do armazenamento de água. Constitui-se numa ferramenta necessária para o estudo dos processos que envolvem os fluxos de água no solo, tais como, infiltração, redistribuição, evaporação e absorção pela planta, haja vista que, são interdependentes e, na maioria das vezes, ocorrem simultaneamente (Reichardt, 1996).

Braga (1982) utilizou um modelo de balanço hídrico desenvolvido, conjuntamente, a partir dos métodos de Van Bavel (1953), Thornthwaite \& Mather (1955), Denmead \& Shaw (1962) e FAO (1979), para caracterizar a seca agronômica na região de Laguna - SC, tendo como critério o número de dias secos consecutivos.

Para a agricultura, Assis (1991) destaca que o aspecto de maior importância relacionado à chuva, além da quantidade e variabilidade, é a freqüência, ou seja, o número de dias dentro de um mês ou estação, na qual a quantidade de chuva exceda um determinado valor. Thornthwaite (1948) considera como seco, o dia ou mês 
em que a quantidade total de chuva fica abaixo da respectiva evapotranspiração potencial.

Para realizar o balanço hídrico é necessário, portanto, conhecer a evapotranspiração, potencial e real, visto que esta representa a saída de água do volume de contorno e, juntamente com a chuva, determina as condições de umidade de um dado local ou região.

Evapotranspiração é o termo utilizado para descrever a ocorrência simultânea de dois processos físicos: evaporação e transpiração. Evaporação é o processo físico pelo qual a água passa do estado líquido para o gasoso, e transpiração é a evaporação da água utilizada nos processos metabólicos das plantas, através dos estômatos. A evapotranspiração representa o transporte de água da terra de volta para a atmosfera, sendo assim o contrário da chuva (Thornthwaite, 1948).

Os fatores que influenciam a evapotranspiração são: a demanda atmosférica e o suprimento de água no solo disponível às plantas. A demanda atmosférica é controlada pelo poder evaporante do ar, que é uma função do vento e do déficit de pressão de vapor do ar. O suprimento de água do solo às plantas está diretamente relacionado com a demanda atmosférica: quanto maior a demanda menor será a capacidade da planta de extrair água do solo para suprir suas necessidades (Pereira et al., 1997).

As variações espaciais e temporais da precipitação nas diversas regiões são razoavelmente conhecidas e freqüentemente citadas. Já a evapotranspiração não é um elemento facilmente mensurável, devido à sua complexidade, sendo sua medida direta muito onerosa.

Para determinar se o clima de um local ou região é úmido ou seco não é suficiente conhecer apenas o regime de chuvas, é preciso saber também se a quantidade de chuva é suficiente para suprir as necessidades de água para a evapotranspiração. Chuva e evapotranspiração são fatores climáticos igualmente importantes. Quando a chuva é maior que a evapotranspiração, o clima é úmido; quando a situação é inversa, isto é, a chuva não é suficiente para atender à demanda hídrica local, o clima é seco. E 
quando a precipitação e as necessidades de água são iguais, ou aproximadamente iguais, o clima não é nem úmido e nem seco (Thornthwaite, 1948).

Em condições de escassez de água, como nos desertos e regiões semiáridas, a vegetação é esparsa e utiliza pouca água. Se mais água fosse colocada à disposição (como em sistemas irrigados), a vegetação utilizaria uma parcela maior e, conseqüentemente, seria menos esparsa.

Há uma distinção entre a quantidade de água que evapotranspira no momento atual e a que evapotranspiraria se ela estivesse disponível. A quantidade de água que poderia ser utilizada por uma extensa superfície vegetada, cobrindo completamente o terreno, em crescimento ativo, e sem qualquer deficiência hídrica, é denominada Evapotranspiração Potencial. Da mesma forma que a evapotranspiração real, a potencial também se constitui em elemento climático da maior importância, pois, comparando-a com a chuva determina-se racionalmente o fator umidade de uma região (Thornthwaite, 1948; Pereira et al., 1997).

A evapotranspiração potencial é um dos principais componentes do balanço de água no solo, de grande utilidade em climatologia, tanto para classificações climáticas, como na quantificação da disponibilidade de água de uma região (Berlato \& Molion, 1981).

Vários são os métodos de estimativa da evapotranspiração e foram classificados por Pereira et al. (1997), em cinco categorias: (i) empíricos, (ii) aerodinâmico, (iii) balanço de energia, (iv) combinados, (v) correlação dos turbilhões.

Baseando-se no balanço hídrico de bacias hidrográficas e em medidas lisimétricas, Thornthwaite (1948) observou que, quando feitos os ajustes para as variações do comprimento do dia, havia forte correlação entre a temperatura média mensal e a evapotranspiração potencial e, a partir daí, desenvolveu uma fórmula, relativamente simples, que utiliza apenas a temperatura média do ar como variável independente.

A abordagem realizada por Thornthwaite é um método prático e confiável, que pode ser utilizado experimentalmente, no balanço hídrico, planejamento 
de áreas irrigadas e na classificação climática regional, entre outros, desde que sejam observadas as condições de área tampão necessárias à evapotranspiração potencial. O método não é apropriado para estimar a evapotranspiração sob condições de oásis, ou seja, sob condições de advecção de ar quente e seco para uma região vegetada mais úmida (Pereira \& Camargo, 1989).

Resultados experimentais de Camargo (1962) mostram que a fórmula de Thornthwaite estima bem a evapotranspiração potencial para o Estado de São Paulo, em escala mensal. Camargo \& Sentelhas (1997), avaliando o desempenho de vinte métodos de estimativa de ETp, em três localidades do Estado de São Paulo, concluíram que o método de Thornthwaite estava entre os que apresentaram os melhores resultados para a região.

$\mathrm{Na}$ tentativa de criar um sistema eficaz de monitoramento de secas, diversas metodologias têm sido desenvolvidas para a identificação, caracterização e classificação de períodos de seca e, vários foram os índices elaborados com este propósito. Muitos deles utilizam o balanço hídrico para determinar as condições de umidade de uma região.

Palmer (1965) definiu período seco como um intervalo de tempo, geralmente da ordem de meses ou anos de duração, durante o qual o suprimento de água é menor que o climaticamente esperado, ou apropriado, e a partir dessa definição, desenvolveu um Índice de Severidade de Seca (Palmer Drought Severity Index - PDSI). Desde então, o Índice de Palmer tem sido utilizado, tanto para classificar períodos secos como períodos com umidade acima da necessária às plantas.

Bhalme \& Mooley (1980) desenvolveram um índice simples, o Bhalme Mooley Drought Index (BMDI), para a classificação de secas, que necessita somente da chuva para ser calculado. O BMDI pode também ser considerado uma versão simplificada do PDSI, utilizando inclusive a mesma tabela de classificação elaborada por Palmer para o PDSI. De acordo com Bogardi et al. (1994), tanto o PDSI como o BMDI são índices recursivos, que expressam os efeitos cumulativos de Deficiências prolongados de umidade - meses ou anos. Heddinghaus \& Sabol (1991) fizeram uma 
revisão sobre o PDSI e sugeriram que o mesmo poderia ser utilizado em conjunto com outros índices, com o intuito de aumentar sua faixa de abrangência.

O PDSI tem sido alvo de muitas críticas, ao longo dos anos, sendo as mais comuns relacionadas às regras para quantificar a intensidade, início e fim de um período seco, ou extremamente úmido, e na determinação do fator $\mathrm{K}$ - função regional do clima, considerada fraca em relação à fundamentação física e estatística. Sob certas condições, o PDSI tende a superestimar a influência da chuva sobre o fim de um período de "seca estabelecida" (Chagnon, 1980; Wilhite, 1983; Alley, 1984).

Mas, apesar das críticas ao PDSI, ainda não foi desenvolvido um índice que seja operacionalmente melhor, ou que implique em margem mínima de erro, para servir de instrumento ao monitoramento de secas. Comparado a outros índices, exceto talvez o BMDI (Bhalme \& Mooley, 1980), o PDSI é bem menos complexo e, certamente fornece melhores resultados. Tanto assim que é utilizado por usuários das mais diversas áreas, tais como: hidrologistas, fazendo o acompanhamento do nível de rios, lagos e reservatórios de água; técnicos em planejamento agro-econômico; técnicos florestais, para indicar condições de risco de incêndios; entre outros (Heddinghaus \& Sabol, 1991).

Felch (1978) utilizou o Índice de Palmer para comparar três décadas de seca - as décadas de 30, 50 e 60 - nos Estados Unidos. Estudos sobre as características espaciais e temporais de secas no Estado de Nebrasca e, para determinação de frequiências de secas de várias classes de severidade no Nordeste dos Estados Unidos, foram realizados por Dickerson \& Dethier (1970) e Lawson et al. (1971), utilizando o indice desenvolvido por Palmer. Scian \& Donnari (1997) aplicaram o modelo de Palmer para calcular índices de anomalias de umidade, $Z$, para três regiões ecológicas da Argentina, analisando a freqüência de períodos sob condições de seca, úmidas e normais.

Assis et al. (1997) utilizaram o índice de Palmer para analisar a freqüência de secas com diferentes intensidades no Rio Grande do Sul, observando que há a possibilidade de uso apenas de dados correntes de precipitação e dados normais de evapotranspiração nos procedimentos de cálculo do PDSI. 


\section{3 - MATERIAL E MÉTODOS}

\section{1 - Material}

\subsection{1 - Área de Estudo}

O Estado de São Paulo ocupa uma área de aproximadamente 248.000 $\mathrm{km}^{2}$, localizado na região Sudeste brasileira. A região leste do Estado apresenta um forte crescimento industrial, enquanto que a região oeste ainda é essencialmente agrícola. $\mathrm{O}$ relevo é constituído por uma escarpa litorânea e um platô que se eleva ligeiramente para nordeste. A escarpa litorânea é uma área irregular de afloramentos, com altas declividades e solos complexos. O platô, margeado por serras a leste e nordeste, é uma área levemente ondulada, constituída em média por solos de boa qualidade (Braga Jr. et al., 1991).

A área do presente estudo compreende a região oeste paulista, entre $50^{\circ} \mathrm{e}$ $53^{\circ} \mathrm{W}$ e, $20^{\circ}$ e $23^{\circ} \mathrm{S}$ - Oeste do Planalto Ocidental (Figura 1). Foi escolhida devido à sua representatividade agrícola no Estado e, portanto, a necessidade de um sistema de auxílio à previsão de períodos de estiagem prejudiciais a produção agrícola regional, bem como aos níveis das barragens existentes na região, o que pode também comprometer o abastecimento de água e energia elétrica, visto que a mesma apresenta, ao longo do ano, os maiores valores de deficiência hídrica do Estado (Camargo, 1960; Braga Jr. et al., 1991). 


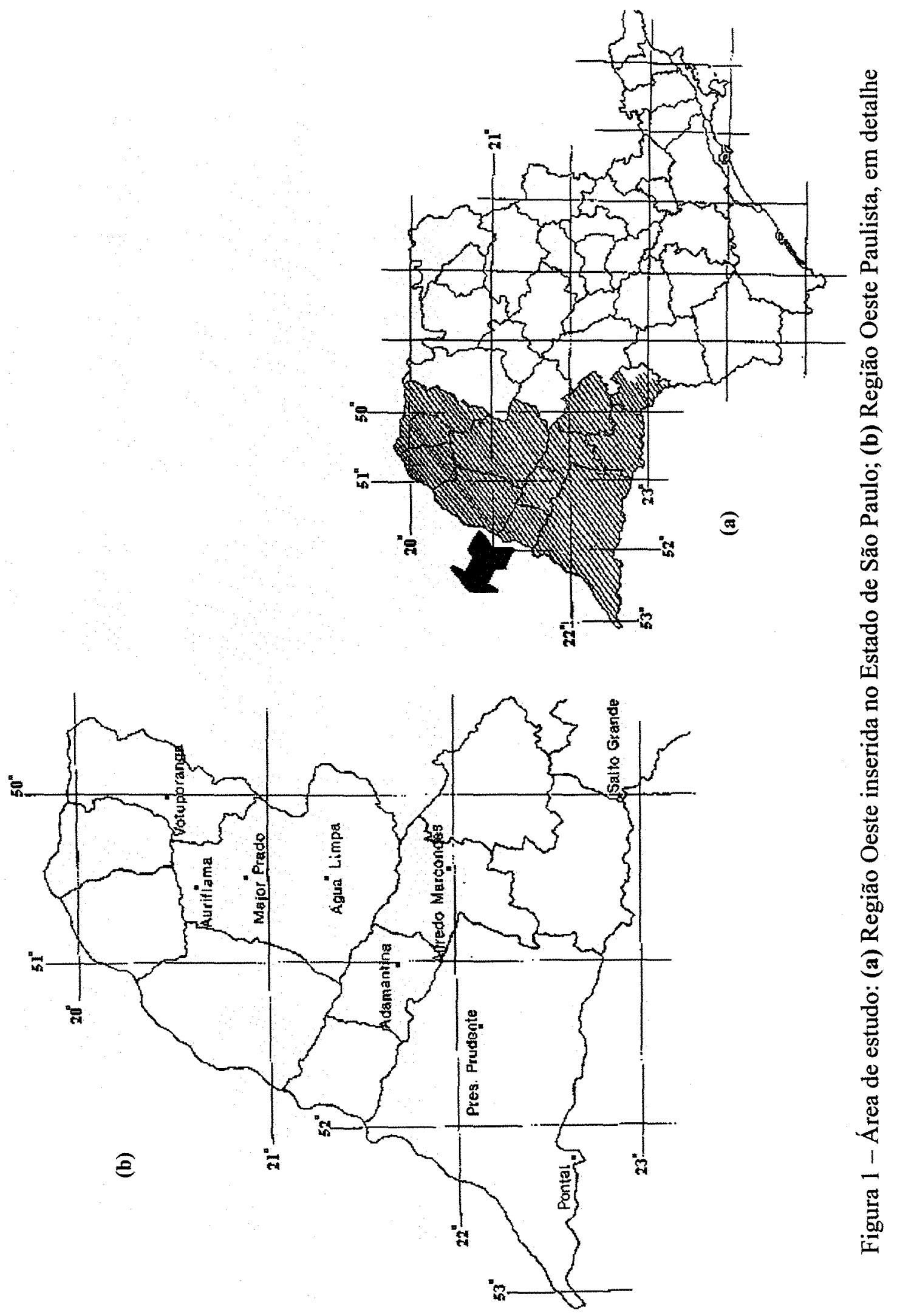




\subsubsection{1 - Clima}

O clima do Estado pode ser classificado como subtropical, com possibilidades de ocorrência de geadas. As condições geográficas e topográficas são os principais fatores que influenciam o macroclima. Por estar localizado em uma região de transição climática, o Estado sofre a influência tanto das massas de ar frio, provenientes do sul, como das massas tropicais de ar quente e úmido, vindas do norte e oeste. Além disso, sua situação no lado oriental de um continente do hemisfério Sul, o deixa sujeito, também, à forte influência da massa Tropical Marítima do Atlântico Sul, produzindo intenso processo de evaporação e condensação (Schröder, 1956; DAEE, 1973; Tubelis \& Nascimento, 1986; Braga Jr. et al., 1991). Todos estes fatores contribuem para a caracterização do Estado de São Paulo como uma região de transição climática.

Sant'Anna Neto (1995) destaca a variabilidade espacial e irregularidade temporal das chuvas no território paulista como função do caráter transicional do clima do Estado. Monteiro (1973) apresentou uma classificação climática para o Estado de São Paulo, na qual aparecem dois climas zonais, três climas regionais e nove feições climáticas, distribuídas em seis regiões geográficas: Litoral, Vale do Paraíba, Planalto Atlântico, Mantiqueira, Depressão e Planalto Ocidental (Figura 2).

Na Região do Planalto Paulista (Oeste do Estado) o ritmo das chuvas segue a movimentação das grandes massas que atuam na América do Sul. No período da primavera-verão, quando o continente encontra-se mais aquecido, a influência da massa Equatorial Continental se faz sentir com maior intensidade, deixando a região mais quente e úmida. Há predominância de chuvas convectivas pontuais de desenvolvimento local ou regional e de curta duração, mas quase sempre são de grande intensidade. As chuvas frontais, mais prolongadas, são menos freqüentes nesta época do ano, devido a escassez de interações entre massas de ar. Já no periodo de outono-inverno, as chuvas frontais ocorrem com maior freqüência, haja vista a diminuição da radiação solar nos trópicos e conseqüente desintensificação dos movimentos convectivos (Pereira, 1997). 


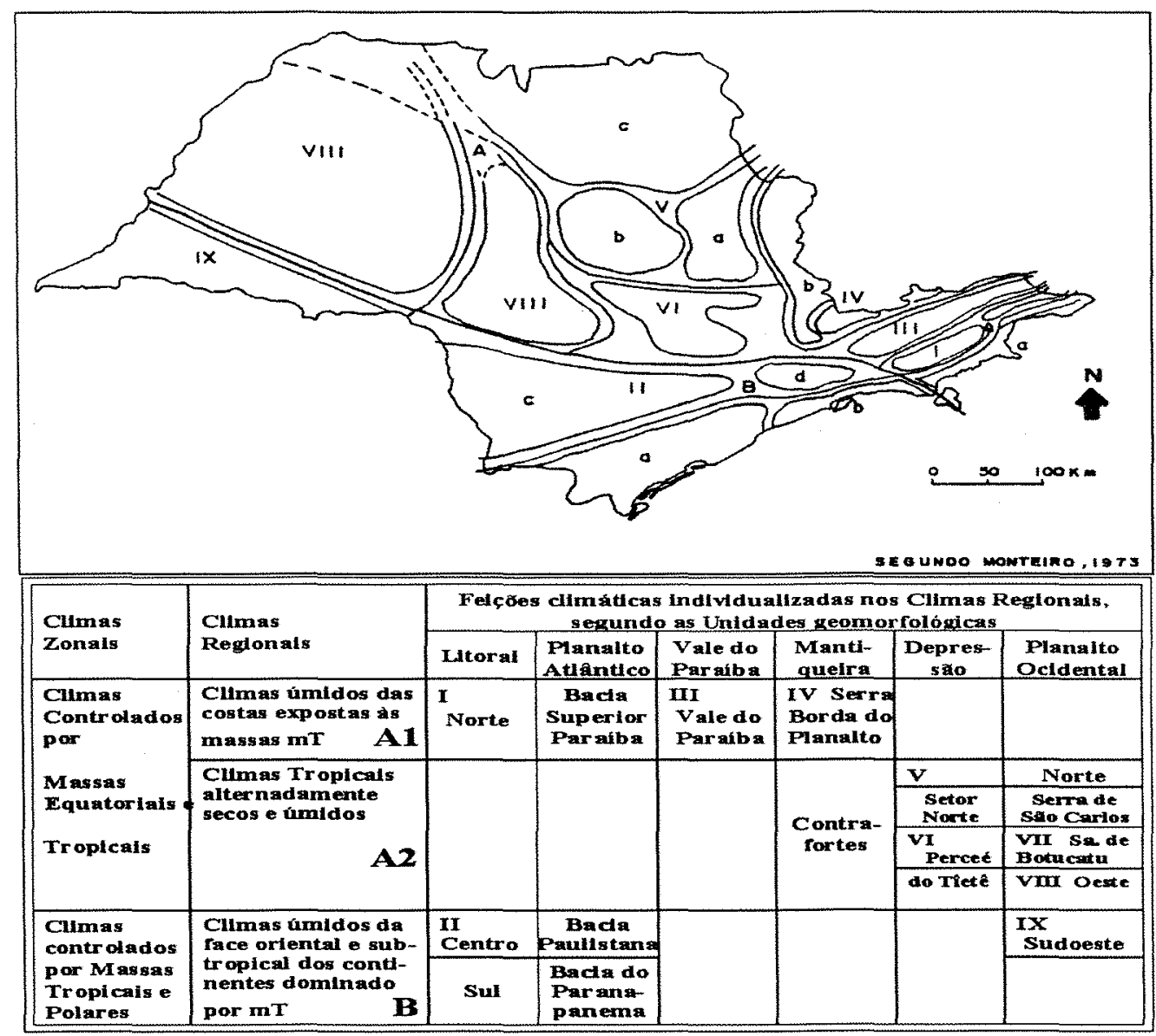

Figura 2 - Esquema representativo das feições climáticas individualizadas no território paulista dentro das células climáticas regionais e das articulações destas nas faixas zonais (Monteiro, 1973)

Tarifa (1973) realizou uma análise do balanço hídrico para a região sudoeste do Estado de São Paulo e verificou que, durante o período de primavera-verão, o mês mais seco é setembro, ainda como uma conseqüência do inverno seco, outubro apresenta as maiores reservas hídricas e, normalmente, podem ocorrer deficiências durante novembro, as quais podem acarretar sérios prejuízos à economia local. Os meses mais chuvosos e com excedentes hídricos são dezembro, janeiro e fevereiro, entretanto, dezembro pode apresentar baixas reservas devido à influência do mês anterior. Durante o outono-inverno os meses mais secos são, normalmente, julho e agosto, sendo que o mês de abril apresenta as piores condições hídricas no outono. Apesar disso, observa-se 
que, de um modo geral, $70 \%$ da região não apresenta deficiência de água no solo, embora o reabastecimento superficial seja irregular.

\subsubsection{2 - Solos}

Geologicamente, o Estado de São Paulo é um monoclinal desenvolvido, com o interior do Estado situado entre o Rio Paraná e a Escarpa da Serra do Mar, de aproximadamente $1000 \mathrm{~m}$, e um "plateau" levemente inclinado para noroeste. Destacamse três principais grupos de solos: latossólicos, podzólicos, e um complexo de outros solos. No Planalto Ocidental predominam os latossólicos: Latossolo Vermelho Escuro orto e Latossolo Vermelho Escuro fase arenosa (DAEE, 1973).

Os solos latossólicos são argilosos, apresentando boas propriedades físicas, com horizonte B caracterizado pela intensa intemperização sem acúmulo de argila. No caso do Latossolo Vermelho Escuro, o horizonte A é moderado, com textura média ou argilosa, estrutura granular pequena ou moderada, consistência friável ou muito friável (úmida) e, a transição para o horizonte $\mathrm{B}$ é gradual e plana. $\mathrm{O}$ horizonte $\mathrm{B}$ possui textura média ou, de argilosa à muito argilosa, estrutura subangular média fraca, consistência friável ou úmida (PRADO,1995 e 1997). Tais propriedades podem favorecer a penetração das raízes.

\subsection{2 - Base de Dados}

Foram utilizados totais mensais de chuva e temperatura do ar (máxima, mínima e média), de nove postos de observação, sendo oito deles pertencentes à rede do Departamento de Água e Energia Elétrica - SP (DAEE-SP) e um ao Instituto Nacional de Meteorologia (INMET $/ 7^{\circ}$ DISME - SP), conforme mostra o Quadro 1. 
QUADRO 1 - Postos de observação na área de abrangência do trabalho.

\begin{tabular}{|c|c|c|c|c|c|c|}
\hline POSTO & LAT & LONG & ALT & ORGÃO & Período & Série \\
\hline Adamantina & $21^{\circ} 41^{\prime} \mathrm{S}$ & $51^{\circ} 05^{\prime} \mathrm{W}$ & $440 \mathrm{~m}$ & DAEE & Jan/60-Dez/96 & 31 anos \\
\hline Alfredo Marcondes & $21^{\circ} 577^{\prime} \mathrm{S}$ & $51^{\circ} 25^{\prime} \mathrm{W}$ & $440 \mathrm{~m}$ & DAEE & Jan/61 - Dez/96 & 30 anos \\
\hline Major Prado (Araçatuba) & $20^{\circ} 52^{\prime} \mathrm{S}$ & $50^{\circ} 29^{\prime} \mathrm{W}$ & $415 \mathrm{~m}$ & DAEE & Jan/70-Dez/96 & 27 anos \\
\hline Agua Limpa (Araçatuba) & $21^{\circ} 20^{\prime} \mathrm{S}$ & $50^{\circ} 31^{\prime} \mathrm{W}$ & $410 \mathrm{~m}$ & DAEE & Jan/70-Dez/96 & 27 anos \\
\hline Auriflama & $20^{\circ} 42^{\prime} \mathrm{S}$ & $50^{\circ} 33^{\prime} \mathrm{W}$ & $450 \mathrm{~m}$ & DAEE & Jan/71 - Dez/96 & 26 anos \\
\hline Pontal (Teodoro Sampaio) & $22^{\circ} 37 \mathrm{~S}$ & $52^{\circ} 10^{\prime} \mathrm{W}$ & $255 \mathrm{~m}$ & DAEE & Jan/76-Dez/96 & 21 anos \\
\hline Presidente. Prudente & $22^{\circ} 07 \mathrm{~S}$ & $51^{\circ} 23^{\prime} \mathrm{W}$ & $436 \mathrm{~m}$ & INEMET & Jan/61 - Dez/96 & 30 anos \\
\hline Salto Grande & $22^{\circ} 54^{\prime} \mathrm{S}$ & $50^{\circ} 00^{\prime} \mathrm{W}$ & $400 \mathrm{~m}$ & DAEE & Jan/73 - Dez/96 & 24 anos \\
\hline Votuporanga & $20^{\circ} 26^{\prime} \mathrm{S}$ & $49^{\circ} 59^{\prime} \mathrm{W}$ & $510 \mathrm{~m}$ & DAEE & Jan/73 - Dez/96 & 24 anos \\
\hline
\end{tabular}

\section{2 - Métodos}

\subsection{1. - Tratamento preliminar dos dados}

As temperaturas médias mensais ( $T$ ) foram estimadas a partir das temperaturas máximas $(\mathrm{Tx})$ e mínimas $(\mathrm{Tm})$, ou seja, $\mathrm{T}=(\mathrm{Tx}+\mathrm{Tm}) / 2$. Devido à indisponibilidade de dados de temperatura, para alguns postos (Adamantina, Auriflama, Andradina e Alfredo Marcondes), houve a necessidade de estimá-la. Para isto, utilizouse as equações de regressão múltipla, desenvolvidas por Pedro Júnior et al. (1991), que estimam médias mensais das temperaturas máximas e mínimas, em função das coordenadas geográficas locais (latitude e altitude):

$$
\mathbf{y}=\mathbf{a}+\mathbf{b x}_{1}+\mathbf{c x _ { 2 }}
$$

sendo, y a temperatura média mensal máxima ou mínima $\left({ }^{\circ} \mathrm{C}\right) ; \mathbf{a}, \mathbf{b}$ e c os coeficientes da equação de regressão, em ${ }^{\circ} \mathrm{C},{ }^{\circ} \mathrm{C} \mathrm{m}{ }^{-1} \mathrm{e}^{\circ} \mathrm{C}$ min, respectivamente; $\mathbf{x}_{1}$ a altitude (m) e; $\mathbf{x}_{2}$ a latitude (min). 


\subsection{2 - Índice de Palmer para Severidade de seca (PDSI) - Procedimentos preliminares}

Palmer (1965) propôs um método empírico para classificar períodos de seca. O Índice de Severidade de Seca de Palmer (PDSI), baseia-se nos princípios do balanço entre o suprimento e a demanda hídrica, e utiliza longas séries de dados mensais de temperatura média do ar e chuva, para identificar períodos de seca (e períodos úmidos), sua duração e intensidade.

\subsubsection{1 - Balanço Hídrico Climático - BHC}

O ponto de partida para os cálculos do PDSI é o balanço hídrico, segundo Thornthwaite \& Mather (1955), o qual foi computado para a série de dados de cada posto de observação. O balanço hídrico normal foi calculado, utilizando o programa computacional elaborado por Barbieri et al. (1991) e, o balanço hídrico seqüencial foi realizado por meio da Planilha Eletrônica, desenvolvida por Rolim \& Sentelhas² ${ }^{2}$ O valor utilizado para a Capacidade de Água Disponível no Solo (CAD) foi de $100 \mathrm{~mm}$, para haver condições de comparação com os resultados encontrados por Palmer (1965). Dos resultados do BHC, encontrou-se as variáveis que serviram de base para os procedimentos de cálculo dos índices de severidade de seca: Evapotranspiração Potencial (ETp), Evapotranspiração Real (ETr), Recarga Potencial (RP), Recarga (ou reposição) Real de água no solo (R), Perda Potencial de água do solo (L), Perda Real de água do solo (B), Escoamento Potencial (ROP) e Escoamento Real (RO).

A ETp (mm), pela a disponibilidade dos dados, foi calculada de acordo com a fórmula de Thornthwaite (1948) e, a ETr (mm) foi estimada a partir do Balanço, para cada posto de observação. Considerou-se que: a Perda Potencial de água no solo ou Perda de água por evapotranspiração - L (mm), é equivalente ao valor negativo de PETp (mm), ou seja, 


$$
L=(P-E T p) \Leftrightarrow(P-E T p)<0
$$

e a Recarga Potencial, RP (mm), é igual ao valor absoluto de L,

$$
\mathbf{R P}=|\mathbf{L}|
$$

Os valores positivos de P-ETp representam o Escoamento Potencial, ROP (mm),

$$
\text { ROP }=(P-\text { ETp }) \Leftrightarrow(P-E T p)>0
$$

A alteração, ALT (mm), negativa no armazenamento de água constituiu a Perda Real por evapotranspiração, B (mm), e ALT positiva no armazenamento de água a Recarga Real, $\mathrm{R}(\mathrm{mm})$ :

$$
\mathbf{B}=\mathbf{A L T} \Leftrightarrow \mathbf{A L T}<\mathbf{0}
$$

e

$$
\mathbf{R}=\mathbf{A L T} \Leftrightarrow \mathbf{A L T} \geq \mathbf{0}
$$

O Escoamento Superficial Real (RO) foi determinado pelos valores do Excesso de água no solo, EXC (mm)

$$
\mathbf{R O}=\mathbf{E X C}
$$




\subsubsection{2 - Procedimentos para o cálculo do índice de anomalia de umidade (z)}

A partir das variáveis determinadas pelo balanço hídrico foram calculados os parâmetros para o cálculo do índice de anomalia de umidade (z). A Figura 3 apresenta o fluxograma contendo os procedimentos para o cálculo de $\mathrm{z}$.

Primeiramente, calculou-se os coeficientes de Evapotranspiração $(\alpha)$, Recarga $(\beta)$, Perda $(\sigma)$ e Escoamento $(\gamma)$, dados pela razão entre a média mensal de seus valores reais e potenciais. Deste modo:

$$
\begin{gathered}
\alpha=\frac{\overline{\text { ETr }}}{\overline{\text { ETp }}} \\
\beta=\frac{\overline{\mathbf{R}}}{\overline{\mathbf{R P}}} \\
\sigma=\frac{\overline{\mathbf{B}}}{\overline{\mathbf{L}}} \\
\gamma=\frac{\overline{\mathbf{R O}}}{\overline{\mathbf{R O P}}}
\end{gathered}
$$

Estes coeficientes foram utilizados para determinar os valores de evapotranspiração, recarga, perda e escoamento, climaticamente apropriados para as condições existentes - CAFEC (Climatically Appropriate For Existing Conditions). Assim sendo, os valores CAFEC destes parâmetros foram obtidos da seguinte forma:

$$
\begin{gathered}
\mathbf{E T}_{\mathbf{C A F E C}}=\hat{\mathbf{E T}}=\alpha \cdot \mathbf{E T} \mathbf{p} \\
\mathbf{R}_{\text {CAFEC }}=\hat{\mathbf{R}}=\beta \cdot \mathbf{R P} \\
\mathbf{B}_{\text {CAFEC }}=\hat{\mathbf{B}}=\sigma \cdot \mathbf{L}
\end{gathered}
$$




$$
\mathbf{R O}_{\text {CAFEC }}=\hat{\mathbf{R O}}=\gamma \cdot \mathbf{R O P}
$$

A soma algébrica dos valores CAFEC de Evapotranspiração (ET), Recarga $(\hat{\mathrm{R}})$, Perda $(\hat{B})$ e Escoamento ( $\hat{R O})$, constitui a Chuva Climaticamente Apropriada ou Chuva $\operatorname{CAFEC}(\hat{\mathrm{P}})$ :

$$
\mathbf{P}_{\text {CAFEC }}=\hat{\mathbf{P}}=\hat{\mathbf{E T}}+\hat{\mathbf{R}}+\hat{\mathbf{B}}+\hat{\mathbf{R O}}
$$

A diferença entre a chuva observada $(\mathrm{P})$ e $\hat{\mathrm{P}}$ determina o desvio da chuva, $\mathbf{d}(\mathrm{mm})$, calculado mensalmente.

$$
\mathbf{d}=\mathbf{P}-\hat{\mathbf{P}}
$$

A etapa seguinte foi encontrar o Fator de Ajuste Climático $(\overline{\mathbf{K}})$ médio mensal, para cada local, dado pela razão entre a demanda e o suprimento de umidade, de acordo com a definição de Palmer (1965):

$$
\overline{\mathbf{K}}_{j}=1,5 \cdot \log \left(\frac{\mathbf{k}_{j}+2,8}{\overline{\mathbf{D}}_{j}}\right)+0,50
$$

sendo $\overline{\mathbf{D}}_{j}$ a média dos valores absolutos de d para o mês j e, $\mathbf{k}_{j}=\frac{\overline{\mathbf{E T}}_{j}+\overline{\mathbf{R}}_{j}+\overline{\mathbf{R O}}_{j}}{\left(\overline{\mathbf{P}}_{j}+\overline{\mathbf{B}}_{j}\right)}$.

$\mathrm{O}$ produto do fator $\overline{\mathrm{K}}$ pelo desvio da chuva (d) determinou o valor mensal do Índice de Anomalia de Umidade, $\mathbf{z}(\mathrm{mm})$. Esse índice expressa o desvio relativo das condições de umidade local, em determinado mês, em relação às condições médias normais para o mês em questão, e é dado por: 


$$
z=\bar{K} \cdot \mathbf{d}
$$

Para possibilitar a utilização da tabela de classificação de Palmer, os valores de $\mathrm{z}$ foram convertidos para polegadas (pol) e obteve-se, então, a seguinte fórmula para o índice $z$ (pol):

$$
z=\frac{\bar{K} \cdot d}{25}
$$

Após os procedimentos acima descritos, pôde-se obter o fator que determina os valores do PDSI. 


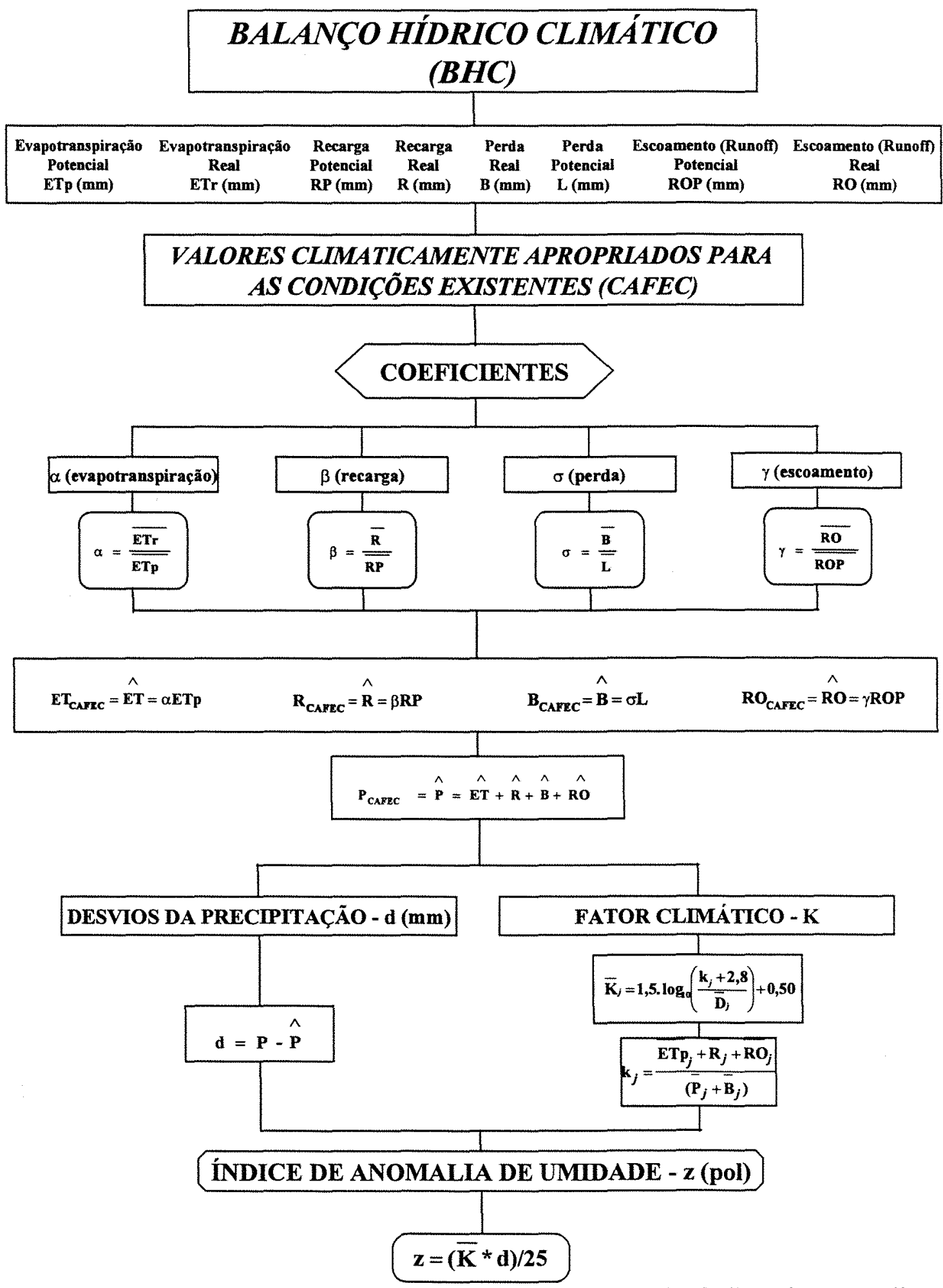

Figura 3 - Fluxograma metodológico para os cálculos do índice de anomalia de umidade, $\mathrm{z}$ 


\subsection{3 - Determinação do PDSI}

\subsubsection{1 - Fator de Duração $\left(X_{i}\right)$}

Sabe-se que um período relativamente curto sob condições de seca poderá baixar os níveis dos reservatórios e lagos, entretanto, o problema não se tornará realmente grave até que um período prolongado de seca faça com que o suprimento de água venha a atingir níveis criticamente baixos. Sendo assim, não são os primeiros meses com pouca chuva, e sim o prolongamento desse período de escassez de chuvas, por um ou mais anos, que poderá ter conseqüências desastrosas para as atividades agrícolas de um determinado local ou região. $O$ parâmetro responsável pela determinação do grau de severidade do período de seca é o fator de duração $\left(\mathbf{X}_{\mathbf{i}}\right)$. $\mathrm{O}$ PDSI é representado pelo valor do fator $\mathrm{X}_{\mathrm{i}}$ para o período de seca.

A equação que determina o valor de $X_{i}$ a cada mês, foi deduzida a partir dos intervalos mais secos. Foram identificados intervalos, iguais ou maiores que quatro meses, que apresentaram índices $\mathrm{z}$ negativos. Efetuando-se a regressão linear entre a média da soma acumulada de $\mathrm{z}$, nestes intervalos, e seus respectivos períodos de duração, em número de meses, chegou-se a equação representativa do índice $X_{i}$, conforme ilustra a Figura 4. 


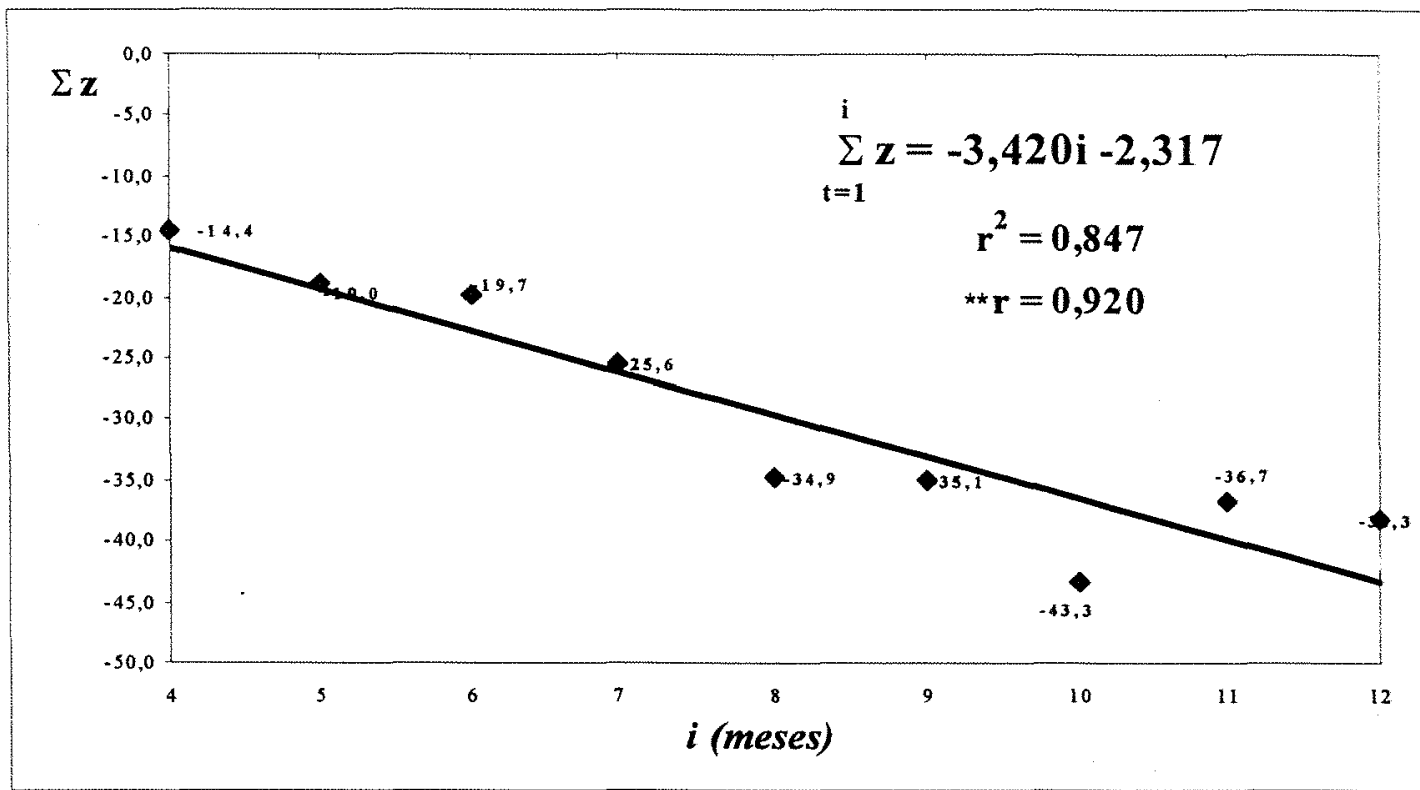

Figura 4 - Gráfico de z acumulado, em relação à duração do período (i, meses), durante os períodos mais secos.

**significante ao nível de $1 \%$ de probabilidade (Weiss \& Hassett, 1982)

Quanto maior o período de duração de uma seca, menor será o valor de $\mathrm{z}$ negativo acumulado. Haja vista que o valor de $\mathrm{X}_{\mathrm{i}}$ varia proporcionalmente em relação ao $\Sigma \mathrm{z}$ e, convencionando-se que o índice $\mathrm{X}$ é proporcional ao inverso simétrico do comprimento do período (i), $\mathbf{X}_{\mathbf{i}} \propto \frac{1}{(\mathbf{3 , 4 2 0} \mathbf{i}+\mathbf{2 , 3 1 7 )}}$, chegou-se à equação de $X_{\mathrm{i}}$, na forma abaixo descrita:

$$
X_{i}=\frac{\sum_{t=1}^{i} z_{t}}{(3,420 i+2,317)}
$$

em que i refere-se ao mês corrente, ou seja, o mês que está sendo calculado, e t é o período (em meses), a partir do primeiro mês do intervalo seco. 
Para determinar os incrementos mensais de severidade de seca e, deste modo, determinar a contribuição de cada mês para o valor de $X_{i}$, fez-se $i=1$ na equação 22 e obteve-se,

$$
\mathbf{X}_{1}=\frac{\mathbf{z}_{1}}{\mathbf{5 , 7 3 7}}
$$

Deste modo, para o mês inicial $\left(\mathrm{X}_{\mathrm{o}}=0\right)$ de um dado período seco:

$$
\mathbf{X}_{1}-\mathbf{X}_{0}=\Delta \mathbf{X}_{1}=\mathbf{z}_{1} / 5,737
$$

Observa-se, a partir da equação 22 e da Figura 4, que $\Sigma z$ deve aumentar com o aumento de $t$ para manter um determinado valor de $X$, isto é, para que $\Delta X=0$. Portanto, a taxa à qual $\mathrm{z}$ deve aumentar para que a variação de $\mathrm{X}$ seja constante, $\Delta \mathrm{X}=0$, depende dos valores precedentes de X. Sendo assim, sugere-se que para os meses subsequentes ao mês inicial de um período seco, deve-se adicionar um termo à equação 24:

$$
\Delta \mathbf{X}_{\mathrm{i}}=\left(\mathbf{z}_{\mathrm{i}} / \mathbf{5 , 7 3 7 )}+\mathbf{c} \mathbf{X}_{\mathrm{i}-1}\right.
$$

sendo $\Delta \mathrm{X}_{\mathrm{i}}=\mathrm{X}_{\mathrm{i}}-\mathrm{X}_{\mathrm{i}-1}$. Logo, substituindo $\Delta \mathrm{X}_{\mathrm{i}}$ na equação 25 teremos, $\mathbf{X}_{\mathrm{i}}=\mathbf{X}_{\mathrm{i}-1}+\frac{\mathbf{z}_{\mathrm{i}}}{\mathbf{5 , 7 3 7}}+\mathbf{c} \mathbf{X}_{\mathrm{i}-1}$, ou simplificando:

$$
X_{i}=\frac{z_{i}}{5,737}+(1+c) X_{i-1}
$$




\subsubsection{2 - Coeficiente $c$}

A tabela 1 mostra os meses em que $\Delta \mathrm{X}=0$, nas diversas localidades estudadas, bem como os valores de $\mathrm{z}, \Sigma \mathrm{z}, \mathrm{X}_{\mathrm{i}}, \mathrm{X}_{\mathrm{i}-1}$ e c, correspondentes.

Tabela 1 - Valores de $\mathrm{z}, \Sigma \mathrm{z}, \mathrm{X}_{\mathrm{i}}, \mathrm{X}_{\mathrm{i}-1}$ e c, nos meses em que $\Delta \mathrm{X}_{\mathrm{i}}=0$, na área de estudo.

\begin{tabular}{|c|c|c|c|c|c|c|c|c|}
\hline LOCALIDADE & ANO & MÊS & i & $\mathbf{z}_{\mathbf{i}}$ & $\Sigma \mathbf{z}$ & $\mathbf{X}_{\mathbf{i}}$ & $\mathbf{X}_{\mathbf{i}-1}$ & c \\
\hline Auriflama & 1978 & out & 5 & $-1,99$ & $-11,2$ & $-0,58$ & $-0,58$ & $-0,20$ \\
\hline Auriflama & 1985 & jul & 3 & $-1,71$ & $-6,2$ & $-0,49$ & $-0,49$ & $-0,15$ \\
\hline Auriflama & 1991 & set & 5 & $-1,60$ & $-9,3$ & $-0,48$ & $-0,48$ & $-0,13$ \\
\hline Alfredo Marcondes & 1986 & set & 4 & $-2,06$ & $-9,6$ & $-0,60$ & $-0,60$ & $-0,22$ \\
\hline Alfredo Marcondes & 1986 & nov & 6 & $-2,06$ & $-13,9$ & $-0,61$ & $-0,61$ & $-0,22$ \\
\hline Adamantina & 1994 & set & 7 & $-2,74$ & $-21,5$ & $-0,82$ & $-0,82$ & $-0,39$ \\
\hline Adamantina & 1996 & ago & 7 & $-5,64$ & $-43,3$ & $-1,65$ & $-1,65$ & $-1,62$ \\
\hline Presidente Prudente & 1968 & jun & 3 & $-1,69$ & $-6,3$ & $-0,50$ & $-0,50$ & $-0,15$ \\
\hline Presidente Prudente & 1968 & set & 6 & $-1,70$ & $-10,9$ & $-0,48$ & $-0,48$ & $-0,14$ \\
\hline Salto Grande & 1985 & dez & 6 & $-2,34$ & $-15,4$ & $-0,67$ & $-0,67$ & $-0,27$ \\
\hline Votuporanga & 1988 & jul & 3 & $-3,75$ & $-13,8$ & $-1,09$ & $-1,09$ & $-0,71$ \\
\hline Votuporanga & 1993 & nov & 7 & $-3,32$ & $-25,8$ & $-0,98$ & $-0,98$ & $-0,57$ \\
\hline Votuporanga & 1996 & ago & 3 & $-4,40$ & $-16,2$ & $-1,29$ & $-1,29$ & $-0,99$ \\
\hline
\end{tabular}

A partir da equação 26 foram calculados os valores de c para cada localidade, obtendo-se um valor médio de c - $\overline{\mathbf{c}}=\mathbf{- 0 , 4 4}$ - e substituindo na equação 26 . Deste modo, a mesma pôde ser escrita da seguinte forma:

$$
X_{i}=\frac{z_{i}}{5,737}+0,56 X_{i-1}
$$




\subsubsection{3 - Início e fim de um período seco}

Considerou-se que um período de seca estava estabelecido, isto é, definitivamente iniciado, sempre que o índice $\mathrm{X}$ atingisse um valor menor ou igual à $1,00(\mathrm{X} \leq-1,00)$ e, o mesmo era considerado encerrado sempre que o índice de anomalia de umidade, $\mathrm{z}$ fosse maior ou igual ao valor de $\mathrm{z}_{e}\left(\mathrm{z} \geq \mathrm{z}_{e}\right)$. Sendo $\mathrm{z}_{e}$ definido como a umidade necessária para reduzir a severidade de uma seca até o valor de $-0,50$, em um dado mês e descrito na forma:

$$
z_{e}=-2,869-3,213 \cdot X_{i-1}
$$

\subsubsection{4 - Classificação de um período de seca}

Após os cálculos de $\mathbf{X}_{\mathbf{i}}$, observados os critérios que condicionam o fim $\mathrm{e}$ o início de uma seca e identificados os períodos de ocorrência desses eventos, os índices foram agrupados conforme a tabela desenvolvida por Palmer (1965), que classifica os eventos de seca de acordo com os valores de $X_{i}$ associados a cada classe de seca (Quadro 2).

QUADRO 2 - Classificação de Palmer para períodos secos.

\begin{tabular}{|c|c|}
\hline $\mathbf{X}_{\mathbf{i}}$ & Classe \\
\hline 0,49 a $-0,49$ & aproximadamente normal - $\mathbf{n}$ \\
\hline$-0,50$ a $-0,99$ & seca incipiente - si \\
\hline$-1,00$ a $-1,99$ & seca suave - ss \\
\hline$-2,00$ a $-2,99$ & seca moderada - sm \\
\hline$-3,00$ a $-3,99$ & seca severa - sse \\
\hline$\leq-4,00$ & seca extrema - se \\
\hline
\end{tabular}




\section{4 - RESULTADOS E DISCUSSÃO}

Deve-se esclarecer que, as localidades utilizadas neste trabalho, estão sendo representadas por ocorrência de chuvas em poucos pontos de coleta. Admite-se, portanto que, tais pontos sejam representativos de uma grande área o que, no caso da chuva, por sua natureza descontínua, pode não ser verdade. Reichardt et al. (1995), analisando a variabilidade das chuvas em Piracicaba, Estado de São Paulo, observou que os dados colhidos em um ponto padrão de observação, não permitiam uma boa representação de áreas à distâncias maiores que $1.000-2.500 \mathrm{~m}$, para médias diárias, mensais, ou trimestrais, fato que enfatiza a importância da variabilidade espacial.

Haja vista a indisponibilidade de uma malha de postos mais abrangente, optou-se por trabalhar com os pontos de observação disponíveis.

\section{1 - Freqüência de meses secos}

A Tabela 2 mostra para toda a região, e dentro do período analisado, a freqüência de meses com seca, ou seja, meses que apresentaram valores de $X_{i}<-1,00$. Os meses mais secos foram agosto e setembro, com uma freqüência relativa média de $26 \% \mathrm{e}$ $22 \%$ dos eventos, respectivamente. Os meses menos secos foram novembro e dezembro, com $5 \%$ e $4 \%$ dos eventos. Adamantina foi a localidade com a maior freqüência de meses com seca, com um total de $46 \%$ dos meses secos, enquanto que Salto Grande apresentou apenas $4 \%$ dos meses com seca. 
Tabela 2 - Freqüência relativa $(\%)$ de meses com seca de qualquer intensidade $\left(\mathrm{X}_{\mathrm{i}}<-1,00\right)$

\begin{tabular}{|c|c|c|c|c|c|c|c|c|c|c|c|c|c|}
\hline LOCALIDADE & Jan & $\mathrm{Fev}$ & Mar & $A b r$ & $M a i$ & Jun & Jul & Ago & Set & Out & Nov & Dez & NONS \\
\hline Auriflama & 19 & 35 & 23 & 15 & 23 & 19 & 12 & 8 & 15 & 8 & 4 & 8 & 16 \\
\hline Major Prado & 11 & 22 & 26 & 26 & 19 & 11 & 4 & 7 & 15 & 7 & 4 & 7 & 13 \\
\hline Água Limpa & 15 & 26 & 26 & 19 & 19 & 11 & 7 & 0 & 7 & 0 & 0 & 7 & 11 \\
\hline $\begin{array}{c}\text { Alfredo } \\
\text { Marcondes }\end{array}$ & 17 & 3 & 3 & 14 & 14 & 8 & 11 & 42 & 28 & 8 & 6 & 0 & 13 \\
\hline Adamantina & 24 & 54 & 54 & 73 & 51 & 30 & 41 & 65 & 41 & 19 & 5 & 5 & 39 \\
\hline Pontal & 24 & 38 & 19 & 14 & 10 & 5 & 5 & 0 & 0 & 0 & 0 & 0 & 10 \\
\hline $\begin{array}{c}\text { Presidente } \\
\text { Prudente }\end{array}$ & 8 & 3 & 6 & 8 & 17 & 6 & 3 & 25 & 25 & 8 & 8 & 3 & 10 \\
\hline Salto Grande & 8 & 8 & 8 & 4 & 0 & 0 & 0 & 0 & 4 & 0 & 8 & 4 & 4 \\
\hline Votuporanga & 8 & 0 & 0 & 0 & 4 & 33 & 83 & 92 & 67 & 13 & 8 & 0 & 26 \\
\hline W16ula & 15 & 21 & 18 & 19 & 17 & 14 & 18 & 26 & 22 & 7 & 5 & 4 & 16 \\
\hline
\end{tabular}

Esses resultados são coerentes, quando relacionados com aqueles obtidos para a deficiência hídrica (DEF) estimada pelo balanço hídrico para a região (Tabela 3). Os meses que mais apresentaram deficiência hídrica foram julho, agosto e setembro, com uma média de $78 \%, 83 \%$ e $67 \%$ dos eventos, respectivamente. Dezembro, janeiro e fevereiro, com $26 \%, 27 \%$ e $38 \%$, apresentaram a menor frequiência de DEF.

As localidades que obtiveram as maiores freqüências de meses com DEF foram Água Limpa, Alfredo Marcondes, Adamantina e Votuporanga, com freqüência média entre $57 \%$ e $58 \%$ de meses secos. As menores freqüências de meses secos ocorreram em Salto Grande e Pontal, com média de $47 \%$ e $49 \%$ dos eventos, respectivamente.

Vale ressaltar aqui que, obviamente, a frequêencia de meses com deficiência hídrica é maior que a quantidade de meses que aparecem com índice $X_{i} \leq-$ 1,00 . Isso porque o método considera como mês seco aquele em que $\mathrm{d}<0$, isto é, aquele em que a precipitação estimada, $\hat{\mathrm{P}}$ é maior que a precipitação observada, $\mathrm{P}$; portanto, um mês que apresente deficiência hídrica não significa, necessariamente, que há uma seca estabelecida. Tal fato é decorrente do caráter acumulativo do PDSI (Alley, 1984, Heddinghaus \& Sabol, 1991). 
Tabela 3 - Freqüência relativa (\%) de meses com Deficiência Hídrica (DEF)

\begin{tabular}{|c|c|c|c|c|c|c|c|c|c|c|c|c|c|}
\hline LOCALIDADE & Jan & $\mathrm{Fev}$ & Mar & $A b r$ & Mai & Jun & Jul & Ago & Set & Out & Nov & Dez & NIOUL \\
\hline Auriflama & 23 & 27 & 31 & 62 & 50 & 81 & 92 & 88 & 73 & 64 & 28 & 19 & 53 \\
\hline Major Prado & 11 & 26 & 44 & 63 & 59 & 81 & 85 & 93 & 78 & 59 & 30 & 19 & 54 \\
\hline Água Limpa & 19 & 30 & 41 & 70 & 59 & 78 & 85 & 89 & 70 & 63 & 67 & 26 & 58 \\
\hline $\begin{array}{c}\text { Alfredo } \\
\text { Marcondes }\end{array}$ & 36 & 28 & 61 & 75 & 50 & 67 & 75 & 81 & 72 & 53 & 57 & 36 & 58 \\
\hline Adamantina & 27 & 30 & 51 & 78 & 59 & 65 & 76 & 92 & 76 & 51 & 49 & 27 & 57 \\
\hline Pontal & 48 & 67 & 52 & 48 & 29 & 43 & 62 & 62 & 43 & 52 & 48 & 33 & 49 \\
\hline $\begin{array}{c}\text { Presidente } \\
\text { Prudente }\end{array}$ & 31 & 44 & 53 & 72 & 39 & 61 & 69 & 75 & 64 & 44 & 53 & 36 & 53 \\
\hline Salto Grande & 29 & 38 & 42 & 50 & 38 & 42 & 63 & 75 & 54 & 46 & 54 & 33 & 47 \\
\hline Votuporanga & 17 & 50 & 33 & 58 & 63 & 83 & 96 & 92 & 75 & 71 & 50 & 8 & 58 \\
\hline$=4,1 / \mathrm{J} / \mathrm{b}$ & 27 & 38 & 45 & 64 & 49 & 67 & 78 & 83 & 67 & 56 & 48 & 26 & 54 \\
\hline
\end{tabular}

Quando se especifica a classe de seca, a distribuição de freqüência com a qual elas ocorrem tende a se alterar. A Figura 5 ilustra a variação mensal e anual do PDSI $\left(X_{i}\right)$, na região. Percebe-se que os períodos de ocorrência de secas suaves e/ou moderadas estiveram concentrados entre os meses de abril e setembro, ocorrendo com maior freqüência em agosto, normalmente mais seco. No entanto, as secas severas e/ou extremas concentraram-se em janeiro e fevereiro, no auge da estação chuvosa na região, conforme verificado por vários autores (Schröder, 1956; Monteiro, 1973; Sant'Anna Neto, 1996). Adamantina foi a localidade onde se verificou a maior freqüência de secas, tanto suaves e moderadas, como severas e extremas. 

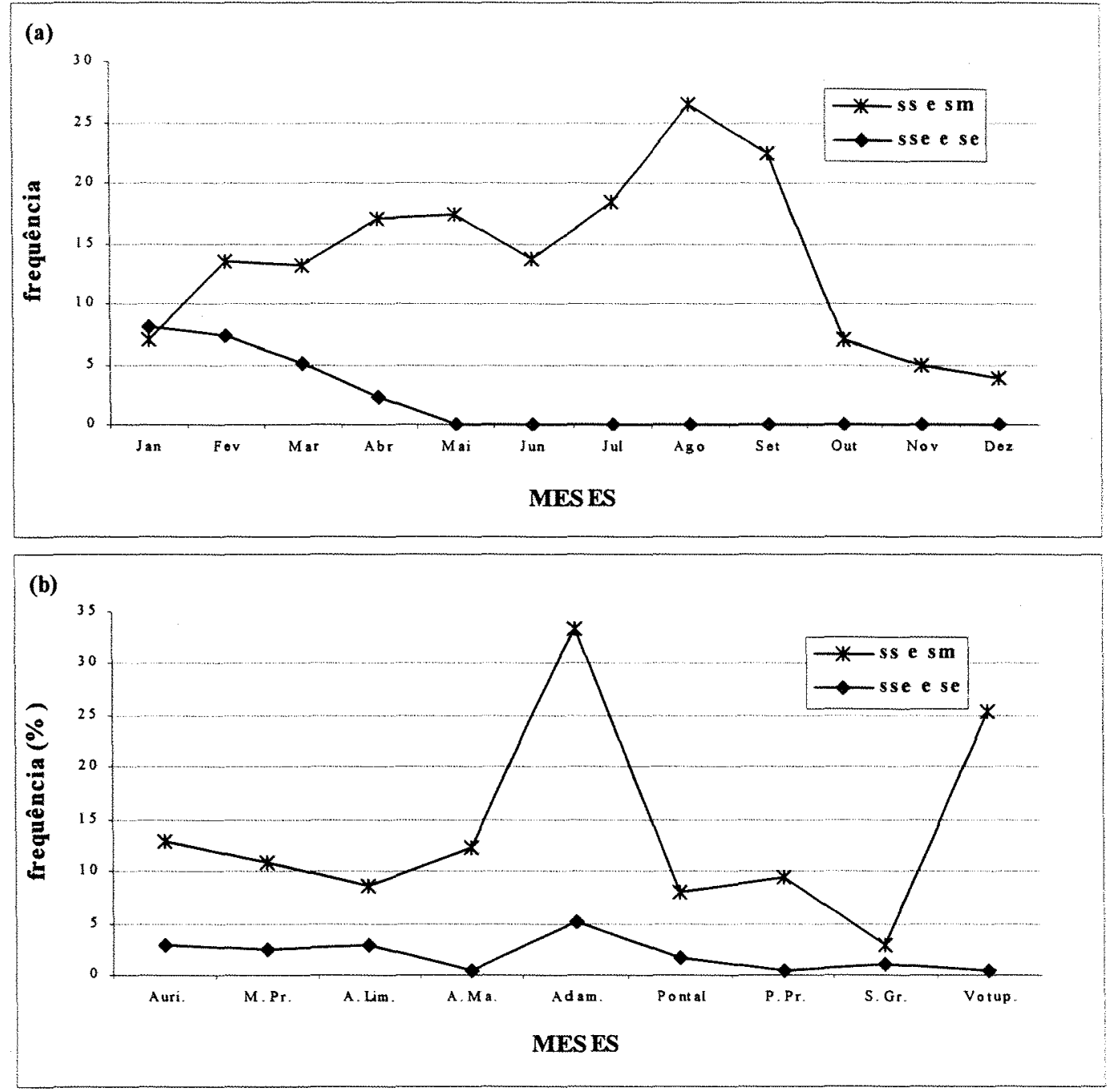

Figura 5 - (a) Freqüência média mensal de secas suave (ss) e moderada (sm), severa (sse) e extrema (se); (b) Freqüência média anual de meses com seca suave (ss), moderada (sm), severa (sse) e extrema (se), na região estudada.

\section{2 - Períodos de seca identificados}

Foram identificados 69 eventos de seca, com duração entre 4 e 11 meses (Quadro 3). Períodos com 5 meses contínuos de seca ocorreram mais frequentemente, totalizando 17 eventos. Períodos mais longos foram menos frequentes. De modo geral, pode-se afirmar que a região oeste e sudoeste do Estado de São Paulo é submetida a 
períodos de seca que, dependendo da duração, podem ocorrer a cada 1 e 6 anos, aproximadamente (Figura 6).

QUADRO 3 - Sumário do número de secas ocorridas nas diferentes localidades, durante as séries de anos estudadas, de acordo com seus períodos de duração (meses)

\begin{tabular}{|c|c|c|c|c|c|c|c|c|c|}
\hline \multirow{2}{*}{ LOCALIDADES } & \multicolumn{10}{|c|}{ Período (meses) } & \multirow{2}{*}{ REGIÃO } \\
\cline { 2 - 10 } & $\mathbf{4}$ & $\mathbf{5}$ & $\mathbf{6}$ & $\mathbf{7}$ & $\mathbf{8}$ & $\mathbf{9}$ & $\mathbf{1 0}$ & $\mathbf{1 1}$ \\
\hline Auriflama & 1 & 2 & 1 & 1 & 0 & 1 & 0 & 0 & 6 \\
\hline Major Prado & 1 & 1 & 1 & 1 & 2 & 0 & 0 & 0 & 6 \\
\hline Água Limpa & 1 & 1 & 0 & 1 & 1 & 0 & 0 & 0 & 4 \\
\hline Alfredo Marcondes & 0 & 2 & 0 & 3 & 1 & 0 & 0 & 0 & 6 \\
\hline Adamantina & 5 & 4 & 2 & 1 & 2 & 5 & 5 & 1 & 25 \\
\hline Pontal & 1 & 0 & 1 & 1 & 0 & 0 & 0 & 0 & 3 \\
\hline Presidente Prudente & 1 & 1 & 1 & 1 & 0 & 1 & 0 & 0 & 5 \\
\hline Salto Grande & 0 & 0 & 0 & 0 & 1 & 0 & 0 & 0 & 1 \\
\hline Votuporanga & 1 & 6 & 4 & 2 & 0 & 0 & 0 & 0 & 13 \\
\hline REGIÃO & 11 & 17 & 10 & 11 & 7 & 7 & 5 & 1 & 69 \\
\hline
\end{tabular}

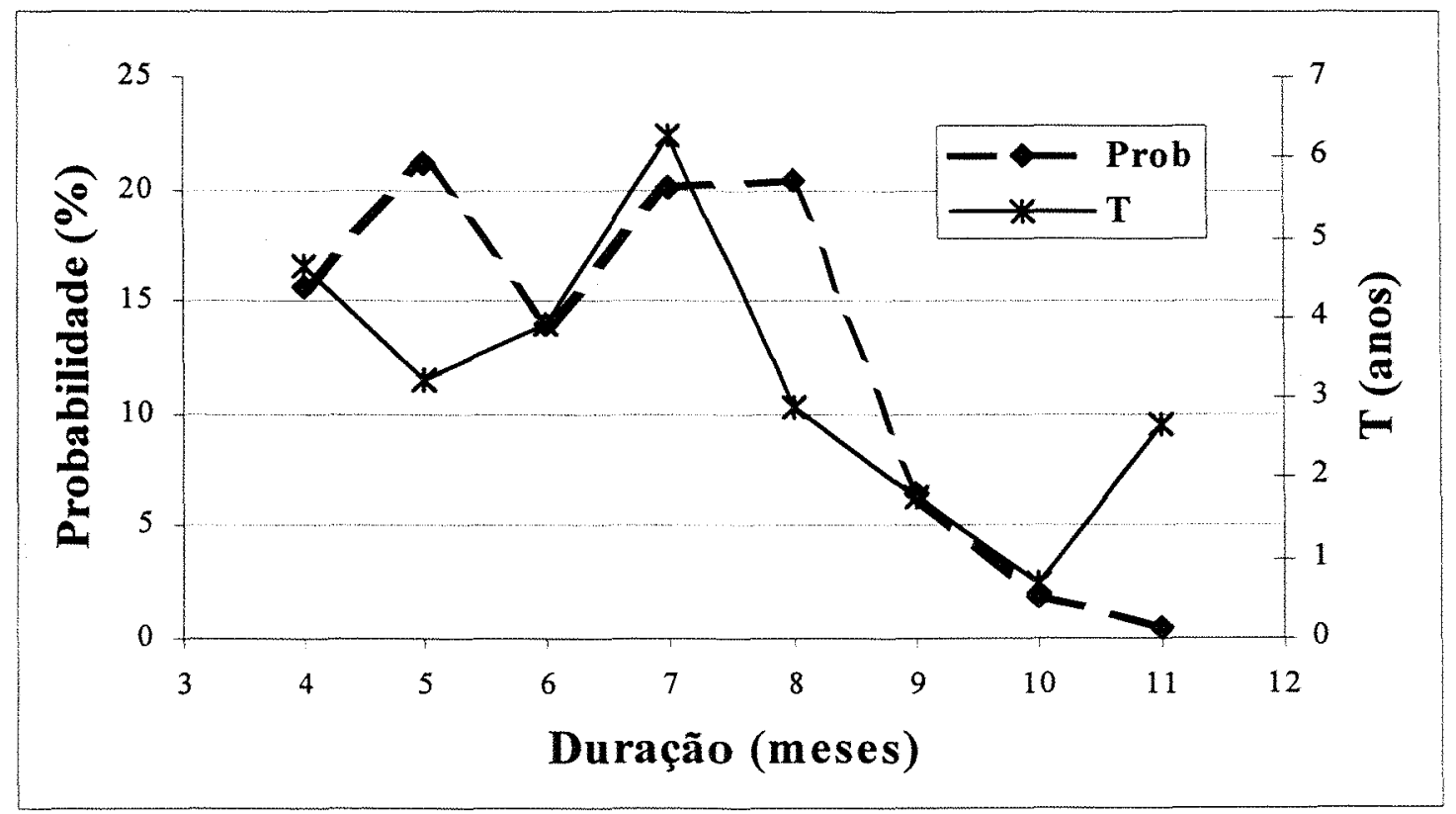

Figura 6 - Probabilidade (\%) e período de retorno T (anos), das secas na região 
O Quadro 4 mostra um resumo das maiores e/ou mais intensas secas, ocorridas na área de trabalho. A seca de maior intensidade ocorreu em Major Prado (Araçatuba/SP), com índice $\mathrm{X}_{\mathrm{i}}=-28,26 \mathrm{e}$, a mais longa ocorreu em Adamantina, com 11 meses de duração, embora tenha apresentado $X_{i}$ de apenas $-1,82$.

QUADRO 4 - Probabilidade (\%) de ocorrência de secas com, pelo menos, o número de meses indicado e, resumo dos períodos secos mais longos e de maior intensidade

\begin{tabular}{|c|c|c|c|c|c|c|c|c|c|c|c|c|c|c|c|}
\hline \multirow{3}{*}{ POSTOS } & \multirow{2}{*}{\multicolumn{8}{|c|}{$\begin{array}{c}\text { Probabilidade (\%) de ocorrência de } \\
\text { secas com, pelo menos, o } N^{\circ} \text { de meses } \\
\text { indicados }\end{array}$}} & \multicolumn{7}{|c|}{$\begin{array}{c}\text { Maior seca observada (duração e } \\
\text { intensidade) }\end{array}$} \\
\hline & & & & & & & & & \multicolumn{2}{|c|}{ Período } & \multirow{2}{*}{$\mathbf{X}_{\mathbf{i}} \operatorname{Max}$} & \multicolumn{4}{|c|}{$\mathrm{X}_{\mathrm{i}} \leq$} \\
\hline & d & (3) & 6 & 27 & 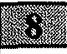 & 9 & 10 & 211 & $\mathrm{De}$ & Até & & -4 & -3 & -2 & -1 \\
\hline \multirow{2}{*}{ Auriflama } & \multirow{2}{*}{17} & \multirow{2}{*}{33} & \multirow{2}{*}{17} & \multirow{2}{*}{17} & \multirow{2}{*}{0} & \multirow{2}{*}{17} & \multirow{2}{*}{0} & \multirow{2}{*}{0} & $\operatorname{Jan} / 82$ & $\mathrm{Jul} / 82$ & $-25,10$ & 4 & 0 & 0 & 3 \\
\hline & & & & & & & & & Fev/94 & Out/94 & $-1,94$ & 0 & 0 & 0 & 6 \\
\hline Major Prado & 17 & 17 & 17 & 17 & 33 & 0 & 0 & 0 & $\operatorname{Jan} / 96$ & Ago/96 & $-28,26$ & 4 & 0 & 0 & 4 \\
\hline \multirow{2}{*}{ Água Limpa } & \multirow{2}{*}{25} & \multirow{2}{*}{25} & \multirow{2}{*}{0} & \multirow{2}{*}{25} & \multirow{2}{*}{25} & \multirow{2}{*}{0} & \multirow{2}{*}{0} & \multirow{2}{*}{0} & $\operatorname{Jan} / 79$ & $\mathrm{Jul} / 79$ & $-17,00$ & 3 & 1 & 0 & 1 \\
\hline & & & & & & & & & $\operatorname{Jan} / 96$ & Ago/96 & $-9,82$ & 2 & 1 & 1 & 3 \\
\hline $\begin{array}{c}\text { Alfredo } \\
\text { Marcondes }\end{array}$ & 0 & 33 & 0 & 50 & 17 & 0 & 0 & 0 & --- & --- & --- & $\cdots$ & $\cdots$ & -- & --- \\
\hline \multirow{3}{*}{ Adamantina } & \multirow{3}{*}{21} & \multirow{3}{*}{17} & \multirow{3}{*}{8} & \multirow{3}{*}{4} & \multirow{3}{*}{8} & \multirow{3}{*}{21} & \multirow{3}{*}{17} & \multirow{3}{*}{4} & $\operatorname{Jan} / 79$ & Ago/79 & $-11,36$ & 3 & 0 & 1 & 3 \\
\hline & & & & & & & & & Fev/88 & Dez/88 & $-1,82$ & 0 & 0 & 0 & 9 \\
\hline & & & & & & & & & $\operatorname{Jan} / 92$ & Abr/92 & $-15,41$ & 3 & 1 & 0 & 0 \\
\hline Pontal & 33 & 0 & 33 & 33 & 0 & 0 & 0 & 0 & $\operatorname{Jan} / 79$ & Abr/79 & $-4,10$ & 1 & $\cdots$ & 1 & 2 \\
\hline Presidente & 20 & 20 & 20 & 20 & 0 & 20 & 0 & 0 & $\operatorname{Jan} / 64$ & Set/64 & $-3,10$ & 0 & 1 & 2 & 2 \\
\hline Prudente & & 20 & & & & 20 & 0 & & $\operatorname{Jan} / 79$ & $\mathrm{Abr} / 79$ & $-4,30$ & 1 & $\ldots$ & $\cdots$ & 2 \\
\hline Salto Grande & 0 & 0 & 0 & 0 & 100 & 0 & 0 & 0 & $\operatorname{Jan} / 84$ & Ago/84 & $-3,75$ & - & 2 & $-\cdots$ & 1 \\
\hline Votuporanga & 8 & 46 & 31 & 15 & 0 & 0 & 0 & 0 & $\mathrm{Mai} / 94$ & Nov/94 & $-2,14$ & 0 & 0 & 1 & 3 \\
\hline
\end{tabular}

\subsection{1 - Secas em Auriflama/SP}

A região de Auriflama foi submetida a 6 eventos de seca, com duração média de 6 meses, durante a série de 26 anos analisada. A maioria delas foi classificada como secas suaves (Anexo A1), sem conseqüências muito graves para o setor agrícola. $\mathrm{O}$ período de seca mais longo identificado ocorreu entre fevereiro e outubro de 1994; todavia, o valor mínimo de $\mathrm{X}_{\mathrm{i}}$ durante este período não foi menor que $-1,94$, o que caracteriza uma seca bem amena. A seca mais intensa registrada ocorreu entre janeiro e julho de 1982 , com $X_{i}=-25,10$, no primeiro mês de seca - janeiro/ 82 . 
A Figura 7a e 7b, mostra a variação da precipitação estimada e observada, e relaciona com a deficiência hídrica, ocorridas durante os eventos de 82 e 94 . Em janeiro de 82, quando $X_{i}$ apresentou seu valor mínimo, a deficiência hídrica foi cerca de $64 \mathrm{~mm}$. Entretanto, durante a seca de 94 o maior valor de deficiência $(\mathrm{mm})$ não coincidiu com o valor mínimo de $\mathrm{X}_{\mathrm{i}}$ para o período, embora, note-se uma tendência dos valores de $\mathrm{Xi}$ acompanhar a marcha da deficiência, nos dois períodos de seca.
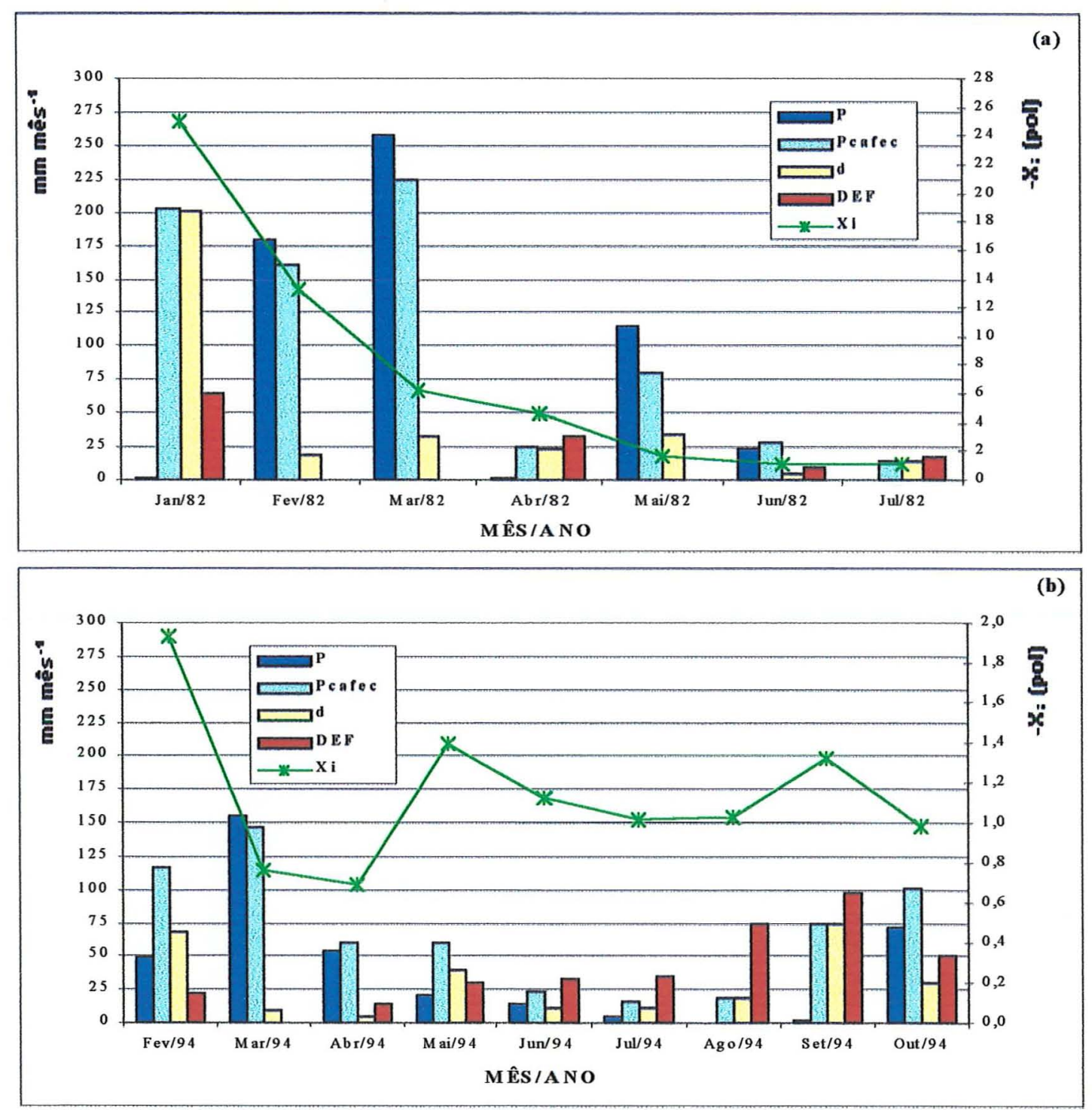

Figura 7 - Representação gráfica de $P$ ( $\mathrm{mm} / \mathrm{mês}), P_{\text {cafec }}(\mathrm{mm} / \mathrm{mês}), d$ ( $\left.\mathrm{mm} / \mathrm{mês}\right)$, DEF (mm/mês) e, $X_{\mathrm{i}}$, em Auriflama - SP: (a) período - Jan/82 a Jul/82; (b) período - Fev/94 a Out/94. 
Observou-se também que sempre que $\mathrm{P}_{\text {cafec }}$ foi maior que $\mathrm{P}$, ocorreu deficiência (DEF), o que poderia inferir uma correlação positiva entre as precipitações observada e estimada $(\mathrm{d}=\mathrm{P}$ - $\hat{\mathrm{P}})$, e a deficiência hídrica.

\subsection{2 - Secas na região de Araçatuba/SP - Major Prado e Água Limpa}

Ao todo, nestas duas localidades, dentro do perímetro de abrangência da região de Araçatuba/SP, ocorreram 10 eventos de seca. A duração média das secas ocorridas nesta região foi de 6 meses. A maioria das secas ocorridas nessas duas localidades foram classificadas como suaves a moderadas (Anexos A2 e A3). Os eventos mais significativos ocorreram de janeiro a agosto de 1996, em Major Prado; e, de janeiro a julho de 1979, e janeiro a agosto de 1996, em Água Limpa.

Dos seis eventos ocorridos em Major Prado, 4 foram considerados de pouca intensidade, ou seja, foram períodos de secas suaves a moderadas. Durante o evento mais intenso, de janeiro/96 a agosto/96, $X_{i}$ chegou a atingir o valor de $-28,26$, em janeiro, e foi o mais alto valor negativo registrado do índice, dentre todos os eventos identificados. $\mathrm{O}$ desvio (d) da precipitação nesse mês foi de $-256 \mathrm{~mm}$, e a deficiência hídrica de $43 \mathrm{~mm}$, fato que explica o elevado valor de $X_{i}$ (Figura 8).

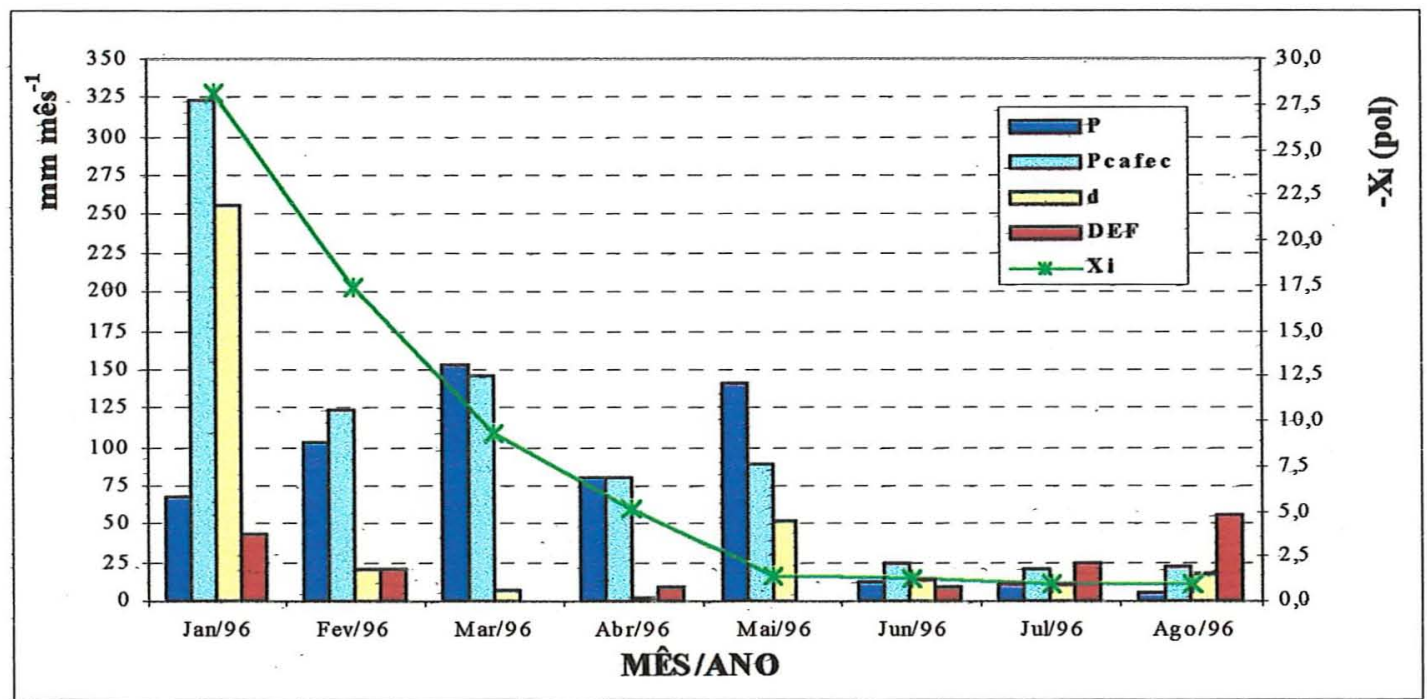

Figura 8 - Representação gráfica de $P$ (mm/mês), e $P_{\text {cafec }}$ ( $\left.\mathrm{mm} / \mathrm{mês}\right)$, d (mm/mês), DEF (mm), e $\mathrm{X}_{\mathrm{i}}$, em Major Prado - Araçatuba/SP (período - Jan/96 a Ago/96). 
Em Água Limpa, dos 4 eventos ocorridos, 3 foram bastante intensos. A seca mais longa ocorreu entre janeiro e agosto de 1996, com $X_{i}=-9,82$, em janeiro, caracterizando uma seca bastante intensa. Entretanto, o período de seca considerado mais intenso foi o de janeiro a julho de 1979 , quando $X_{i}$ alcançou o valor de $-17,00$, também em janeiro (Figura 9a e 9b). Mais uma vez a explicação para tal fato encontra-se no desvio de precipitação, que em janeiro de 1979 foi de $-202 \mathrm{~mm}$, enquanto que, no mesmo mês, em 1996 este valor foi de $-114 \mathrm{~mm}$.
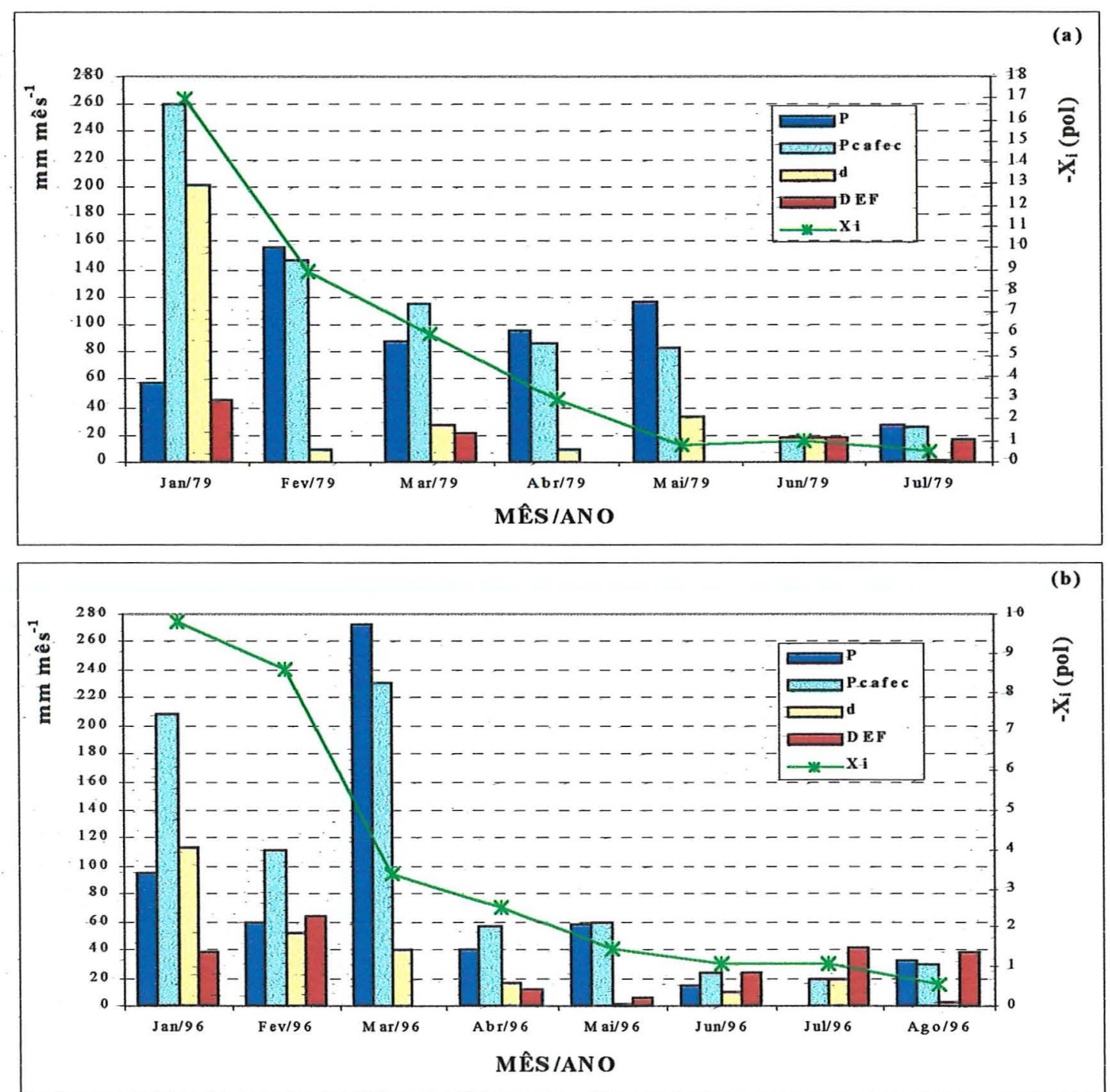

Figura 9 - Representação gráfica de $\mathbf{P}$ ( $\mathrm{mm} / \mathrm{mês}), P_{\text {cafec }}(\mathrm{mm} / \mathrm{mês}), d$ ( $\left.\mathrm{mm} / \mathrm{mês}\right)$, DEF (mm/mês) e, $X_{i}$, em Água Limpa - Araçatuba - SP: (a) período - Jan/79 a $\mathrm{Jul} / 79$; (b) período - Jan/96 a Ago/96) 


\subsection{3 - Secas na região de Adamantina/SP}

A região de Adamantina foi a que apresentou a maior freqüência de secas em toda a área de estudo. Dentre as 69 secas identificadas, 25 ocorreram em Adamantina. Foi também onde se observou a maior incidência de secas severas e extremas, embora a predominância de secas suaves a moderadas seja notória (Anexo A5).

A Figura 10 ilustra os três eventos secos mais significativos ocorridos na região: entre janeiro e agosto de 1996; de fevereiro a dezembro de 1988; e, de janeiro e abril de 1992. Os eventos de 79 e 92 foram muito fortes, chegando a apresentar $X_{i}$ igual à $-11,36$ e $-15,41$, respectivamente. A seca de 88 foi um evento ameno, com o menor valor de $\mathrm{Xi}=-1,82$, entretanto, sua duração prolongada, por quase um ano, pode ter tido consequiências consideráveis sobre os sistemas agro-ecológicos.

Durante o evento de 79 , observou-se a ocorrência de deficiência hídrica em, praticamente, todo o período. Em todos os meses a precipitação observada esteve abaixo da precipitação estimada, à exceção de maio, quando um pequeno desvio positivo de $8 \mathrm{~mm}$, assinalou a desintensificação do evento.

A seca de 92, apesar de sua curta duração, foi extremamente forte. $\mathrm{O}$ único mês com deficiência hídrica, no entanto, foi janeiro (deficiência de $48 \mathrm{~mm}$ ). Tal fato, provavelmente, ocorreu devido aos efeitos de DEF e desvios negativos na precipitação, nos meses que antecederam a este evento, haja vista o caráter acumulativo do método. 

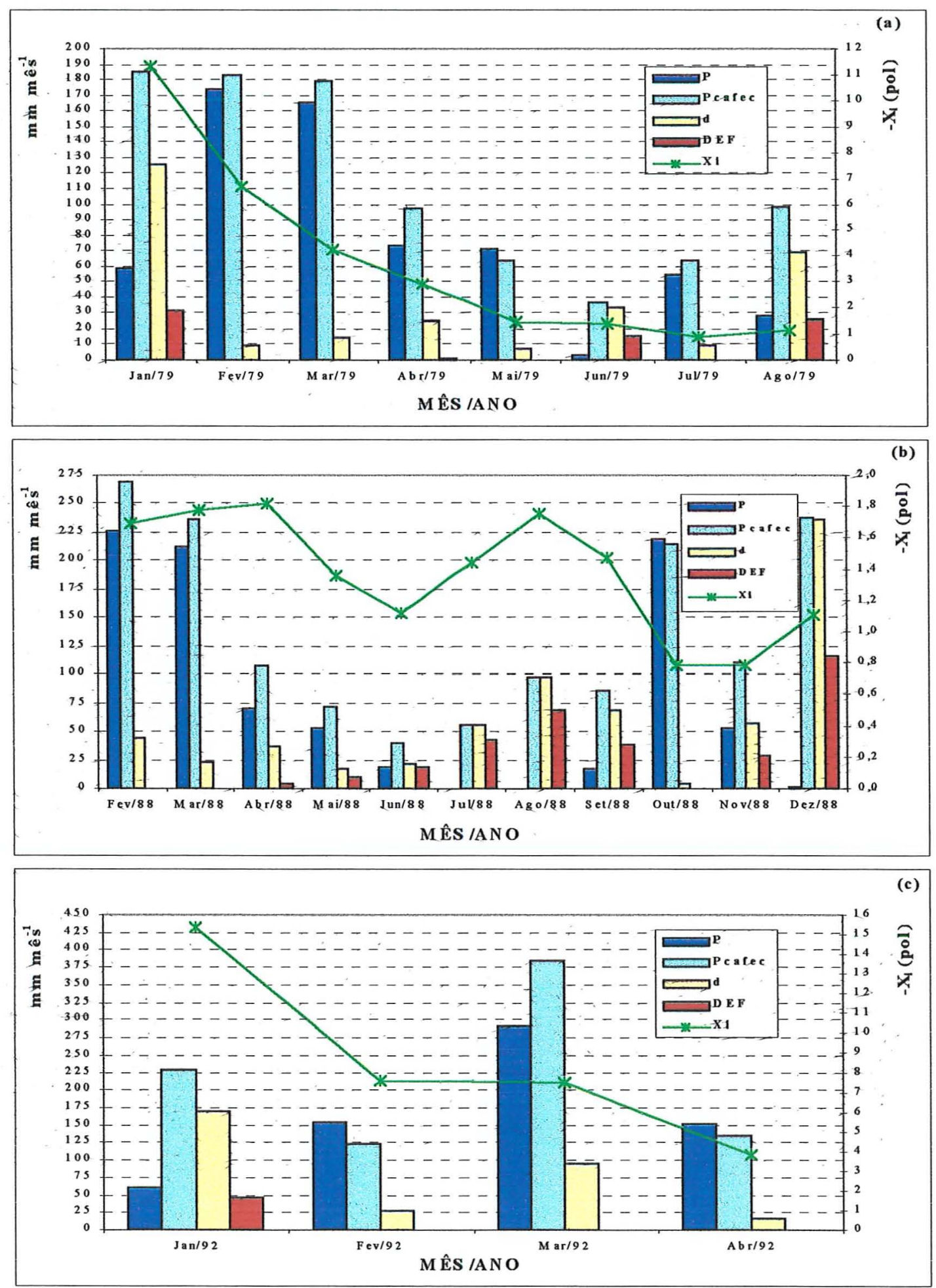

Figura 10 - Representação gráfica de $P$ (mm/mês), $P_{\text {cafec }}(\mathrm{mm} / \mathrm{mês}), \mathrm{d}$ (mm/mês), DEF (mm/mês) e, $X_{i}$, em Adamantina/SP: (a) período - Jan/79 a Ago/79); (b) período - Fev/88 a Dez/88; (c) período - Jan/92 a Abr/92 


\subsection{4 - Secas na região de Presidente Prudente/SP}

Os dois postos analisados nesta região, Presidente Prudente e Pontal, apresentaram 8 eventos de seca: 3 em Pontal e 5 em Presidente Prudente. As secas ocorridas foram, na maioria, de pouca intensidade, sendo classificadas como suaves a moderadas (Anexos A6 e A7). Os eventos mais marcantes ocorreram nos períodos de: janeiro a abril de 1979, em Pontal; - e, de janeiro a setembro de 1964 e janeiro a abril de 1979, em Presidente Prudente.

Os máximos valores negativos de $\mathrm{X}_{\mathrm{i}}$ foram registrados durante os eventos de 79 , sendo de $-4,30$ e $-4,10$, para as secas ocorridas em Presidente Prudente e Pontal, respectivamente (Figuras $11 \mathrm{e}$ 12b). Os maiores desvios negativos da precipitação ocorreram nos meses de março, em Pontal (-109 mm), e janeiro, em Presidente Prudente $(-75 \mathrm{~mm})$; e coincidiram com os maiores valores de DEF em ambos os casos (86 $\mathrm{mm}$ e 87 $\mathrm{mm}$, respectivamente).

A seca de 64, registrada em Presidente Prudente, teve o máximo valor negativo de $X_{i}$ em fevereiro, $-3,10$. Esse, coincidiu com o maior valor de DEF para o período, $91 \mathrm{~mm} / \mathrm{mês}$, no entanto, o desvio negativo máximo da precipitação somente ocorreu em abril (Figura 12a).

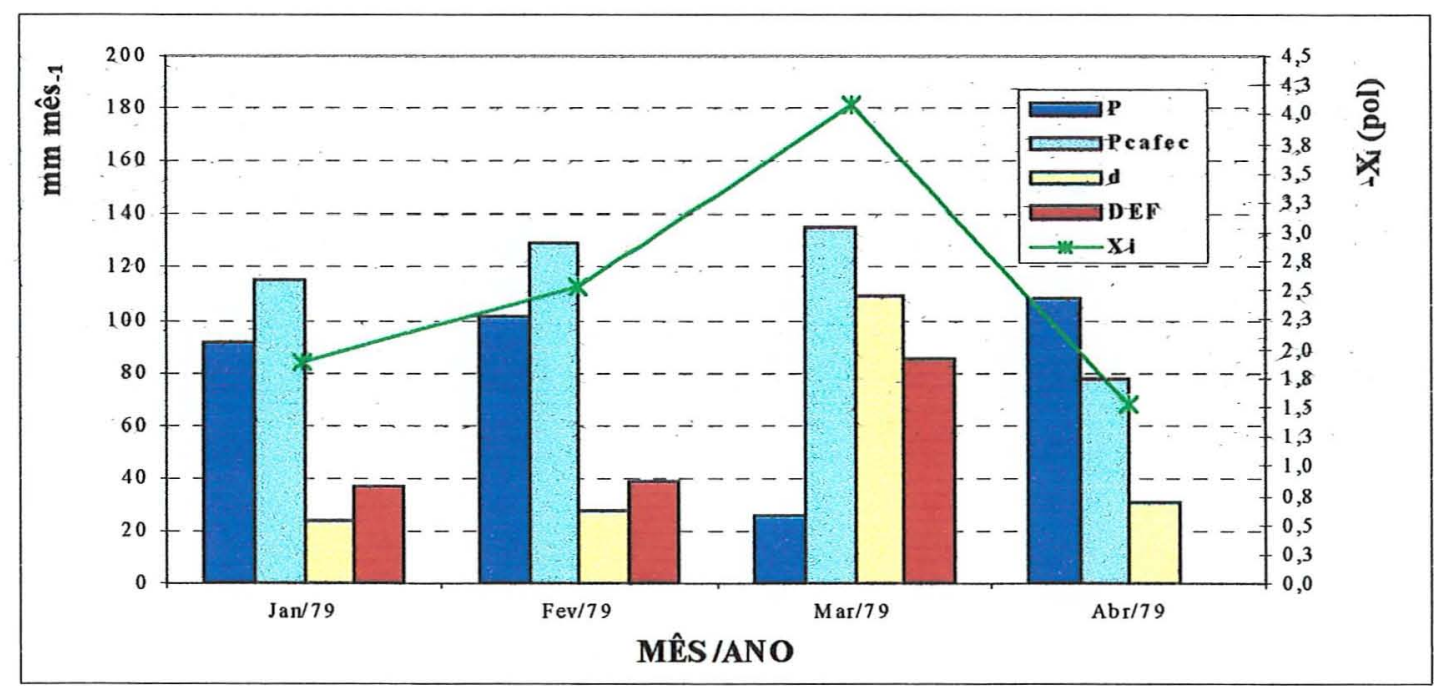

Figura 11 - Representação gráfica de $P$ (mm/mês), $P_{\text {cafec }}(\mathrm{mm} / \mathrm{mês}), d$ (mm/mês), DEF (mm/mês) e, $X_{\mathrm{i}}$, em Pontal - Teodoro Sampaio/SP (período - Jan/79 a $\mathrm{Abr} / 79$ ) 

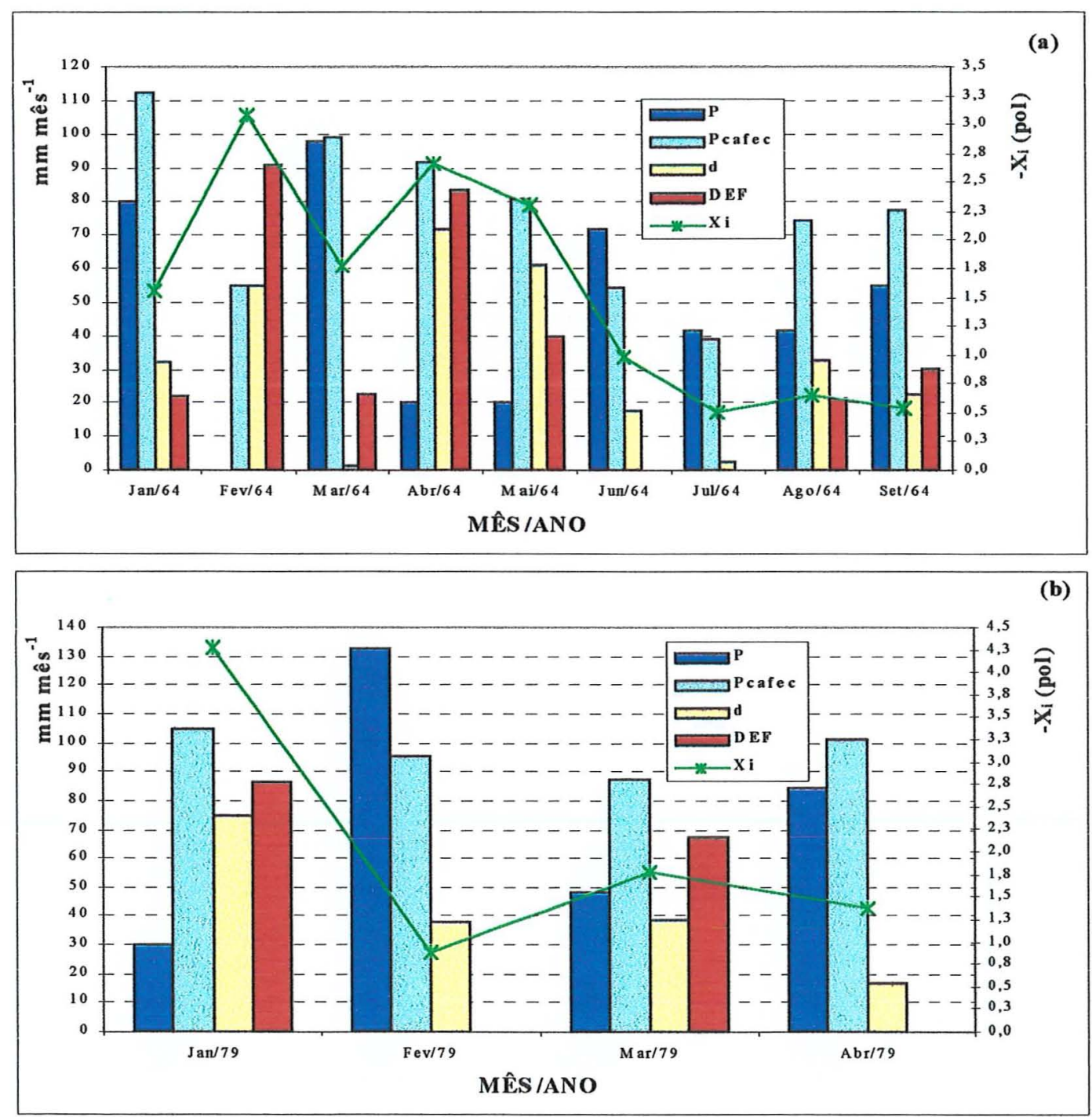

Figura 12 - Representação gráfica de $\mathbf{P}$ ( $\mathrm{mm} / \mathrm{mês}), \mathbf{P}_{\text {cafec }}(\mathrm{mm} / \mathrm{mês})$, d ( $\left.\mathrm{mm} / \mathrm{mês}\right)$, DEF (mm/mês) e, $X_{i}$, em Presidente Prudente/SP: (a) período - Jan/64 a Set/64; (b) período - Jan/79 a Abr/79. 


\subsection{5 - Secas na região de Salto Grande - SP}

Salto grande apresentou somente um evento de seca durante toda a série analisada, com intensidade variando entre suave e severa. O máximo valor negativo de $\mathrm{Xi}$ registrado foi de $-3,75$ e coincidiu com o maior desvio negativo ocorrido, $d=-62 \mathrm{~mm}$. A deficiência hídrica acompanhou a variação dos desvios na precipitação (Figura 13).

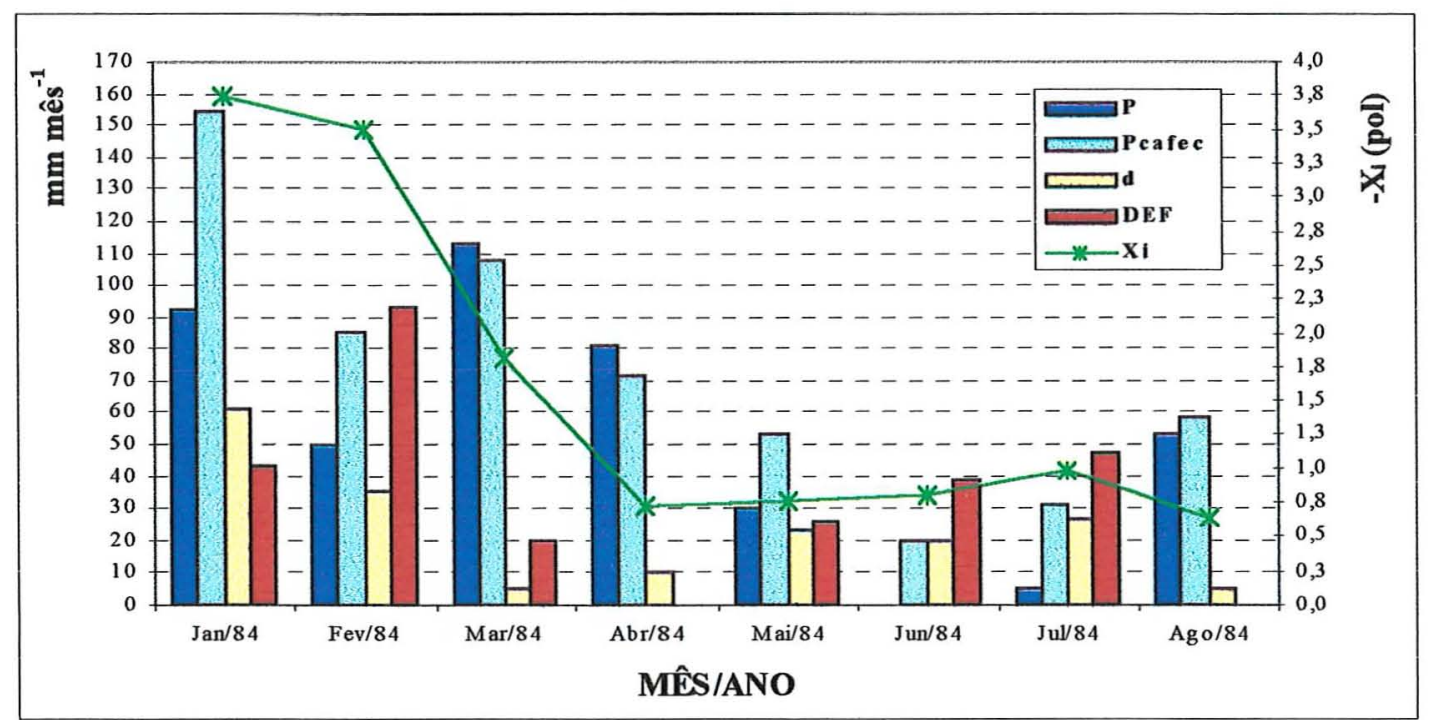

Figura 13 - Representação gráfica de $P$ ( $\mathrm{mm} / \mathrm{mês})$, e $P_{\text {cafec }}(\mathrm{mm} / \mathrm{mês})$, d ( $\left.\mathrm{mm} / \mathrm{mês}\right)$, DEF (mm/mês), e X $X_{i}$, em Salto Grande - SP (período - Jan/79 a Abr/79)

\subsection{6 - Eventos secos em Alfredo Marcondes - SP e Votuporanga - SP}

Apesar do número de eventos ocorridos nestas duas localidades $(6 \mathrm{em}$ Alfredo Marcondes e 13 em Votuporanga) não houve períodos significativos de seca. Não ocorreram, em nenhuma das secas registradas, valores de $X_{i} \leq-3,00$. A maioria foi classificada como seca suave, não chegando nem a atingir valores próximos de $-2,00$. $\mathrm{O}$ menor valor de $\mathrm{Xi}$, ocorrido em Votuporanga foi de -2,64, em agosto de 1995; e em Alfredo Marcondes foi de -1,59, em maio de 1968 (Anexos A4 e A9). 


\section{3 - Análise geral para o Oeste Paulista}

O Balanço Hídrico mostrou que para a região, ocorreu deficiência hídrica na maioria dos meses das séries analisadas. As menores deficiências ocorreram entre dezembro e março, com o valor médio mínimo de $5 \mathrm{~mm}$, em janeiro; as maiores deficiências ocorreram entre junho e novembro, com valor médio máximo de 32 $\mathrm{mm} / \mathrm{mês}$, em agosto - mês com maior suscetibilidade a períodos de estiagem, naquela região, segundo Mariano et al. (1997). As diferenças negativas entre as precipitações observada e estimada $\left(\mathrm{d}=\mathrm{P}-\mathrm{P}_{\mathrm{cafec}}\right)$, coincidiram com os meses de maior deficiência hídrica. Ou seja, $P_{\text {cafec }}$ foi maior que $P$, nos meses em que a deficiência hídrica média foi maior ou igual a $10 \mathrm{~mm}$ (Figura 14).

Tanto a precipitação observada, quanto a estimada, apresentaram seus valores mais elevados durante os meses de dezembro a março. Isso pode explicar porque em alguns destes meses, mesmo sem haver deficiência hídrica, o PDSI apresentou valores elevados; durante estes meses, quando a precipitação observada fica abaixo da normal climática para a região, o desvio de precipitação $(\mathrm{d}=\mathrm{P}-\hat{\mathrm{P}})$ torna-se negativo e bastante acentuado, influenciando diretamente os valores de $\mathrm{X}_{\mathrm{i}}$.

Essa influência se faz notar também, quando se considera a variação espacial desses parâmetros (Figura 15). Observou-se que, nas regiões de Araçatuba (que abrange os postos de Auriflama, Major Prado e Água Limpa) e Alfredo Marcondes, por exemplo, onde a precipitação observada é, normalmente, igual ou superior à precipitação estimada, os valores do PDSI mantiveram-se sempre maiores ou iguais a zero. Enquanto que, na região de Adamantina, onde a precipitação observada foi, geralmente, menor que a estimada, o valor médio de $\mathrm{X}_{\mathrm{i}}$ foi negativo. 


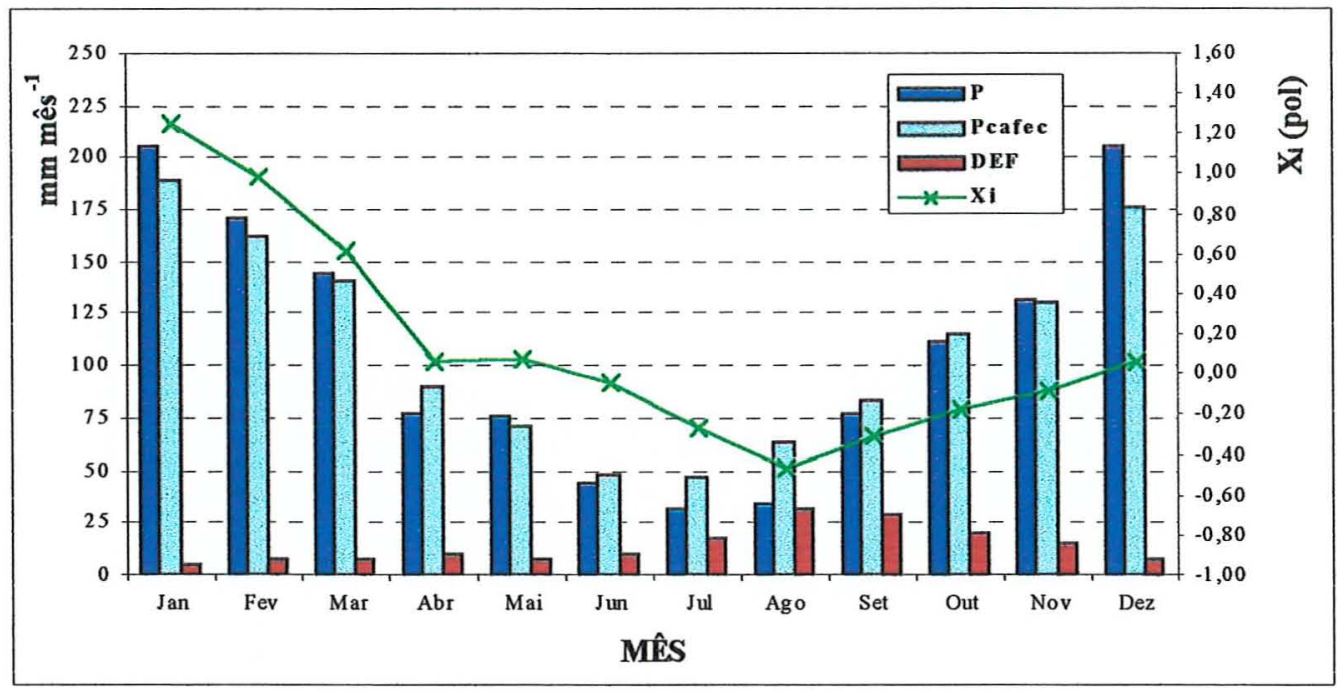

Figura 14 - Variação Média Mensal de $P$ (mm/mês), $P_{\text {cafec }}(\mathrm{mm} / \mathrm{mês})$, DEF (mm/mês) e $X_{i}$ (pol), para a região Oeste Estado de São Paulo.

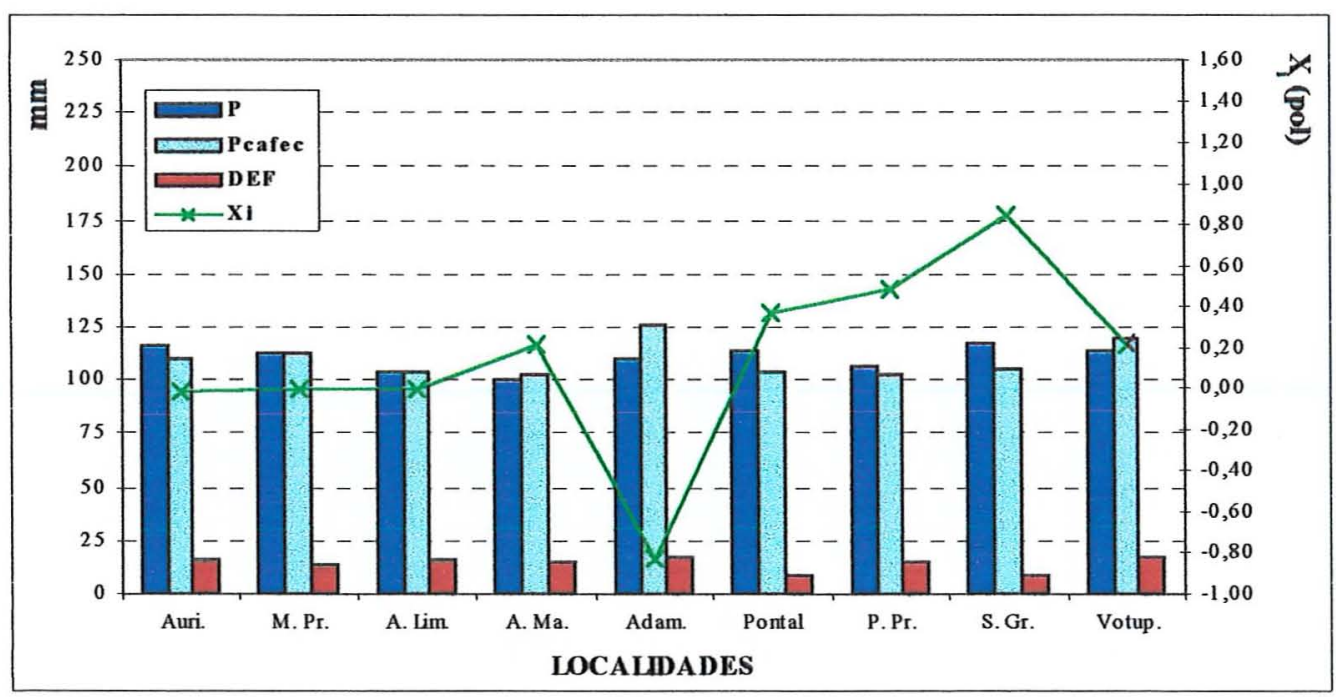

Figura 15 - Variação Média Espacial de $\mathrm{P}(\mathrm{mm}), \mathrm{P}_{\text {cafec }}(\mathrm{mm}), \mathrm{DEF}(\mathrm{mm})$ e $\mathrm{X}_{\mathrm{i}}($ pol), para a região Oeste do Estado de São Paulo.

A Figura 16 mostra a variação média anual do PDSI na área estudada. A maior parte da série de anos apresentou PDSI positivo, ou próximo de zero. Os valores médios máximos negativos de $\mathrm{X}_{\mathrm{i}}$ ocorreram durante os anos de 1964, 1979, 1992, e 1996. De fato, durante estes anos, foram identificadas secas em quase todas as localidades (Anexo B). 


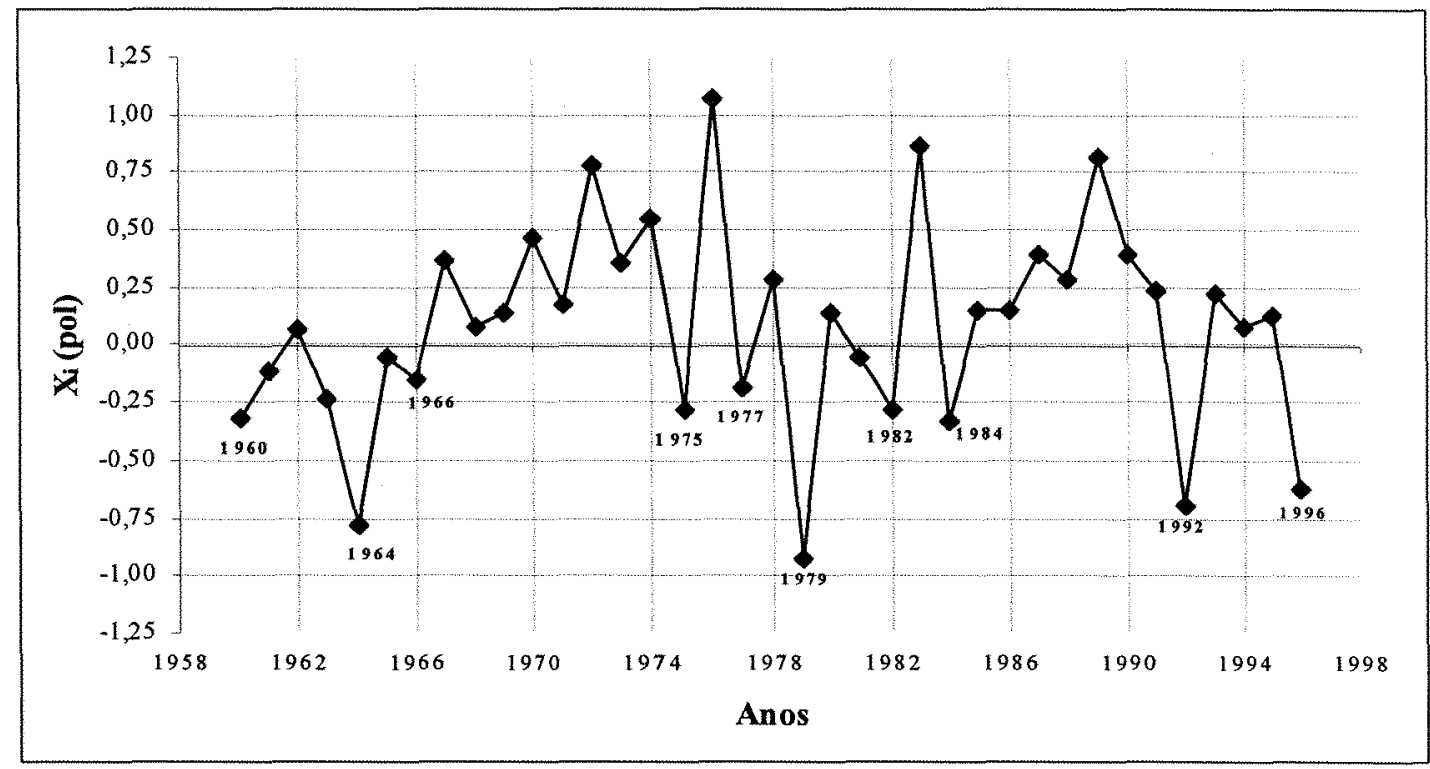

Figura 16 - Variação média anual do PDSI na região Oeste do Estado de São Paulo.

\section{4 - Considerações Finais}

Como já foi afirmado, o PDSI é um método empírico, que se propõe a identificar e classificar períodos de seca, em uma área. Através do método, Palmer e outros pesquisadores que utilizaram, e ainda utilizam, o PDSI em suas pesquisas - como exemplos podemos citar os trabalhos de Karl \& Quayle (1981), Hecht (1983) e, mais recentemente, Assis (1997) - procuraram solucionar dois dos principais problemas para aqueles que trabalham com monitoramento de secas: sua intensidade e seu período de duração (mais especificamente, início e fim de um período). Entretanto, a utilização do PDSI para o monitoramento de períodos de seca no Estado, deve ser realizada com o auxílio de outras ferramentas de análise, tal como é realizado nos diversos países onde o método e utilizado operacionalmente.

Estudos mais aprofundados, utilizando uma malha de postos de observação mais densa $\mathrm{e}$, relacionando os resultados obtidos pelo índice aos desempenhos das principais culturas agrícolas na região, deverão ser realizados. 


\section{5 - CONCLUSÕES}

- O método foi coerente ao identificar os períodos de seca ocorridos, sendo identificados cerca de 69 eventos em toda a área. A duração média das secas ocorridas na região foi de 5 a 6 meses, com período de retorno entre 1 e 6 anos, sendo a maioria dos eventos classificada como suave ou moderado. Adamantina foi a região que apresentou a maior freqüência de meses secos.

- Eventos de maior intensidade ocorreram com maior freqüência, durante a estação das chuvas na região, isto é, entre janeiro e abril. O maior valor negativo, registrado para $\mathrm{X}_{\mathrm{i}}$, ocorreu em Major Prado, em janeiro de $96(-28,26)$, e marcou o início daquele evento. As secas na região tenderam a iniciar entre janeiro e abril, e a terminar entre agosto e novembro.

- Os resultados também mostraram que $X_{i}$ sofre maior influência do desvio da precipitação (d) que da deficiência hídrica (DEF). Ou seja, $X_{i}$ acompanhou melhor a variação espacial e temporal de d, do que a variação do $D E F$.

- Os anos que apresentaram a maior incidência de secas severas e extremas foram 1979, 1992 e 1996, com períodos de seca identificados em quase todas as estações.

- A princípio, o PDSI conseguiu se adaptar bem às condições climáticas do território paulista. 
ANEXOS 


\section{ANEXO A}

A1. Períodos de seca identificados em Auriflama - SP, classificação e, respectivos valores de $z$ (pol), $z_{e}$ (pol), $X_{\mathrm{i}}(\mathrm{pol}), \mathrm{P}(\mathrm{mm}), \mathrm{P}_{\text {cafec }}(\mathrm{mm}), \mathrm{d}(\mathrm{mm})$ e DEF (mm).

\begin{tabular}{|c|c|c|c|c|c|c|c|c|}
\hline Mrertino & $\mathbf{z}$ & $\mathbf{z}_{\mathbf{e}}$ & $\mathbf{X}_{\mathbf{i}}$ & Classe & $\mathbf{P}$ & $\mathbf{P}_{\text {cafiec }}$ & d & DEF \\
\hline Mai/75 & $-7,78$ & $-2,87$ & $-1,36$ & ss & 5,8 & 59,3 & $-53,5$ & 26 \\
\hline Jun/75 & $-3,19$ & 1,49 & $-1,32$ & ss & 2,4 & 19,7 & $-17,3$ & 37 \\
\hline Jul/75 & $-2,80$ & 1,36 & $-1,22$ & ss & 0,0 & 14,3 & $-14,3$ & 20 \\
\hline Ago/75 & $-2,62$ & 1,07 & $-1,14$ & ss & 0,0 & 19,1 & $-19,1$ & 71 \\
\hline Set/75 & $-2,68$ & 0,80 & $-1,11$ & ss & 27,7 & 73,3 & $-45,6$ & 71 \\
\hline$=$ & $=$ & $\overline{=}$ & $\overline{\overline{=}}$ & $\bar{\square}$ & $\overline{\overline{ }}$ & $=$ & $\bar{\square}$ & 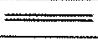 \\
\hline Fev/79 & $-28,27$ & $-5,17$ & $-4,53$ & se & 0,9 & 117,9 & $-117,0$ & 53 \\
\hline Mar/79 & $-10,52$ & 11,68 & $-4,37$ & se & 94,6 & 147,9 & $-53,3$ & 24 \\
\hline Abr/79 & 1,31 & 11,17 & $-2,22$ & sm & 83,7 & 79,0 & 4,7 & 8 \\
\hline Mai/79 & 1,90 & 4,26 & $-0,91$ & $\mathrm{si}$ & 80,4 & 67,3 & 13,1 & 0 \\
\hline Jun/79 & $-3,41$ & 0,06 & $-1,10$ & ss & 0,4 & 18,8 & $-18,4$ & 45 \\
\hline$\overline{=}$ & $\bar{\square}$ & $\overline{\overline{ }}$ & $\Longrightarrow$ & $\overline{\bar{~}}$ & $\bar{\square}$ & $\bar{\square}$ & $\overline{\overline{ }}$ & $=$ \\
\hline Jan/82 & $-145,43$ & $-4,31$ & $-25,10$ & se & 0,9 & 202,5 & $-201,6$ & 64 \\
\hline Fev/82 & 4,44 & 77,77 & $-13,28$ & se & 178,4 & 160,0 & 18,4 & 0 \\
\hline Mar/82 & 6,54 & 39,80 & $-6,30$ & se & 257,3 & 224,1 & 33,2 & 0 \\
\hline Abr/82 & $-6,60$ & 17,36 & $-4,68$ & se & 0,9 & 24,4 & $-23,5$ & 32 \\
\hline Mai/82 & 5,01 & 12,16 & $-1,75$ & ss & 115,0 & 80,5 & 34,5 & 0 \\
\hline Jun/82 & $-0,89$ & 2,74 & $-1,13$ & ss & 23,9 & 28,7 & $-4,8$ & 10 \\
\hline $\mathrm{Jul} / 82$ & $-2,80$ & 0,77 & $-1,12$ & ss & 0,0 & 14,3 & $-14,3$ & 17 \\
\hline$=$ & $=$ & $=$ & 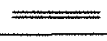 & $=$ & $\overline{=}$ & $=$ & $=$ & $\Longrightarrow$ \\
\hline Dez/92 & $-12,11$ & $-4,85$ & $-1,77$ & ss & 55,3 & 603,6 & $-548,3$ & 26 \\
\hline $\operatorname{Jan} / 93$ & $-32,82$ & 2,80 & $-6,71$ & se & 106,4 & 151,9 & $-45,5$ & 21 \\
\hline Fev/93 & 4,65 & 18,69 & $-2,95$ & $\mathrm{sm}$ & 182,8 & 163,6 & 19,2 & 0 \\
\hline Mar/93 & 2,91 & 6,60 & $-1,14$ & ss & 179,0 & 164,3 & 14,7 & 0 \\
\hline$\overline{\overline{ }}$ & $\overline{\bar{~}}$ & 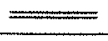 & $=$ & $\bar{\square}$ & $\bar{\square}$ & $\bar{\square}$ & $\overline{\overline{ }}$ & $\bar{\square}$ \\
\hline Fev/94 & $-16,40$ & $-8,12$ & $-1,94$ & ss & 49,7 & 117,5 & $-67,8$ & 22 \\
\hline Mar/94 & 1,80 & 3,37 & $-0,77$ & si & 155,2 & 146,1 & 9,1 & 0 \\
\hline $\mathrm{Abr} / 94$ & $-1,53$ & $-0,38$ & $-0,70$ & si & 54,0 & 59,4 & $-5,4$ & 15 \\
\hline Mai/94 & $-5,76$ & $-0,62$ & $-1,40$ & ss & 20,7 & 60,3 & $-39,6$ & 30 \\
\hline Jun/94 & $-1,97$ & 1,61 & $-1,13$ & ss & 13,8 & 24,5 & $-10,7$ & 33 \\
\hline Jul/94 & $-2,27$ & 0,75 & $-1,03$ & ss & 4,6 & 16,2 & $-11,6$ & 34 \\
\hline Ago/94 & $-2,62$ & 0,43 & $-1,03$ & ss & 0,0 & 19,1 & $-19,1$ & 74 \\
\hline Set/94 & $-4,32$ & 0,44 & $-1,33$ & ss & 1,1 & 74,6 & $-73,5$ & 98 \\
\hline Out/94 & $-1,39$ & 1,40 & $-0,99$ & si & 71,2 & 100,6 & $-29,4$ & 50 \\
\hline$\overline{\overline{ }}$ & 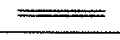 & $=$ & $=$ & $=$ & $=$ & $=$ & $\overline{=}$ & 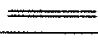 \\
\hline Mar/95 & $-23,47$ & $-10,43$ & $-2,77$ & $\mathrm{sm}$ & 57,5 & 176,4 & $-118,9$ & 19 \\
\hline Abr/95 & 0,53 & 6,04 & $-1,46$ & ss & 75,5 & 73,6 & 1,9 & 10 \\
\hline Mai/95 & $-5,92$ & 1,83 & $-1,85$ & ss & 19,5 & 60,3 & $-40,8$ & 35 \\
\hline Jun/95 & $-1,63$ & 3,08 & $-1,32$ & ss & 17,9 & 26,7 & $-8,8$ & 25 \\
\hline Jul/95 & $-0,30$ & 1,37 & $-0,79$ & si & 21,8 & 23,3 & $-1,5$ & 32 \\
\hline Ago/95 & $-2,62$ & $-0,33$ & $-0,90$ & si & 0,0 & 19,1 & $-19,1$ & 75 \\
\hline
\end{tabular}


A2. Períodos de seca identificados em Major Prado - Araçatuba/SP, classificação e, respectivos valores de $\mathrm{z}(\mathrm{pol}), \mathrm{z}_{\mathrm{e}}(\mathrm{pol}), \mathrm{X}_{\mathrm{i}}(\mathrm{pol}), \mathrm{P}(\mathrm{mm}), \mathrm{P}_{\text {cafec }}(\mathrm{mm}), \mathrm{d}(\mathrm{mm})$ e DEF (mm).

\begin{tabular}{|c|c|c|c|c|c|c|c|c|}
\hline Mestano & $z$ & $\mathbf{z}_{\mathrm{e}}$ & $\mathbf{X}_{i}$ & Classe & $\mathbf{P}$ & $\mathbf{P}_{\text {carfec }}$ & d & DEF \\
\hline Fev/75 & $-9,95$ & $-4,59$ & $-1,43$ & ss & 97,2 & 119,5 & $-22,3$ & 4 \\
\hline Mar/75 & 1,65 & 1,74 & $-0,52$ & si & 131,0 & 126,4 & 4,6 & 0 \\
\hline $\mathrm{Abr} / 75$ & $-1,44$ & $-1,21$ & $-0,54$ & si & 71,8 & 77,0 & $-5,2$ & 8 \\
\hline Mai/75 & $-7,58$ & $-1,14$ & $-1,62$ & ss & 10,0 & 57,0 & $-47,0$ & 34 \\
\hline Jun/75 & $-3,63$ & 2,35 & $-1,54$ & ss & 2,0 & 20,4 & $-18,4$ & 42 \\
\hline Jul/75 & $-0,62$ & 2,08 & $-0,97$ & si & 21,7 & 25,1 & $-3,4$ & 32 \\
\hline Ago/75 & $-2,94$ & 0,25 & $-1,06$ & ss & 0,0 & 21,1 & $-21,1$ & 75 \\
\hline Set/75 & $-4,42$ & 0,53 & $-1,36$ & ss & 10,7 & 68,8 & $-58,1$ & 89 \\
\hline$\overline{\overline{=}}$ & 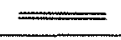 & $\overline{=}$ & $\overline{\overline{ }}$ & $\overline{\overline{ }}$ & $\overline{\overline{ }}$ & $\Longrightarrow$ & $=$ & $=$ \\
\hline Fev/77 & $-23,03$ & $-13,69$ & $-2,13$ & $\mathrm{sm}$ & 62,7 & 114,4 & $-51,7$ & 17 \\
\hline Mar/77 & 0,05 & 3,97 & $-1,18$ & ss & 120,6 & 120,5 & 0,1 & 4 \\
\hline Abr/77 & $-8,63$ & 0,93 & $-2,17$ & sm & 23,5 & 54,5 & $-31,0$ & 47 \\
\hline Mai/77 & $-8,31$ & 4,10 & $-2,66$ & $\mathrm{sm}$ & 5,0 & 56,6 & $-51,6$ & 55 \\
\hline Jun/77 & 5,20 & 5,68 & $-0,58$ & si & 72,5 & 46,1 & 26,4 & 0 \\
\hline $\mathrm{Jul} / 77$ & $-3,13$ & $-0,99$ & $-0,87$ & ss & 0,0 & 17,1 & $-17,1$ & 47 \\
\hline Ago/77 & $-1,74$ & $-0,07$ & $-0,79$ & si & 11,4 & 23,9 & $-12,5$ & 63 \\
\hline$\overline{=}$ & $\overline{\bar{~}}$ & $\overline{=}$ & $\overline{\bar{\nu}}$ & $=$ & $=$ & $\bar{\square}$ & $\bar{\square}$ & $\Longrightarrow$ \\
\hline Jan/79 & $-11,91$ & $-3,71$ & $-1,93$ & ss & 137,5 & 156,2 & $-18,7$ & 0 \\
\hline Fev/79 & 3,17 & 3,33 & $-0,53$ & si & 168,2 & 161,1 & 7,1 & 0 \\
\hline Mar/79 & $-9,08$ & $-1,17$ & $-1,88$ & ss & 71,7 & 97,2 & $-25,5$ & 14 \\
\hline Abr/79 & $-0,37$ & 3,17 & $-1,12$ & ss & 79,0 & 80,3 & $-1,3$ & 8 \\
\hline Mai/79 & $-1,88$ & 0,72 & $-0,95$ & si & 49,0 & 60,7 & $-11,7$ & 13 \\
\hline $\mathrm{Jun} / 79$ & $-3,85$ & 0,19 & $-1,20$ & ss & 0,0 & 19,5 & $-19,5$ & 41 \\
\hline 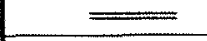 & $=$ & 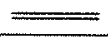 & $=$ & 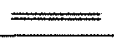 & $\bar{\square}$ & 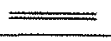 & $\overline{=}$ & $\overline{=}$ \\
\hline Ago/85 & $-2,86$ & $-2,41$ & $-0,58$ & si & 0,8 & 21,3 & $-20,5$ & 66 \\
\hline Set/85 & $-4,07$ & $-1,01$ & $-1,03$ & ss & 15,5 & 68,9 & $-53,4$ & 80 \\
\hline Out/85 & $-3,63$ & 0,45 & $-1,21$ & ss & 48,0 & 119,7 & $-71,7$ & 73 \\
\hline Nov/85 & $-1,30$ & 1,02 & $-0,90$ & si & 113,2 & 147,3 & $-34,1$ & 15 \\
\hline Dez/85 & $-9,95$ & 0,03 & $-2,24$ & $\mathrm{sm}$ & 82,9 & 433,2 & $-350,3$ & 56 \\
\hline$=$ & $=$ & $=$ & 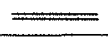 & $\overline{\overline{ }}$ & $\overline{\bar{\nu}}$ & $\overline{=}$ & $\overline{ }$ & $=$ \\
\hline $\mathrm{Jan} / 92$ & $-64,30$ & $-3,67$ & $-11,07$ & se & 113,4 & 214,6 & $-101,2$ & 4 \\
\hline Fev/92 & 6,61 & 32,69 & $-5,05$ & se & 262,2 & 247,4 & 14,8 & 0 \\
\hline Mar/92 & $-3,09$ & 13,34 & $-3,36$ & sse & 103,8 & 112,5 & $-8,7$ & 3 \\
\hline $\mathrm{Abr} / 92$ & 4,71 & 7,94 & $-1,06$ & ss & 123,6 & 106,7 & 16,9 & 0 \\
\hline$=$ & $\overline{=}$ & $\overline{\overline{ }}$ & $\overline{\overline{ }}$ & $\bar{\square}$ & $=$ & $\overline{=}$ & $=$ & $\overline{=}$ \\
\hline $\operatorname{Jan} / 96$ & $-162,34$ & $-3,09$ & $-28,26$ & se & 68,3 & 323,9 & $-255,6$ & 43 \\
\hline Fev/96 & $-9,27$ & 87,93 & $-17,44$ & se & 103,4 & 124,2 & $-20,8$ & 22 \\
\hline Mar/96 & 2,47 & 53,17 & $-9,34$ & se & 153,8 & 146,9 & 6,9 & 0 \\
\hline Abr/96 & $-0,31$ & 27,13 & $-5,28$ & se & 79,4 & 80,5 & $-1,1$ & 9 \\
\hline Mai/96 & 8,37 & 14,10 & $-1,50$ & ss & 140,5 & 88,5 & 52,0 & 0 \\
\hline Jun/96 & $-2,58$ & 1,95 & $-1,29$ & ss & 11,5 & 24,6 & $-13,1$ & 9 \\
\hline Jul/96 & $-1,95$ & 1,27 & $-1,06$ & ss & 10,2 & 20,9 & $-10,7$ & 25 \\
\hline Ago/96 & $-2,39$ & 0,54 & $-1,01$ & ss & 5,2 & 22,4 & $-17,2$ & 56 \\
\hline
\end{tabular}


A3. Períodos de seca identificados em Água Limpa - Araçatuba/SP, classificação e, respectivos valores de $z(\mathrm{pol}), \mathrm{z}_{\mathrm{e}}(\mathrm{pol}), \mathrm{X}_{\mathrm{i}}(\mathrm{pol}), \mathrm{P}(\mathrm{mm}), \mathrm{P}_{\mathrm{cafec}}(\mathrm{mm}), \mathrm{d}(\mathrm{mm})$ e DEF $(\mathrm{mm})$.

\begin{tabular}{|c|c|c|c|c|c|c|c|c|}
\hline Mrapano & $\mathbf{z}$ & $z_{t}$ & $\mathbf{X}_{\mathrm{i}}$ & Classe & $\mathbf{P}$ & $\mathbf{P}_{\text {catec }}$ & d & DEF \\
\hline Mai/75 & $-6,47$ & $-2,70$ & $-1,16$ & ss & 10,8 & 59,3 & $-48,5$ & 31 \\
\hline Jun/75 & $-2,37$ & 0,85 & $-1,06$ & ss & 7,5 & 21,0 & $-13,5$ & 35 \\
\hline $\mathrm{Jul} / 75$ & $-0,04$ & 0,54 & $-0,60$ & si & 25,7 & 25,9 & $-0,2$ & 25 \\
\hline Ago/75 & $-2,71$ & $-0,94$ & $-0,81$ & si & 0,0 & 21,9 & $-21,9$ & 70 \\
\hline Set/75 & $-3,27$ & $-0,27$ & $-1,02$ & ss & 10,3 & 66,3 & $-56,0$ & 84 \\
\hline$\overline{\underline{ }}$ & $\Longrightarrow$ & $=$ & $=$ & $\Longrightarrow$ & $\Longrightarrow$ & $\Longrightarrow$ & $\underline{\overline{ }}$ & 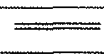 \\
\hline $\mathrm{Jan} / 79$ & $-97,75$ & $-4,72$ & $-17,00$ & se & 57,8 & 259,6 & $-201,8$ & 46 \\
\hline Fev/79 & 3,19 & $-3,17$ & $-8,96$ & se & 155,4 & 146,3 & 9,1 & 0 \\
\hline Mar/79 & $-5,69$ & 1,66 & $-6,01$ & se & 87,1 & 114,6 & $-27,5$ & 21 \\
\hline Abr/79 & 2,12 & $-2,08$ & $-3,00$ & sse & 95,9 & 86,8 & 9,1 & 0 \\
\hline Mai/79 & 4,39 & 1,28 & $-0,91$ & si & 116,0 & 83,1 & 32,9 & 0 \\
\hline Jun/79 & $-3,07$ & $-2,33$ & $-1,05$ & ss & 0,0 & 17,5 & $-17,5$ & 19 \\
\hline Jul/79 & 0,17 & $-1,22$ & $-0,56$ & si & 27,5 & 26,4 & 1,1 & 17 \\
\hline$=$ & $\overline{=}$ & $\bar{\square}$ & $=$ & $=$ & $=$ & $=$ & 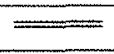 & $=$ \\
\hline $\mathrm{Jan} / 92$ & $-71,00$ & $-1,67$ & $-12,59$ & se & 80,9 & 227,5 & $-146,6$ & 44 \\
\hline Fev/92 & $-7,97$ & 37,57 & $-8,44$ & se & 94,7 & 117,5 & $-22,8$ & 30 \\
\hline Mar/92 & 2,61 & 24,24 & $-4,27$ & se & 154,8 & 142,2 & 12,6 & 0 \\
\hline Abr/92 & 5,69 & 10,85 & $-1,40$ & ss & 115,8 & 91,4 & 24,4 & 0 \\
\hline 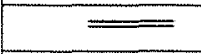 & $=$ & $=$ & $\Longrightarrow$ & $=$ & $\Longrightarrow$ & $\overline{=}$ & $=$ & $=$ \\
\hline $\operatorname{Jan} / 96$ & $-55,03$ & $-1,54$ & $-9,82$ & se & 94,7 & 208,3 & $-113,6$ & 39 \\
\hline Fev/96 & $-18,02$ & 28,69 & $-8,64$ & se & 59,5 & 111,0 & $-51,5$ & 63 \\
\hline Mar/96 & 8,38 & 24,90 & $-3,38$ & sse & 272,1 & 231,6 & 40,5 & 0 \\
\hline Abr/96 & $-3,92$ & 7,99 & $-2,57$ & $\mathrm{sm}$ & 39,6 & 56,4 & $-16,8$ & 12 \\
\hline Mai/96 & $-0,23$ & 5,40 & $-1,48$ & ss & 57,7 & 59,5 & $-1,8$ & 5 \\
\hline Jun/96 & $-1,70$ & 1,90 & $-1,13$ & ss & 14,7 & 24,4 & $-9,7$ & 24 \\
\hline Jul/96 & $-2,84$ & 0,75 & $-1,13$ & ss & 0,7 & 19,3 & $-18,6$ & 42 \\
\hline Ago/96 & 0,35 & 0,75 & $-0,57$ & si & 32,4 & 29,6 & 2,8 & 39 \\
\hline
\end{tabular}


A4. Períodos de seca identificados em Alfredo Marcondes - SP, classificação e, respectivos valores de z (pol), $\mathrm{z}_{\mathrm{e}}(\mathrm{pol}), \mathrm{X}_{\mathrm{i}}(\mathrm{pol}), \mathrm{P}(\mathrm{mm}), \mathrm{P}_{\text {cafec }}(\mathrm{mm}), \mathrm{d}(\mathrm{mm})$ e DEF (mm).

\begin{tabular}{|c|c|c|c|c|c|c|c|c|}
\hline Mayleno & $\mathbf{z}$ & $z_{\varepsilon}$ & $\mathbf{X}_{i}$ & Classe & $\mathbf{P}$ & $\mathbf{P}_{\text {cafer }}$ & d & DEF \\
\hline Jun/61 & $-3,79$ & $-1,95$ & $-0,82$ & si & 6,9 & 42 & -36 & 22 \\
\hline Jul/61 & $-4,03$ & $-0,23$ & $-1,16$ & ss & 0,0 & 47 & -47 & 37 \\
\hline Ago/61 & $-3,71$ & 0,86 & $-1,30$ & ss & 15,5 & 75 & .59 & 47 \\
\hline Set/61 & $-3,27$ & 1,30 & $-1,30$ & ss & 13,8 & 86 & -72 & 69 \\
\hline Out/61 & $-0,87$ & 1,30 & $-0,88$ & si & 78,9 & 103 & -25 & 30 \\
\hline 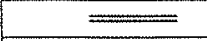 & 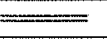 & $\overline{\overline{ }}$ & $=$ & $\underline{\underline{ }}$ & $\Longrightarrow$ & 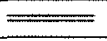 & $=$ & 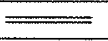 \\
\hline Mai/63 & $-5,77$ & $-1,73$ & $-1,20$ & ss & 9,0 & 77 & -68 & 43 \\
\hline Jun/63 & $-4,37$ & 1,00 & $-1,44$ & ss & 0,0 & 41 & -41 & 45 \\
\hline Jul/63 & $-4,03$ & 1,74 & $-1,51$ & ss & 0,0 & 47 & -47 & 49 \\
\hline Ago/63 & $-4,24$ & 1,97 & $-1,58$ & ss & 4,0 & 72 & -68 & 65 \\
\hline Set/63 & $-3,17$ & 2,22 & $-1,44$ & ss & 15,9 & 86 & -70 & 72 \\
\hline Out/63 & $-1,63$ & 1,75 & $-1,09$ & ss & 61,7 & 108 & -46 & 49 \\
\hline Nov/63 & $-0,36$ & 0,63 & $-0,67$ & si & 96,9 & 106 & -10 & 22 \\
\hline$\overline{\overline{=}}$ & $=$ & $=$ & $\overline{\bar{\square}}$ & $=$ & $\overline{\overline{=}}$ & $=$ & $=$ & 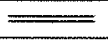 \\
\hline Abr/67 & $-8,78$ & $-8,41$ & $-0,56$ & si & 5 & 72 & .69 & 50 \\
\hline Mai/67 & $-6,84$ & $-1,05$ & $-1,51$ & ss & 0 & 80 & .81 & 54 \\
\hline Jun/67 & $-0,19$ & 1,98 & $-0,88$ & si & 50 & 52 & -2 & 2 \\
\hline Jul/67 & $-2,89$ & $-0,05$ & $-0,99$ & si & 18 & 51 & -34 & 32 \\
\hline Ago/67 & $-4,43$ & 0,33 & $-1,33$ & ss & 0 & 71 & -71 & 68 \\
\hline Set/67 & $-3,09$ & 1,40 & $-1,28$ & ss & 17 & 86 & -68 & 70 \\
\hline Out/67 & 0,63 & 1,25 & $-0,61$ & si & 114 & 97 & 18 & 0 \\
\hline$\Longrightarrow$ & $=$ & $=$ & $\Longrightarrow$ & $=$ & $=$ & 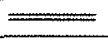 & $=$ & $=$ \\
\hline Mar/68 & $-5,59$ & $-5,52$ & $-0,51$ & si & 67 & 92 & -24 & 37 \\
\hline Abr/68 & $-5,83$ & $-1,22$ & $-1,30$ & ss & 46 & 91 & -45 & 35 \\
\hline Mai/68 & $-4,94$ & 1,32 & $-1,59$ & ss & 16 & 74 & -59 & 44 \\
\hline Jun/68 & $-1,55$ & 2,24 & $-1,16$ & ss & 34 & 48 & -15 & 17 \\
\hline $\mathrm{Jul} / 68$ & $-3,94$ & 0,86 & $-1,34$ & ss & 2 & 47 & -46 & 49 \\
\hline Ago/68 & $-2,14$ & 1,42 & $-1,12$ & ss & 49 & 83 & -34 & 22 \\
\hline Set $/ 68$ & $-2,34$ & 0,73 & $-1,03$ & ss & 32 & 84 & -52 & 56 \\
\hline$\overline{\bar{\nu}}$ & $=$ & $=$ & $\overline{=}$ & $\overline{ }$ & $\overline{\overline{ }}$ & $\overline{=}$ & $\overline{=}$ & $=$ \\
\hline Mai/75 & $-5,07$ & $-2,49$ & $-0,95$ & si & 15 & 74 & -60 & 15 \\
\hline Jun/75 & $-2,90$ & 0,18 & $-1,04$ & ss & 18 & 45 & -27 & 19 \\
\hline Jul/75 & $-0,31$ & 0,46 & $-0,63$ & si & 59 & 63 & -4 & 0 \\
\hline Ago/75 & $-4,43$ & $-0,83$ & $-1,13$ & ss & 0 & 71 & -71 & 50 \\
\hline Set/75 & $-2,72$ & 0,75 & $-1,11$ & ss & 25 & 85 & -60 & 55 \\
\hline$\Longrightarrow$ & $\overline{\overline{ }}$ & $=$ & $=$ & $\overline{ }$ & 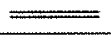 & $=$ & $\overline{=}$ & $\overline{\overline{ }}$ \\
\hline Jun/85 & $-3,24$ & $-2,35$ & $-0,66$ & si & 14 & 44 & -31 & 20 \\
\hline $\mathbf{J u l} / \mathbf{8 5}$ & $\frac{-3,47}{3}$ & $-0,76$ & $-0,97$ & si & 9 & 49 & -40 & 31 \\
\hline Ago/85 & $-3,89$ & 0,25 & $-1,22$ & ss & 12 & 74 & -62 & 49 \\
\hline Set/85 & $-3,69$ & 1,05 & $-1,33$ & ss & 6 & 87 & .82 & 77 \\
\hline Out/85 & $-3,76$ & 1,39 & $-1,40$ & ss & 14 & 120 & -106 & 94 \\
\hline Nov/85 & $-1,69$ & 1,62 & $-1,08$ & ss & 68 & 113 & -45 & 50 \\
\hline Dez/85 & $-1,98$ & 0,59 & $-0,95$ & si & 55 & 150 & -96 & 77 \\
\hline Jan/86 & $-3,14$ & 0,18 & $-1,08$ & ss & 95 & 104 & -9 & 45 \\
\hline
\end{tabular}


A5. Períodos de seca identificados em Adamantina - SP, classificação e, respectivos valores de $z$ (pol), $z_{e}$ (pol), $X_{\mathrm{i}}(\mathrm{pol}), \mathrm{P}(\mathrm{mm}), \mathrm{P}_{\mathrm{cafec}}(\mathrm{mm}), \mathrm{d}(\mathrm{mm})$ e DEF (mm).

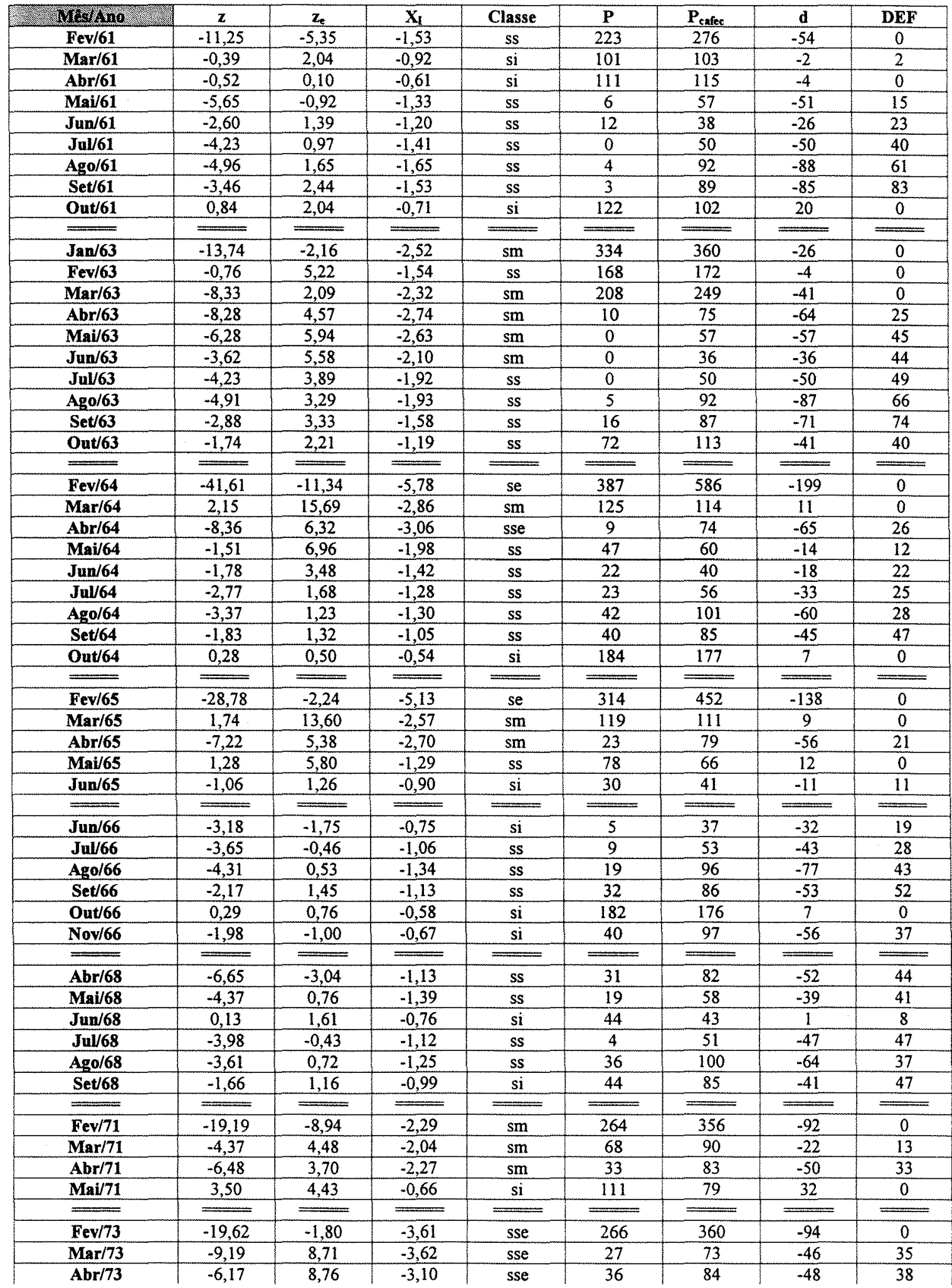


Continuação:

A5. Períodos de seca identificados em Adamantina - SP, classificação e, respectivos valores de $z(p o l), z_{e}(p o l), X_{i}(p o l), P(m m)$, $P_{\text {cafec }}(\mathrm{mm}), d(\mathrm{~mm})$ e DEF $(\mathrm{mm})$.

\begin{tabular}{|c|c|c|c|c|c|c|c|c|}
\hline $\mathrm{Mai} / 73$ & $-0,51$ & 7,10 & $-1,83$ & ss & 57 & 61 & -5 & 8 \\
\hline Jun/73 & $-1,51$ & 3,00 & $-1,29$ & ss & 25 & 40 & -15 & 24 \\
\hline $\mathrm{Jul} / 73$ & $-0,38$ & 1,27 & $-0,79$ & si & 63 & 67 & -5 & 0 \\
\hline Ago/73 & $-2,72$ & $-0,34$ & $-0,91$ & si & 57 & 106 & -48 & 14 \\
\hline Set/73 & $-2,19$ & 0,07 & $-0,89$ & si & 32 & 86 & -54 & 52 \\
\hline$\Longrightarrow$ & $=$ & $=$ & $=$ & $=$ & 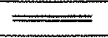 & $\overline{\underline{ }}$ & $\bar{\square}$ & $\Longrightarrow$ \\
\hline Jan/77 & $-40,15$ & $-3,69$ & $-6,86$ & se & 466 & 542 & -77 & 0 \\
\hline Fev/77 & 0,90 & 19,16 & $-3,68$ & sse & 90 & 86 & 4 & 5 \\
\hline $\operatorname{Mar} / 77$ & 0,16 & 8,96 & $-2,03$ & $\mathrm{sm}$ & 106 & 105 & 1 & 6 \\
\hline Abr/77 & $-2,63$ & 3,67 & $-1,60$ & ss & 80 & 100 & -20 & 5 \\
\hline Mai/77 & $-5,16$ & 2,26 & $-1,79$ & ss & 11 & 57 & -47 & 33 \\
\hline$\overline{=}$ & $=$ & 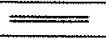 & $\square$ & $\Longrightarrow$ & $\bar{\square}$ & $\overline{\overline{ }}$ & $\underline{\underline{ }}$ & $=$ \\
\hline $\mathrm{Jul} / 77$ & $-4,06$ & $-1,38$ & $-0,97$ & si & 3 & 51 & -48 & 18 \\
\hline Ago/77 & $-4,69$ & 0,23 & $-1,36$ & ss & 10 & 93 & -83 & 41 \\
\hline Set/77 & $-1,95$ & 1,49 & $-1,10$ & ss & 37 & 85 & -48 & 44 \\
\hline Out/77 & $-2,24$ & 0,66 & $-1,01$ & ss & 65 & 117 & -52 & 43 \\
\hline$=$ & $=$ & $\bar{\square}$ & $\bar{\square}$ & $=$ & $\Longrightarrow$ & $=$ & $=$ & $=$ \\
\hline $\mathrm{Jan} / 78$ & $-8,88$ & $-3,23$ & $-1,49$ & ss & 110 & 127 & -17 & 4 \\
\hline Fev/78 & $-3,71$ & 1,90 & $-1,48$ & ss & 67 & 85 & -18 & 25 \\
\hline Mar/78 & 0,87 & 1,88 & $-0,68$ & si & 112 & 108 & 4 & 7 \\
\hline $\mathrm{Abr} / 78$ & $-4,78$ & $-0,70$ & $-1,21$ & ss & 54 & 91 & -37 & 26 \\
\hline$\underline{\underline{ }}$ & $=$ & $\bar{\square}$ & $\overline{=}$ & $=$ & $=$ & $\bar{\square}$ & $=$ & 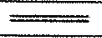 \\
\hline $\mathrm{Jan} / 79$ & $-65,64$ & $-3,32$ & $-11,36$ & se & 59 & 185 & -126 & 31 \\
\hline Fev/79 & $-1,97$ & 33,64 & $-6,71$ & se & 174 & 184 & -9 & 0 \\
\hline Mar/79 & $-2,91$ & 18,68 & $-4,26$ & se & 165 & 180 & -14 & 0 \\
\hline Abr/79 & $-3,19$ & 10,83 & $-2,94$ & $\mathrm{sm}$ & 73 & 98 & -25 & 1 \\
\hline Mai/79 & 0,87 & 6,59 & $-1,50$ & ss & 72 & 64 & 8 & 0 \\
\hline Jun/79 & $-3,37$ & 1,94 & $-1,43$ & ss & 3 & 37 & -34 & 16 \\
\hline $\mathrm{JuV} / 79$ & $-0,80$ & 1,71 & $-0,94$ & si & 55 & 64 & -9 & 0 \\
\hline Ago/79 & $-3,92$ & 0,14 & $-1,21$ & ss & 29 & 98 & -70 & 27 \\
\hline$=$ & $\square$ & 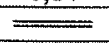 & 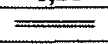 & $=$ & $=$ & $=$ & $=$ & $=$ \\
\hline $\mathrm{Jan} / 80$ & $-36,09$ & $-3,70$ & $-6,15$ & se & 86 & 155 & -69 & 13 \\
\hline Fev/80 & $-9,80$ & 16,88 & $-5,15$ & se & 221 & 268 & -47 & 0 \\
\hline Mar/80 & 0,76 & 13,68 & $-2,75$ & $\mathrm{sm}$ & 111 & 107 & 4 & 1 \\
\hline Abr $/ 80$ & $-3,35$ & 5,97 & $-2,12$ & $\mathrm{sm}$ & 71 & 97 & -26 & 4 \\
\hline Mai/80 & 1,73 & 3,96 & $-0,89$ & si & 84 & 69 & 16 & 0 \\
\hline$=$ & $=$ & $=$ & $=$ & $=$ & $=$ & 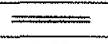 & $\Longrightarrow$ & 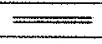 \\
\hline $\mathrm{Jan} / 82$ & $-31,64$ & $-3,17$ & $-5,46$ & se & 102 & 163 & -61 & 12 \\
\hline Fev/82 & 5,71 & 14,68 & $-2,06$ & sm & 119 & 92 & 27 & 5 \\
\hline Mar/82 & $-25,76$ & 3,76 & $-5,65$ & se & 354 & 482 & -128 & 0 \\
\hline Abr/82 & $-7,19$ & 15,27 & $-4,41$ & se & 40 & 96 & -56 & 17 \\
\hline Mai/82 & 0,30 & 11,31 & $-2,42$ & sm & 73 & 71 & 3 & 2 \\
\hline Jun/82 & 1,72 & 4,91 & $-1,06$ & ss & 76 & 59 & 17 & 0 \\
\hline Jul/82 & $-2,93$ & 0,52 & $-1,10$ & ss & 45 & 79 & -35 & 12 \\
\hline Ago/82 & $-6,11$ & 0,67 & $-1,68$ & ss & 15 & 124 & -109 & 55 \\
\hline Set/82 & $-3,26$ & 2,54 & $-1,51$ & ss & 25 & 106 & -81 & 75 \\
\hline Out $/ 82$ & $-0,20$ & 1,99 & $-0,88$ & $\mathrm{si}$ & 273 & 277 & -5 & 0 \\
\hline$=$ & $=$ & $\Longrightarrow$ & $=$ & $=$ & $=$ & $=$ & $=$ & $\square$ \\
\hline Fev/84 & $-16,23$ & $-12,09$ & $-1,22$ & ss & 0,9 & 78,5 & $-77,6$ & 49 \\
\hline Mar/84 & $-0,90$ & 1,06 & $-0,84$ & si & 146,1 & 150,5 & $-4,4$ & 0 \\
\hline $\mathrm{Abr} / 84$ & $-3,08$ & $-0,17$ & $-1,01$ & ss & 75,9 & 99,8 & $-23,9$ & 8 \\
\hline Mai/84 & $-3,33$ & 0,37 & $-1,14$ & SS & 43,3 & 73,3 & $-30,0$ & 24 \\
\hline Jun/84 & $-4,59$ & 0,81 & $-1,44$ & ss & 0,4 & 46,5 & $-46,1$ & 52 \\
\hline Jul/84 & $-4,61$ & 1,76 & $-1,61$ & Ss & 0,9 & 55,6 & $-54,7$ & 53 \\
\hline Ago/84 & $-1,29$ & 2,31 & $-1,13$ & ss & 65,3 & 88,1 & $-22,8$ & 0 \\
\hline Set/84 & 0,20 & 0,75 & $-0,60$ & si & 81,9 & 76,9 & 5,0 & 6 \\
\hline Out/84 & $-5,76$ & $-0,96$ & $-1,34$ & ss & 44,2 & 178,9 & $-134,7$ & 98 \\
\hline Nov/84 & $-2,24$ & 1,43 & $-1,14$ & ss & 47,0 & 110,8 & $-63,8$ & 89 \\
\hline$=$ & 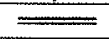 & $=$ & $\overline{=}$ & ב_E & $\bar{\square}$ & 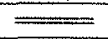 & $\Longrightarrow$ & $=$ \\
\hline Jun/85 & $-2,78$ & $-2,11$ & $-0,62$ & si & 8,1 & 36 & -28 & 19 \\
\hline $\mathrm{Jul} / 85$ & $-3,28$ & $-0,89$ & $-0,92$ & si & 14,4 & 53 & -39 & 26 \\
\hline
\end{tabular}


Continuação:

A5. Períodos de seca identificados em Adamantina - $S P$, classificação e, respectivos valores de $z(p o l), z_{e}(p o l), X_{i}(p o l), P(m m)$, $P_{\text {cafec }}(\mathrm{mm}), d(\mathrm{~mm})$ e DEF $(\mathrm{mm})$.

\begin{tabular}{|c|c|c|c|c|c|c|c|c|}
\hline Ago/85 & $-5,44$ & 0,08 & $-1,46$ & ss & 15,9 & 112 & -97 & 58 \\
\hline Set/85 & $-2,91$ & 1,83 & $-1,33$ & SS & 27,5 & 99 & -72 & 71 \\
\hline Out/85 & $-8,52$ & 1,39 & $-2,23$ & $\mathrm{sm}$ & 8,5 & 208 & -199 & 145 \\
\hline Nov/85 & $-2,00$ & 4,29 & $.1,60$ & ss & 72 & 129 & -57 & 91 \\
\hline Dez/85 & $-2,58$ & 2,26 & $-1,34$ & ss & 68,5 & 227 & -158 & 117 \\
\hline 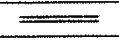 & $=$ & 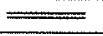 & $\square$ & $=$ & $\bar{\square}$ & $=$ & $=$ & 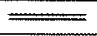 \\
\hline $\mathrm{Jan} / 87$ & $-17,50$ & $-3,32$ & $-2,97$ & sm & 400,7 & 434,2 & $-33,5$ & 0 \\
\hline Fev/87 & 0,43 & 6,68 & $-1,59$ & ss & 165,5 & 163,5 & 2,0 & 0 \\
\hline Mar/87 & $-9,66$ & 2,24 & $-2,57$ & sm & 32,5 & 80,4 & $-47,9$ & 38 \\
\hline $\mathrm{Abr} / 87$ & $-10,03$ & 5,40 & $-3,19$ & sse & 33,3 & 111,2 & $-77,9$ & 71 \\
\hline Mai/87 & 6,17 & 7,38 & $-0,71$ & si & 150,8 & 95,1 & 55,7 & 0 \\
\hline Jun/87 & $-2,39$ & $-0,59$ & $-0,81$ & si & 19,5 & 43,5 & $-24,0$ & 8 \\
\hline Jul/87 & $-4,65$ & $-0,25$ & $-1,27$ & ss & 40,8 & 96,0 & $-55,2$ & 26 \\
\hline Ago/87 & $-4,76$ & 1,20 & $-1,54$ & ss & 11,9 & 96,5 & $-84,6$ & 47 \\
\hline Set/87 & $-1,40$ & 2,08 & $-1,11$ & ss & 50,4 & 84,9 & $-34,5$ & 36 \\
\hline Out/87 & $-1,69$ & 0,68 & $-0,91$ & si & 97,2 & 136,7 & $-39,5$ & 39 \\
\hline \multirow[t]{2}{*}{$=$} & 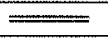 & 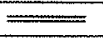 & $=$ & $\bar{\square}$ & 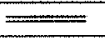 & 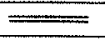 & $=$ & $\bar{\square}$ \\
\hline & $\mathbf{z}$ & $\mathbf{z}_{\boldsymbol{t}}$ & $\mathrm{X}_{\mathrm{i}}$ & Classe & $\mathbf{P}$ & $\mathbf{P}_{\text {cafec }}$ & $\mathrm{d}(\mathrm{mm})$ & DEF \\
\hline Fev/88 & $-9,14$ & $-2,24$ & $-1,70$ & ss & 226,1 & 270 & -44 & 0 \\
\hline $\operatorname{Mar} / 88$ & $-4,76$ & 2,60 & $-1,78$ & ss & 212,3 & 236 & -24 & 0 \\
\hline Abr/88 & $-4,73$ & 2,86 & $-1,82$ & ss & 70,6 & 107 & -37 & 5 \\
\hline Mai/88 & $-1,98$ & 2,99 & $-1,37$ & ss & 53,4 & 71 & -18 & 10 \\
\hline Jun/88 & $-2,09$ & 1,52 & $-1,13$ & ss & 18,8 & 40 & -21 & 19 \\
\hline $\mathrm{Jul} / 88$ & $-4,65$ & 0,76 & $-1,44$ & ss & 0 & 55 & -55 & 43 \\
\hline Ago/88 & $-5,48$ & 1,77 & $-1,76$ & ss & 0 & 97 & -97 & 69 \\
\hline Set/88 & $-2,80$ & 2,80 & $-1,47$ & ss & 17,4 & 86 & -69 & 39 \\
\hline Oat/88 & 0,20 & 1,87 & $-0,79$ & si & 219,8 & 215 & 5 & 0 \\
\hline Nov/88 & $-2,00$ & $-0,33$ & $-0,79$ & si & 53,2 & 110 & -57 & 28 \\
\hline Dez/88 & $-3,85$ & $-0,32$ & $-1,11$ & ss & 0,9 & 237 & -237 & 117 \\
\hline $\bar{\square}$ & $=$ & $=$ & $=$ & $=$ & $=$ & $=$ & $=$ & $=$ \\
\hline $\operatorname{Jan} / 90$ & $-3,52$ & $-3,29$ & $-0,54$ & si & 309 & 316 & -7 & 0 \\
\hline Fev/90 & $-8,50$ & $-1,13$ & $-1,78$ & SS & 57 & 97 & -41 & 29 \\
\hline Mar/90 & $-2,31$ & 2,87 & $-1,40$ & ss & 182 & 194 & -11 & 0 \\
\hline Abr $/ 90$ & $-3,52$ & 1,63 & $-1,40$ & ss & 109 & 136 & -27 & 3 \\
\hline$=$ & $\overline{\bar{L}}$ & $=$ & $\overline{=}$ & 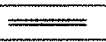 & $=$ & $=$ & 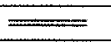 & 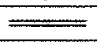 \\
\hline Jan/91 & $-32,78$ & $-2,55$ & $-5,77$ & se & 439 & 502 & -63 & 0 \\
\hline Fev/91 & $-0,43$ & 15,67 & $-3,31$ & sse & 156 & 158 & -2 & 0 \\
\hline Mar/91 & $-5,28$ & 7,76 & $-2,77$ & $\mathrm{sm}$ & 171 & 197 & -26 & 0 \\
\hline Abr/91 & $-2,03$ & 6,04 & $-1,91$ & ss & 90 & 106 & -16 & 0 \\
\hline Mai/91 & $-6,24$ & 3,26 & $-2,16$ & $\mathrm{sm}$ & 2 & 59 & -56 & 19 \\
\hline Jun/91 & 1,29 & 4,06 & $-0,98$ & si & 69 & 56 & 13 & 0 \\
\hline $\mathrm{Jul} / 91$ & $-3,38$ & 0,29 & $-1,14$ & ss & 15 & 56 & -40 & 23 \\
\hline Ago/91 & $-6,00$ & 0,79 & $-1,68$ & ss & 0 & 107 & -107 & 67 \\
\hline Set/91 & $-3,05$ & 2,54 & $-1,48$ & ss & 18 & 93 & -75 & 73 \\
\hline Out/91 & 0,15 & 1,87 & $-0,80$ & si & 113 & 110 & 4 & 13 \\
\hline \multirow[t]{2}{*}{$\Longrightarrow$} & $=$ & $=$ & $\bar{\square}$ & $\Longrightarrow$ & 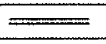 & $=$ & $\Longrightarrow$ & $\bar{\square}$ \\
\hline & $\mathbf{z}$ & $z_{t}$ & $\mathbf{X}_{\mathbf{i}}$ & Classe & $\mathbf{P}$ & $\mathbf{P}_{\text {cufec }}$ & d (mm) & DEF \\
\hline $\mathrm{Jan} / 92$ & $-88,34$ & $-2,81$ & $-15,41$ & $\mathrm{se}$ & 60 & 230 & -169 & 48 \\
\hline Fev/92 & 5,97 & 46,64 & $-7,59$ & se & 153 & 125 & 29 & 0 \\
\hline Mar/92 & $-19,12$ & 21,51 & $-7,58$ & se & 291 & 386 & -95 & 0 \\
\hline $\mathrm{Abr} / 92$ & 1,98 & 21,49 & $-3,90$ & sse & 151 & 135 & 15 & 0 \\
\hline $\bar{\square}$ & $\Longrightarrow$ & 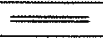 & 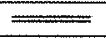 & $=$ & $=$ & $\underline{\underline{ }}$ & $\bar{\square}$ & $=$ \\
\hline Fev/93 & $-28,95$ & $-17,39$ & $-2,52$ & $\mathrm{sm}$ & 286,4 & 425 & -138 & 0 \\
\hline Mar/93 & $-1,52$ & 5,21 & $-1,67$ & ss & 171 & 179 & -8 & 0 \\
\hline $\mathrm{Abr} / 93$ & $-3,59$ & 2,51 & $-1,56$ & ss & 91,8 & 120 & -28 & 2 \\
\hline Mai/93 & $-3,79$ & 2,15 & $-1,54$ & ss & 30,3 & 65 & -34 & 14 \\
\hline $\mathrm{Jun} / 93$ & 1,12 & 2,07 & $-0,66$ & si & 58,3 & 47 & 11 & 0 \\
\hline Jul/93 & $-3,78$ & $-0,73$ & $-1,03$ & ss & 3,7 & 49 & -45 & 26 \\
\hline Ago/93 & $-3,24$ & 0,44 & $-1,14$ & ss & 34,7 & 92 & -58 & 23 \\
\hline Set/93 & $-0,17$ & 0,80 & $-0,67$ & si & 73,7 & 78 & -4 & 12 \\
\hline Out/93 & $-4,13$ & $-0,72$ & $-1,10$ & ss & 55,4 & 152 & -97 & 68 \\
\hline
\end{tabular}


Continuação:

A5. Períodos de seca identificados em Adamantina - SP, classificação e, respectivos valores de $\mathbf{z}(\mathrm{pol}), \mathrm{z}_{\mathrm{e}}(\mathrm{pol}), \mathrm{X}_{\mathrm{i}}(\mathrm{pol}), \mathrm{P}(\mathrm{mm})$, $\mathrm{P}_{\mathrm{cafec}}(\mathrm{mm}) \mathrm{d}(\mathrm{mm})$ e DEF $(\mathrm{mm})$

\begin{tabular}{|c|c|c|c|c|c|c|c|c|}
\hline$=$ & $=$ & $=$ & $=$ & $=$ & $=$ & $=$ & $\Longrightarrow$ & $=$ \\
\hline Jul/94 & $-3,14$ & $-1,40$ & $-0,80$ & $\mathrm{si}$ & 24,5 & 62 & -37 & 22 \\
\hline Ago/94 & $-5,84$ & $-0,29$ & $-1,47$ & Ss & 0 & 104 & -104 & 66 \\
\hline Set/94 & $-2,74$ & 1,85 & $-1,30$ & ss & 42,4 & 110 & -68 & 69 \\
\hline Out/94 & $-6,17$ & 1,30 & $-1,80$ & ss & 33,4 & 178 & -144 & 108 \\
\hline Nov/94 & 0,22 & 2,93 & $-0,97$ & si & 115,7 & 109 & 6 & 27 \\
\hline$=$ & $=$ & $=$ & $=$ & $=$ & $=$ & $\overline{=}$ & 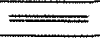 & 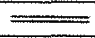 \\
\hline Fev/95 & $-18,23$ & $-11,38$ & $-1,69$ & ss & 259,1 & 346 & -87 & 0 \\
\hline Mar/95 & $-5,33$ & 2,57 & $-1,88$ & Ss & 67,2 & 94 & -26 & 17 \\
\hline Abr/95 & $-0,48$ & 3,17 & $-1,14$ & ss & 111,9 & 116 & -4 & 0 \\
\hline Mai/95 & $-5,31$ & 0,78 & $-1,56$ & SS & 43,4 & 91 & -48 & 27 \\
\hline Jun/95 & $-3,33$ & 2,15 & $-1,46$ & ss & 18,7 & 52 & -33 & 37 \\
\hline Jul/95 & $-4,49$ & 1,81 & $-1,60$ & ss & 29,6 & 83 & -53 & 44 \\
\hline Ago/95 & $-7,59$ & 2,26 & $-2,22$ & $\mathrm{sm}$ & 0 & 135 & -135 & 102 \\
\hline Set/95 & $-2,15$ & 4,25 & $-1,62$ & ss & 43,7 & 97 & -53 & 59 \\
\hline Out/95 & 0,47 & 2,32 & $-0,82$ & si & 155,7 & 145 & 11 & 0 \\
\hline$=$ & $=$ & $=$ & $\bar{\square}$ & $\bar{\square}$ & $=$ & $\bar{\square}$ & $=$ & $=$ \\
\hline Fev/96 & $-19,85$ & $-17,63$ & $-0,89$ & si & 1 & 96 & -95 & 68 \\
\hline Mar/96 & $-0,71$ & $-0,02$ & $-0,62$ & si & 157 & 161 & -4 & 0 \\
\hline Abr/96 & $-10,61$ & $-0,87$ & $-2,20$ & $\mathrm{sm}$ & 1 & 83 & -82 & 74 \\
\hline Mai/96 & $-1,25$ & 4,19 & $-1,45$ & ss & 57 & 69 & -11 & 16 \\
\hline Jun/96 & $-1,42$ & 1,78 & $-1,06$ & ss & 22 & 36 & -14 & 23 \\
\hline Jul/96 & $-3,85$ & 0,53 & $-1,26$ & ss & 2 & 47 & -46 & 46 \\
\hline Ago/96 & $-5,64$ & 1,19 & $-1,69$ & Ss & 12 & 113 & -100 & 74 \\
\hline Set/96 & 1,42 & 2,56 & $-0,70$ & $\mathrm{si}$ & 125 & 90 & 35 & 0 \\
\hline Out/96 & $-1,74$ & $-0,62$ & $-0,69$ & si & 91 & 132 & -41 & 30 \\
\hline
\end{tabular}

A6. Períodos de seca identificados em Pontal - Teodoro Sampaio/SP, classificação e, respectivos valores de $z(p o l), z_{e}(p o l), X_{i}(p o l), P(m m), P_{\text {cafec }}(\mathrm{mm}), d(\mathrm{~mm})$ e DEF (mm).

\begin{tabular}{|c|c|c|c|c|c|c|c|c|}
\hline Mtering & $\bar{z}$ & $\mathbf{z}_{\mathrm{e}}$ & $\mathbf{X}_{\mathrm{i}}$ & Classe & $\mathbf{P}$ & $P_{\text {cafec }}$ & $\mathbf{d}$ & DEF \\
\hline $\mathrm{Jan} / 79$ & $-11,29$ & $-3,23$ & $-1,91$ & ss & 91 & 115 & -24 & 37 \\
\hline Fev/79 & $-8,46$ & 3,26 & $-2,54$ & sm & 102 & 129 & -28 & 38 \\
\hline Mar/79 & $-15,37$ & 5,30 & $-4,10$ & se & 26 & 135 & -109 & 86 \\
\hline Abr/79 & 4,26 & 10,31 & $-1,55$ & ss & 108 & 77 & 31 & 0 \\
\hline$\overline{ }$ & $=$ & $=$ & $\overline{=}$ & $=$ & $=$ & $\Longrightarrow$ & $\Longrightarrow$ & $\underline{\underline{ }}$ \\
\hline Fev/84 & $-17,71$ & $-10,32$ & $-1,79$ & ss & 67 & 124 & -58 & 55 \\
\hline Mar/84 & $-4,49$ & 2,88 & $-1,78$ & ss & 86 & 118 & -32 & 30 \\
\hline Abr/84 & $-0,60$ & 2,86 & $-1,10$ & ss & 58 & 62 & -4 & 9 \\
\hline Mai/84 & $-4,56$ & 0,68 & $-1,41$ & ss & 19 & 81 & -62 & 37 \\
\hline Jun/84 & $-3,09$ & 1,67 & $-1,33$ & ss & 6 & 41 & -35 & 34 \\
\hline Jul/84 & $-2,97$ & 1,40 & $-1,26$ & ss & 1 & 25 & -24 & 40 \\
\hline Ago/84 & 0,95 & 1,18 & $-0,54$ & $\mathrm{si}$ & 56 & 47 & 9 & 0 \\
\hline$=$ & $\underline{\overline{ }}$ & $=$ & $\underline{\underline{ }}$ & $\overline{=}$ & $=$ & 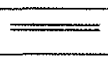 & $=$ & $\Longrightarrow$ \\
\hline Nov/85 & $-2,22$ & $-1,46$ & $-0,63$ & si & 93 & 126 & -33 & 56 \\
\hline Dez/85 & $-3,37$ & $-0,84$ & $-0,94$ & si & 67 & 181 & -114 & 94 \\
\hline Jan/86 & $-31,91$ & 0,15 & $-6,09$ & se & 56 & 125 & -68 & 115 \\
\hline Fev/86 & 1,42 & 16,69 & $-3,16$ & sse & 147 & 142 & 5 & 0 \\
\hline Mar/86 & 4,85 & 7,29 & $-0,92$ & si & 155 & 120 & 35 & 0 \\
\hline Abr/86 & $-2,24$ & 0,10 & $-0,91$ & si & 80 & 96 & -16 & 16 \\
\hline
\end{tabular}


A7. Períodos de seca identificados em Presidente Prudente - SP, classificação e, respectivos valores de $z$ (pol), $\mathrm{z}_{\mathrm{e}}(\mathrm{pol}), \mathrm{X}_{\mathrm{i}}(\mathrm{pol}), \mathrm{P}(\mathrm{mm}), \mathrm{P}_{\mathrm{cafec}}(\mathrm{mm}), \mathrm{d}(\mathrm{mm})$ e DEF (mm).

\begin{tabular}{|c|c|c|c|c|c|c|c|c|}
\hline Mravono & $z$ & $z_{e}$ & $\mathbf{X}_{\mathbf{i}}$ & Classe & $\overline{\mathbf{P}}$ & $\mathbf{P}_{\text {eafec }}$ & d & DEF \\
\hline $\mathbf{J u l} / 61$ & $-4,01$ & $-1,48$ & $-0,94$ & si & 0 & 44 & -44 & 36 \\
\hline Ago/61 & $-4,69$ & 0,16 & $-1,35$ & ss & 10 & 82 & -72 & 63 \\
\hline Set/61 & $-4,49$ & 1,46 & $-1,54$ & ss & 9 & 103 & -94 & 98 \\
\hline Out/61 & $-3,31$ & 2,07 & $-1,44$ & ss & 0 & 110 & -110 & 103 \\
\hline Nov/61 & $-4,57$ & 1,75 & $-1,60$ & ss & 0 & 114 & -114 & 121 \\
\hline Dez/61 & 1,17 & 2,28 & $-0,69$ & si & 150 & 101 & 49 & 0 \\
\hline Jan/62 & $-0,74$ & $-0,64$ & $-0,52$ & si & 100 & 102 & -2 & 45 \\
\hline$\overline{\underline{ }}$ & 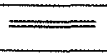 & $\bar{\square}$ & $\underline{\overline{ }}$ & $\underline{\overline{ }}$ & $\overline{\underline{ }}$ & $\overline{\underline{ }}$ & $=$ & $\overline{\overline{ }}$ \\
\hline $\mathrm{Jan} / 64$ & $-10,26$ & $-4,10$ & $-1,57$ & ss & 80 & 112 & -32 & 22 \\
\hline Fev/64 & $-12,71$ & 2,19 & $-3,10$ & sse & 0 & 55 & -55 & 91 \\
\hline Mar/64 & $-0,28$ & 7,08 & $-1,78$ & ss & 98 & 99 & -1 & 23 \\
\hline Abr/64 & $-9,55$ & 2,86 & $-2,66$ & $\mathrm{sm}$ & 20 & 92 & -72 & 83 \\
\hline Mai/64 & $-4,79$ & 5,69 & $-2,33$ & $\mathrm{sm}$ & 20 & 81 & -61 & 40 \\
\hline Jun/64 & 1,80 & 4,60 & $-0,99$ & si & 72 & 54 & 18 & 0 \\
\hline $\mathrm{Jul} / 64$ & 0,25 & 0,31 & $-0,51$ & si & 42 & 39 & 3 & 0 \\
\hline Ago/64 & $-2,14$ & $-1,23$ & $-0,66$ & si & 42 & 74 & -33 & 21 \\
\hline Set/64 & $-1,08$ & $-0,75$ & $-0,56$ & si & 55 & 78 & -23 & 30 \\
\hline$=$ & $\overline{\overline{ }}$ & $\underline{\overline{ }}$ & $\underline{\underline{ }}$ & $=$ & 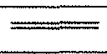 & $=$ & $\underline{ }$ & $=$ \\
\hline Jul/67 & $-2,27$ & $-1,28$ & $-0,67$ & si & 20 & 45 & -25 & 20 \\
\hline Ago/67 & $-4,85$ & $-0,70$ & $-1,22$ & ss & 4 & 79 & -75 & 63 \\
\hline Set/67 & $-4,22$ & 1,06 & $-1,42$ & ss & 7 & 96 & -89 & 90 \\
\hline Ont/67 & $-3,31$ & 1,70 & $-1,37$ & ss & 0 & 110 & -110 & 103 \\
\hline Nov/67 & $-2,34$ & 1,54 & $-1,18$ & ss & 36 & 95 & -59 & 67 \\
\hline Dez/67 & $-0,04$ & 0,91 & $-0,67$ & si & 86 & 88 & -2 & 24 \\
\hline$\Longrightarrow$ & $=$ & $=$ & $=$ & $=$ & $\underline{\underline{ }}$ & $=$ & $\Longrightarrow$ & $=$ \\
\hline Jan/79 & $-23,94$ & $-2,16$ & $-4,30$ & $\mathrm{se}$ & 30 & 105 & -75 & 87 \\
\hline Fev/79 & 8,70 & 10,94 & $-0,89$ & si & 133 & 95 & 38 & 0 \\
\hline Mar/79 & $-7,42$ & $-0,01$ & $-1,79$ & ss & 48 & 87 & -39 & 67 \\
\hline Abr/79 & $-2,20$ & 2,89 & $-1,39$ & ss & 85 & 101 & -17 & 0 \\
\hline$=$ & $\overline{\overline{ }}$ & $=$ & $\underline{\underline{ }}$ & 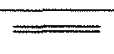 & $=$ & $=$ & $\Longrightarrow$ & $\Longrightarrow$ \\
\hline Ago/85 & $-4,50$ & $-1,53$ & $-1,02$ & ss & 5 & 74 & -69 & 49 \\
\hline Set/85 & $-3,38$ & 0,40 & $-1,16$ & ss & 16 & 87 & -71 & 69 \\
\hline Out/85 & $-3,95$ & 0,86 & $-1,34$ & ss & 12 & 144 & -132 & 123 \\
\hline Nov/85 & $-0,76$ & 1,43 & $-0,88$ & si & 110 & 129 & -19 & 37 \\
\hline Dez/85 & $-2,09$ & $-0,04$ & $-0,86$ & si & 79 & 166 & -87 & 91 \\
\hline
\end{tabular}


A8. Períodos de seca identificados em Salto Grande - SP, classificação e, respectivos valores de $z$ (pol), $z_{e}$ (pol), $X_{\mathrm{i}}(\mathrm{pol}), \mathrm{P}(\mathrm{mm}), \mathrm{P}_{\text {cafec }}(\mathrm{mm}), \mathrm{d}(\mathrm{mm})$ e DEF (mm).

\begin{tabular}{|c|c|c|c|c|c|c|c|c|}
\hline Mres/Ano & $\mathbf{z}$ & $\mathbf{z}_{\boldsymbol{c}}$ & $\mathbf{X}_{\mathbf{i}}$ & Classe & $\mathbf{P}$ & $\mathbf{P}_{\text {caffec }}$ & $\mathbf{d}$ & $\mathbf{D E F}$ \\
\hline $\mathbf{J a n} / \mathbf{8 4}$ & $-22,49$ & $-3,84$ & $-3,75$ & sse & 92 & 154 & -62 & 43 \\
\hline Fev/84 & $-8,07$ & 9,18 & $-3,51$ & sse & 50 & 85 & -36 & 93 \\
\hline Mar/84 & 0,84 & 8,40 & $-1,82$ & ss & 113 & 108 & 5 & 20 \\
\hline Abr/84 & 1,61 & 2,97 & $-0,74$ & si & 82 & 71 & 10 & 0 \\
\hline Mai/84 & $-2,09$ & $-0,50$ & $-0,78$ & si & 30 & 53 & -23 & 26 \\
\hline Jun/84 & $-2,19$ & $-0,37$ & $-0,82$ & si & 0 & 20 & -20 & 38 \\
\hline Jul/84 & $-3,06$ & $-0,25$ & $-0,99$ & si & 5 & 31 & -26 & 47 \\
\hline Ago/84 & $-0,52$ & 0,32 & $-0,65$ & si & 53 & 59 & -6 & 0 \\
\hline
\end{tabular}

A9. Períodos de seca identificados em Votuporanga - SP, classificação e, respectivos valores de $\mathrm{z}$ (pol), $\mathrm{z}_{e}$ (pol), $X_{\mathrm{i}}(\mathrm{pol}), \mathrm{P}(\mathrm{mm}), \mathrm{P}_{\text {cafec }}(\mathrm{mm}), \mathrm{d}(\mathrm{mm})$ e DEF (mm).

\begin{tabular}{|c|c|c|c|c|c|c|c|c|}
\hline Mrorino & $z$ & $z_{e}$ & $\mathbf{X}_{i}$ & Classe & $\mathbf{P}$ & $P_{\text {cafec }}$ & d & DEF \\
\hline $\operatorname{Jun} / 73$ & $-6,64$ & $-6,55$ & $-0,52$ & si & 7,8 & 67,4 & $-59,6$ & 9 \\
\hline Jul/73 & $-4,18$ & $-1,21$ & $-1,02$ & ss & 13,5 & 65,2 & $-51,7$ & 14 \\
\hline Ago/73 & $-4,59$ & 0,40 & $-1,37$ & ss & 0,8 & 96,0 & $-95,2$ & 45 \\
\hline Set/73 & $-2,50$ & 1,53 & $-1,20$ & ss & 18,8 & 102,1 & $-83,3$ & 72 \\
\hline Ont $/ 73$ & 0,84 & 1,00 & $-0,53$ & si & 128,5 & 98,0 & 30,5 & 0 \\
\hline$\Longrightarrow$ & $=$ & $\overline{\overline{ }}$ & $=$ & $=$ & $\Longrightarrow$ & $\bar{\square}$ & $\bar{\square}$ & $\overline{\overline{ }}$ \\
\hline $\mathrm{Jul} / 74$ & $-7,41$ & $-1,30$ & $-1,57$ & ss & 0 & 92 & -92 & 31 \\
\hline Ago/74 & $-5,43$ & 2,16 & $-1,82$ & ss & 3 & 116 & -113 & 59 \\
\hline Set/74 & $-0,86$ & 2,99 & $-1,17$ & ss & 73 & 102 & -29 & 27 \\
\hline Out/74 & $-0,01$ & 0,89 & $-0,66$ & si & 107 & 107 & -1 & 12 \\
\hline Nov/74 & $-1,27$ & $-0,75$ & $-0,59$ & $\mathrm{si}$ & 71 & 128 & -57 & 41 \\
\hline 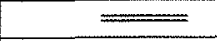 & $=$ & $\bar{\square}$ & $\bar{\square}$ & $\overline{\bar{\square}}$ & $=$ & $=$ & $\overline{\overline{ }}$ & $\overline{\overline{ }}$ \\
\hline Mai/75 & $-6,83$ & $-3,73$ & $-1,04$ & ss & 0 & 46 & -46 & 22 \\
\hline Jun/75 & $-6,07$ & 0,47 & $-1,64$ & ss & 0 & 54 & -54 & 28 \\
\hline $\mathrm{Jul} / 75$ & $-2,26$ & 2,40 & $-1,31$ & ss & 23 & 51 & -28 & 6 \\
\hline Ago $/ 75$ & $-7,35$ & 1,35 & $-2,02$ & $\mathrm{sm}$ & 0 & 152 & -152 & 91 \\
\hline Set/75 & $-3,75$ & 3,61 & $-1,78$ & ss & 3 & 128 & -125 & 122 \\
\hline Out/75 & 0,10 & 2,86 & $-0,98$ & si & 118 & 115 & 4 & 11 \\
\hline & 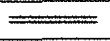 & 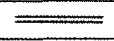 & $=$ & $=$ & $=$ & 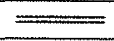 & $=$ & $\Longrightarrow$ \\
\hline $\mathrm{Jun} / 77$ & $-6,54$ & $-3,02$ & $-1,11$ & ss & 31 & 90 & -59 & 25 \\
\hline $\mathrm{Jul} / 77$ & $-10,32$ & 0,71 & $-2,42$ & sm & 0 & 128 & -128 & 80 \\
\hline Ago/77 & $-3,02$ & 4,91 & $-1,88$ & ss & 72 & 134 & -63 & 12 \\
\hline Set $/ 77$ & 0,27 & 3,18 & $-1,01$ & ss & 109 & 100 & 9 & 0 \\
\hline Out/77 & $-1,84$ & 0,37 & $-0,88$ & si & 73 & 139 & -67 & 63 \\
\hline 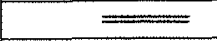 & $=$ & $=$ & $=$ & $=$ & $\bar{\square}$ & $=$ & $\Longrightarrow$ & $=$ \\
\hline Jun/82 & $-10,05$ & $-4,69$ & $-1,43$ & ss & 18 & 108 & -90 & 31 \\
\hline $\mathrm{Jul} / 82$ & $-5,77$ & 1,74 & $-1,81$ & ss & 7 & 78 & -71 & 34 \\
\hline Ago/82 & $-4,93$ & 2,94 & $-1,87$ & ss & 30 & 133 & -102 & 49 \\
\hline Set/82 & $-1,64$ & 3,15 & $-1,33$ & ss & 43 & 98 & -55 & 52 \\
\hline$=$ & $\square$ & $=$ & $=$ & $=$ & $\bar{\square}$ & $=$ & $\bar{\square}$ & $\overline{\underline{ }}$ \\
\hline $\mathrm{Jun} / 84$ & $-8,53$ & $-2,78$ & $-1,50$ & ss & 0 & 76 & -76 & 24 \\
\hline $\mathrm{Jul} / 84$ & $-5,16$ & 1,96 & $-1,74$ & ss & 15 & 79 & -64 & 24 \\
\hline Ago/84 & $-2,36$ & 2,73 & $-1,39$ & ss & 60 & 108 & -49 & 6 \\
\hline Set/84 & $-1,53$ & 1,59 & $-1,04$ & ss & 33 & 83 & -51 & 42 \\
\hline Out/84 & $-0,86$ & 0,48 & $-0,73$ & ss & 82 & 113 & -31 & 33 \\
\hline Nov/84 & $-0,55$ & $-0,51$ & $-0,51$ & si & 141 & 166 & -25 & 28 \\
\hline & & & & {[} & & $\bar{E}$ & 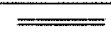 & - \\
\hline
\end{tabular}


Continuação:

A9. Períodos de seca identificados em Votuporanga - SP, classificação e, respectivos valores de $z$ (pol), $z_{e}$ (pol), $X_{i}(\mathrm{pol}), \mathrm{P}(\mathrm{mm}), \mathrm{P}_{\mathrm{cafec}}(\mathrm{mm}), \mathrm{d}(\mathrm{mm})$ e DEF (mm).

\begin{tabular}{|c|c|c|c|c|c|c|c|c|}
\hline Jul/85 & $-4,49$ & $-1,85$ & $-0,96$ & si & 7 & 63 & -56 & 22 \\
\hline Ago/85 & $-4,21$ & 0,21 & $-1,27$ & ss & 0 & 87 & -87 & 48 \\
\hline Set/85 & $-2,57$ & 1,22 & $-1,16$ & ss & 23 & 109 & -86 & 79 \\
\hline Out/85 & $-3,52$ & 0,86 & $-1,26$ & ss & 34 & 162 & -128 & 117 \\
\hline Nov/85 & 0,79 & 1,19 & $-0,57$ & si & 177 & 141 & 36 & 0 \\
\hline$=$ & $\bar{\square}$ & $=$ & $\bar{\square}$ & $=$ & $\bar{\square}$ & 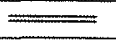 & $=$ & $=$ \\
\hline Jun/86 & $-6,56$ & $-4,11$ & $-0,93$ & si & 0 & 59 & -59 & 22 \\
\hline $\mathrm{Jul} / 86$ & $-5,47$ & 0,11 & $-1,47$ & ss & 41 & 109 & -68 & 17 \\
\hline Ago/86 & $-4,11$ & 1,86 & $-1,54$ & Ss & 55 & 140 & -85 & 27 \\
\hline Set/86 & $-1,64$ & 2,08 & $-1,15$ & ss & 44 & 99 & -55 & 48 \\
\hline Out/86 & $-2,25$ & 0,82 & $-1,04$ & ss & 64 & 146 & -82 & 76 \\
\hline Nov/86 & $-1,02$ & 0,46 & $-0,76$ & si & 84 & 129 & -46 & 37 \\
\hline $\bar{\square}$ & 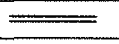 & $\bar{\square}$ & $\bar{\square}$ & $=$ & 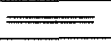 & $=$ & $\overline{\overline{ }}$ & $=$ \\
\hline Jun/87 & $-6,76$ & $-2,67$ & $-1,21$ & ss & 1,6 & 62,3 & $-60,7$ & 26 \\
\hline Jul/87 & $-7,28$ & 1,03 & $-1,95$ & ss & 10,4 & 100,3 & $-89,9$ & 43 \\
\hline Ago/87 & $-4,04$ & 3,39 & $-1,79$ & ss & 8,0 & 91,7 & $-83,7$ & 48 \\
\hline Set/87 & $-0,77$ & 2,90 & $-1,14$ & ss & 83,8 & 109,6 & $-25,8$ & 26 \\
\hline Out/87 & $-1,11$ & 0,79 & $-0,83$ & $\mathrm{si}$ & 95,9 & 136,3 & $-40,4$ & 45 \\
\hline$\Longrightarrow$ & $\overline{=}$ & $=$ & $=$ & $\Longrightarrow$ & $\Longrightarrow$ & $=$ & $\Longrightarrow$ & $=$ \\
\hline Jun/91 & $-7,16$ & $-4,57$ & $-0,95$ & si & 6,4 & 70,6 & $-64,2$ & 25 \\
\hline Jul/91 & $-5,92$ & 0,19 & $-1,56$ & Ss & 0,0 & 73,1 & $-73,1$ & 37 \\
\hline Ago/91 & $-4,78$ & 2,16 & $-1,71$ & ss & 0,0 & 99,2 & $-99,2$ & 59 \\
\hline Set/91 & $-2,91$ & 2,62 & $-1,46$ & ss & 25,6 & 122,6 & $-97,0$ & 93 \\
\hline Out/91 & $-2,17$ & 1,84 & $-1,20$ & ss & 74,5 & 153,5 & $-79,0$ & 79 \\
\hline Nov/91 & $-3,06$ & 0,98 & $-1,20$ & ss & 70,7 & 209,0 & $-138,3$ & 97 \\
\hline Dez/91 & 0,87 & 1,00 & $-0,52$ & si & 185,3 & 109,4 & 75,9 & 0 \\
\hline$\Longrightarrow$ & $=$ & $=$ & 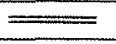 & $=$ & $=$ & $=$ & 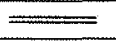 & $=$ \\
\hline Jun/92 & $-10,78$ & $-3,49$ & $-1,77$ & ss & 0 & 97 & -97 & 47 \\
\hline Jul/92 & $-6,46$ & 2,82 & $-2,12$ & $\mathrm{sm}$ & 10 & 90 & -80 & 41 \\
\hline Ago/92 & $-4,96$ & 3,93 & $-2,05$ & $\mathrm{sm}$ & 21 & 123 & -103 & 57 \\
\hline Set $/ 92$ & 0,83 & 3,72 & $-1,00$ & ss & 126 & 98 & 28 & 0 \\
\hline Ont/92 & $-0,06$ & 0,35 & $-0,57$ & si & 113 & 116 & -2 & 10 \\
\hline$\Longrightarrow$ & $=$ & $=$ & $\Longrightarrow$ & $\overline{=}$ & $\overline{\overline{ }}$ & $=$ & $=$ & $=$ \\
\hline Mai/94 & $-6,63$ & $-5,65$ & $-0,67$ & si & 15 & 60 & -45 & 32 \\
\hline Jun/94 & $-6,91$ & $-0,71$ & $-1,58$ & ss & 12 & 74 & -62 & 32 \\
\hline Jul/94 & $-6,26$ & 2,21 & $-1,98$ & ss & 14 & 92 & -77 & 39 \\
\hline Ago/94 & $-5,92$ & 3,48 & $-2,14$ & $\mathrm{sm}$ & 0 & 123 & -123 & 80 \\
\hline Set/94 & $-3,90$ & 4,00 & $-1,88$ & ss & 0 & 130 & -130 & 129 \\
\hline Ont/94 & 1,89 & 3,17 & $-0,72$ & si & 227 & 158 & 69 & 0 \\
\hline Nov/94 & $-1,85$ & $-0,55$ & $-0,73$ & si & 75 & 159 & -84 & 26 \\
\hline$=$ & $=$ & $=$ & $=$ & 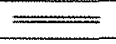 & $\overline{\underline{ }}$ & $=$ & $=$ & $=$ \\
\hline Jun/95 & $-7,35$ & $-2,44$ & $-1,36$ & ss & 16 & 82 & -66 & 24 \\
\hline Jul/95 & $-8,76$ & 1,49 & $-2,29$ & sm & 7 & 115 & -108 & 54 \\
\hline Ago/95 & $-7,83$ & 4,48 & $-2,64$ & $\mathrm{sm}$ & 0 & 162 & -162 & 104 \\
\hline Set/95 & $-2,28$ & 5,63 & $-1,88$ & ss & 31 & 107 & -76 & 76 \\
\hline Out/95 & 0,58 & 3,17 & $-0,95$ & si & 123 & 102 & 21 & 0 \\
\hline Nov/95 & 0,14 & 0,19 & $-0,51$ & si & 118 & 111 & 6 & 7 \\
\hline
\end{tabular}




\section{ANEXO B}

B1. Resumo de todas as secas ocorridas na região Oeste do Estado de São Paulo

\begin{tabular}{|c|c|c|c|}
\hline \multicolumn{4}{|c|}{ AURIFLAMA/SP } \\
\hline DURAÇÃ O & INÍCIO & FIM & ÚLTMMO MÊS SECO \\
\hline 5 meses & Mai/75 & Out/75 & Set/75 \\
\hline 5 meses & Fev/79 & $\mathrm{Jul} / 79$ & Jun/79 \\
\hline 7 meses & $\mathrm{Jan} / 82$ & $\operatorname{Jan} / 83$ & Dez/82 \\
\hline 4 meses & Dez/92 & $\mathrm{Abr} / 93$ & $\mathrm{Mar} / 93$ \\
\hline 9 meses & Fev/94 & Nov/94 & Out/94 \\
\hline 6 meses & $\mathrm{Mar} / 95$ & Set/95 & Ago/95 \\
\hline \multicolumn{4}{|c|}{ MAJOR PRADO - ARAÇATUBA/SP } \\
\hline DURAÇĀO & INICIO & FIM & ÚLTIMO MẾS SECO \\
\hline 8 meses & Fev/75 & Out/75 & Set $/ 75$ \\
\hline 7 meses & Fev/77 & Set/77 & Ago/77 \\
\hline 6 meses & $\operatorname{Jan} / 79$ & $\mathrm{Jul} / 79$ & Jun $/ 79$ \\
\hline 5 meses & Ago/85 & $\mathrm{Jan} / 86$ & Dez/85 \\
\hline 4 meses & $\operatorname{Jan} / 92$ & Mai/92 & $\mathrm{Abr} / 92$ \\
\hline 7 meses & Mai/94 & Dez/94 & Nov/94 \\
\hline 8 meses & $\operatorname{Jan} / 96$ & Set/96 & Ago/96 \\
\hline \multicolumn{4}{|c|}{ ÁGUA LIMPA - ARAÇATUBA/SP } \\
\hline DURAÇÃO & INÍCIO & FIM & ÚLTIMO MÊS SECO \\
\hline 5 meses & Mai/75 & Out/75 & Set/75 \\
\hline 7 meses & $\operatorname{Jan} / 79$ & Ago/79 & $\mathrm{Jul} / 79$ \\
\hline 4 meses & $\mathrm{Jan} / 92$ & Mai/92 & $\mathrm{Abr} / 92$ \\
\hline 8 meses & $\operatorname{Jan} / 96$ & Set/96 & Ago/96 \\
\hline \multicolumn{4}{|c|}{ ALFREDO MARCONDES/SP } \\
\hline DURAÇĀO & INÍCIO & FIM & ÚLTIMO MÊS SECO \\
\hline 5 meses & Jun/61 & Nov/61 & Out/61 \\
\hline 7 meses & Mai/63 & Dez/63 & Nov/63 \\
\hline 7 meses & $\mathrm{Abr} / 67$ & Nov/67 & Out/67 \\
\hline 7 meses & Mar/68 & Out/68 & Set/68 \\
\hline 5 meses & Mai/75 & Out/75 & Set/75 \\
\hline 8 meses & $\operatorname{Jun} / 85$ & Fev/86 & $\operatorname{Jan} / 86$ \\
\hline \multicolumn{4}{|c|}{ ADAMANTINA/SP } \\
\hline DURAÇÃO & INICIO & FIM & ÚLTIMO MẾS SECO \\
\hline 9 meses & Fev/61 & Nov/61 & Out $/ 61$ \\
\hline 10 meses & $\operatorname{Jan} / 63$ & Nov/63 & Out/63 \\
\hline 9 meses & Fev/64 & Nov/64 & Out/64 \\
\hline 5 meses & Fev/65 & $\mathrm{Jul} / 65$ & Jun/65 \\
\hline 6 meses & Jun/66 & Dez/66 & Nov/66 \\
\hline 6 meses & $\mathrm{Abr} / 68$ & Out $/ 68$ & Set/68 \\
\hline 4 meses & Fev/71 & Jun/71 & Mai/71 \\
\hline 8 meses & Fev/73 & Out $/ 73$ & Set $/ 73$ \\
\hline 5 meses & $\operatorname{Jan} / 77$ & Jun/77 & Mai/77 \\
\hline 4 meses & $\mathrm{Jul} / 77$ & Nov/77 & Out/77 \\
\hline 4 meses & $\operatorname{Jan} / 78$ & Mai/78 & $\mathrm{Abr} / 78$ \\
\hline 8 meses & $\operatorname{Jan} / 79$ & Set/79 & Ago/79 \\
\hline 5 meses & $\operatorname{Jan} / 80$ & Jun/80 & $\mathrm{Mai} / 80$ \\
\hline 10 meses & $\operatorname{Jan} / 82$ & Nov/82 & Out/82 \\
\hline 10 meses & $\mathrm{Fev} / 84$ & Dez/84 & Nov/84 \\
\hline 7 meses & Jun/85 & $\operatorname{Jan} / 86$ & $\mathrm{Dez} / 85$ \\
\hline 10 meses & $\operatorname{Jan} / 87$ & Nov/87 & Out/87 \\
\hline 11 meses & Fev/88 & $\operatorname{Jan} / 89$ & $\mathrm{Dez} / 88$ \\
\hline
\end{tabular}


Continuação:

B1. Resumo de todas as secas ocorridas na região Oeste do Estado de São Paulo

\begin{tabular}{|c|c|c|c|}
\hline 4 meses & $\operatorname{Jan} / 90$ & Mai/90 & $\mathrm{Abr} / 90$ \\
\hline 10 meses & Jan/91 & Nov/91 & Out/91 \\
\hline 4 meses & $\operatorname{Jan} / 92$ & Mai/92 & $\mathrm{Abr} / 92$ \\
\hline 9 meses & Fev/93 & Nov/93 & Out/93 \\
\hline 5 meses & Jul/94 & Dez/94 & Nov/94 \\
\hline 9 meses & Fev/95 & Nov/95 & Out/95 \\
\hline 9 meses & Fev/96 & Nov/96 & Out/96 \\
\hline \multicolumn{4}{|c|}{ PONTAL - TEODORO SAMPAIO/SP } \\
\hline DURAÇÃO & INICIO & FIM & ULTTIMO MES SECO \\
\hline 4 meses & $\operatorname{Jan} / 79$ & Mai/79 & $\mathrm{Abr} / 79$ \\
\hline 7 meses & Fev/84 & Set/84 & Ago/84 \\
\hline 6 meses & Nov/85 & Mai/86 & $\mathrm{Abr} / 86$ \\
\hline \multicolumn{4}{|c|}{ PRESIDENTE PRUDENTE/SP } \\
\hline DURAÇĀO & INICIO & FIM & ÚLTIMO MES SECO \\
\hline 7 meses & Jul/61 & Fev/62 & $\operatorname{Jan} / 62$ \\
\hline 9 meses & $\mathrm{Jan} / 64$ & Out/64 & Set/64 \\
\hline 6 meses & $\mathrm{Jul} / 67$ & $\operatorname{Jan} / 68$ & Dez/67 \\
\hline 4 meses & $\operatorname{Jan} / 79$ & $\mathrm{Mai} / 79$ & $\mathrm{Abr} / 79$ \\
\hline 5 meses & Ago/85 & Jan/86 & Dez/86 \\
\hline \multicolumn{4}{|c|}{ SALTO GRANDE/SP } \\
\hline DURACÃO & INICIO & FIM & ÚLTIMO MÊS SECO \\
\hline 8 meses & $\operatorname{Jan} / 84$ & Set/84 & Ago/84 \\
\hline \multicolumn{4}{|c|}{ VOTUPORANGA } \\
\hline DURAÇÃO & INÍCIO & FIM & ÚLTIMO MÊS SECO \\
\hline 5 meses & $\mathrm{Jun} / 73$ & Nov/73 & Out/73 \\
\hline 5 meses & $\mathrm{Jul} / 74$ & $\operatorname{Dez} / 74$ & Nov/74 \\
\hline 6 meses & Mai/75 & Nov/75 & Out/75 \\
\hline 5 meses & Jun/77 & Nov/77 & Out/77 \\
\hline 4 meses & Jun/82 & Out/82 & Set/82 \\
\hline 6 meses & Jun/84 & Dez/84 & Nov/84 \\
\hline 5 meses & $\mathrm{Jul} / 85$ & Dez/85 & Nov/85 \\
\hline 6 meses & Jun/86 & $\mathrm{Dez} / 86$ & Nov/86 \\
\hline 5 meses & Jun/87 & Nov/87 & Out/87 \\
\hline 7 meses & Jun/91 & $\operatorname{Jan} / 92$ & Dez/91 \\
\hline 5 meses & Jun/92 & Nov/92 & Out/92 \\
\hline 7 meses & Mai/94 & $\mathrm{Dez} / 94$ & Nov/94 \\
\hline 6 meses & Jun/95 & $\mathrm{Dez} / 95$ & Nov/95 \\
\hline
\end{tabular}




\section{REFERÊNCIAS BIBLIOGRÁFICAS}

ALLEY, W. M. The Palmer Drought Severity Index: Limitations and Assumptions. Journal of Climate and Applied Meteorology. v. 23, n. 7, p 1100-1109, Jul. 1984.

AMORIM NETO, M. da S. Balanço hídrico segundo Thornthwaite ; Mather (1955). Petrolina: CPATSA, 1989. 18p. (Comunicado Técnico 34)

ASSIS, F. N. Modelagem da ocorrência e da quantidade de chuva e de dias secos em Piracicaba - SP e Pelotas - RS. Piracicaba, 1991. 134 p. Tese (Doutorado) - Escola Superior de Agricultura "Luiz de Queiroz”, Universidade de São Paulo.

ASSIS, F. N.; MARTINS, S. R.; MENDEZ, M. E. G. Índice de severidade da seca de Palmer no Rio Grande do Sul. In: X Congresso Brasileiro de Agrometeorologia, Piracicaba, 1997. Anais. Piracicaba: SBA, 1997. p.383-85.

AYOADE, J. O. Introdução à Climatologia para os Trópicos. Rio de Janeiro: Bertrand Brasil, 1996. 332p.

BARBIERI, V.; TUON, R. L.; ANGELOCCI, L. R. Programa para microcomputador do balanço hídrico (Thornthwaite e Mather, 1955) para dados mensais e decendiais, normais e seqüências. In: Congresso Brasileiro de Agrometeorologia, 7. Resumos. Viçosa: SBA, 1991. p. 297-299. 
BERGAMASCHI, H.; BERLATO, M. A.; MATZENAUER, R.; FONTANA, D. C.; CUNHA, G. R.; SANTOS, M. L. V. dos; FARIAS, J. R. B.; BARNI, N. A. Agrometeorologia aplicada à irrigação. Porto Alegre: Ed. Universidade/UFRGS, 1992. $125 p$.

BERLATO, M. A.; MOLION, L. C. B. Evaporação e evapotranspiração. Porto Alegre: IPAGRO, 1981. 96p. (Boletim Técnico 7)

BHALME, H. N.; MOOLEY, B. Large scale drought/floods and monsoon circulation. Mon. Wea. Rev., v.108, p.1197-1211, 1980.

BOGARDI, I.; MATYASOVSZKY, I.; BARDOSSY, A.; DUCKSTEIN, L. Estimation of local and areal drought reflecting climate change. Transactions of the ASAE, v.37, n.6, p.1771-1781, 1994.

BRAGA Jr., B. P. F.; CONEJO, J. G. L.; PALOS, J. C. F. Balanço Hídrico do Estado de São Paulo. Montevidéu: UNESCO-PHI, ORCYT, 1991, 87p.

BRAGA, H. J. Caracterização de seca agronômica através de novo modelo de balanço hídrico, na região de Laguna, litoral sul do Estado de Santa Catarina. Piracicaba, 1982. 158p. Dissertação (M. S.) - Escola Superior de Agricultura "Luiz de Queiroz"/Universidade de São Paulo.

CAMArgo, A. P. de. Balanço hídrico no Estado de São Paulo. Campinas: IAC, 1960. 15p. (Boletim Técnico 116)

CAMARGO, A. P. de. Contribuição para determinação da evapotranspiração potencial do Estado de São Paulo. Bragantia. v.21 n.12, p.53, 1962. 
CAMARGO, A. P. de; SENTELHAS, P. C. Avaliação do desempenho de diferentes métodos de estimativa da evapotranspiração potencial no Estado de São Paulo. Revista Brasileira de Agrometeorologia, v.5, n.1, p.89-97, 1997.

CHANGNON, S. A. Removing the confusion over droughts and floods: the interface between scientist and policy makers. Water Int., v.5, p.10-18, 1980.

DAEE. Diagnóstico básico do plano de irrigação do Estado de São Paulo: atlas de desenvolvimento. São Paulo, 1973. 38p.

DENMEAD, O. P.; SHAW, R. H. Availability of soil water to plants as affected by soil moisture and meteorological conditions. Agronomy Journal, v. 54, 385-90 p. 1962.

DICKERSON, W. H.; DETHIER, B. E. Drought frequency in the northeastern United States. West Virginia University Agr. Exp. Sta., 1970. 20p. (Bull. 595).

FAO. Yield Response to Water. Irrigation and Dranage. Rome: 1979, n. 33, 193 p.

FARAGO, T.; KOZMA, E.; NEMES, C. Drought indices in meteorology. Idojaras, v. 93, 9-17 p. 1989.

FELCH, R. E. Drought: characteristics and assessment. In: AMER. ASSOC. ADV. SCI. SELECTED SYMP. North American Droughts. Westview Press, v.15, p.25-42, 1978.

FIELDHOUSE, D. J.; PALMER, W. C. Meteorological and Agricultural Drought. Northeast Regional Research Publication. Bulletin, n. 353. 1965. 
HECHT, A. D. Drought in the Great Plains: history of societal response. Journal of Climate and Applied Meteorology. v. 22, p 51-56. 1983.

HEDDINGHAUS, T. R.; SABOL, P. A review of the Palmer Drought Severity Index and where do we go from here? In: Proc. $7^{\text {th }}$ CONF. ON APPLIED CLIMATOLOGY - AMERICAN METEOROLOGICAL SOCIETY, Sep. 10-13, p.242-246, 1991.

KARL, T. R.; QUAYLE, R. G. The 1980 summer heat wave and drought in historical perspective. Mon. Weather Rev., v. 109, p 2055-2072. 1981.

LAWRENCE, E. N. Estimation of the frequency of "runs of dry days". The Meteorological Magazine. v.86, n.1023, p.257-263, Sep. 1957.

LAWSON, M. P.; WEISS, A.; PHILLIPS, R.; LIVINGSTON K. Nebraska droughts: a study of their past chronological and spatial extent with implications for the future. Dep. Geogr. - University of Nebraska, 1971. 147p. Occasional Papers 1.

MARIANO, Z. F.; SANTOS, R. M. N.; SOUSA, S. A. V.; PEREIRA, A. R.; TOMMASELI, J. T. G. Simulação de ocorrência de dias secos na região de Presidente Prudente - SP. In: X CONGRESSO BRASILEIRO DE AGROMETEOROLOGIA, Piracicaba, 1997. Anais. Piracicaba: SBA, 1997. p.113- 115 .

MONTEIRO, C. A. DE F. A dinâmica climática e as chuvas do Estado de São Paulo. Estudo em forma de atlas. São Paulo: USP/IGEO. 1973. 129p. 
MORETTI FILHO, J. Caracterização da seca agronômica na zona canavieira do Estado de São Paulo. Piracicaba, 1965. 94p. Dissertação (M. S.) - Escola Superior de Agricultura "Luiz de Queiroz"/Universidade de São Paulo.

PALMER, W. C. Meteorological Drought. Research Paper, n.45, U. S. Department of Commerce Weather Bureau, Washington, D. C. 1965. 58p.

PEREIRA, A. R.; CAMARGO, A. P. An analysis of the criticism of Thornthwaite's equation for estimating potential evapotranspiration. Agricultural and Forest Meteorology, v. 46, p.149-157, 1989.

PEREIRA, A. R.; VILLA NOVA, N. A.; SEDIYAMA, G. C. Evapo(transpi)ração. Piracicaba: FEALQ, 1997. 183p.

PEREIRA, A. R. As chuvas no planalto paulista. PiraCena, n. 25, p.2, 1997.

PEDRO JÚNIOR, M. J. Estimativa das temperaturas médias mensais das máximas e das mínimas para o Estado de São Paulo. Campinas: IAC, 1991. 11p. (Boletim Técnico 142).

PRADO, H. do. Manual de Classificação de solos do Brasil. Jaboticabal: FUNEP, 1995. $197 \mathrm{p}$.

PRADO, H. do. Os Solos do Estado de São Paulo: Mapas Pedológicos. Piracicaba: H. do Prado, 1997. 205p. 
REICHARDT, K.; ANGELOCCI, L. R.; BACCHI, O. O. S.; PILOTTO, J. E. Daily rainfall variability at a local scale (1,000 ha) in Piracicaba, SP, Brazil and its implications on soil water recharge. In: KEARNEY FOUNDATION OF SOIL SCIENCE INTERNATIONAL CONFERENCE. Vadose zone hydrology: cutting across disciplines. Davis: University of California, 1995. p. 117-118.

REICHARDT, K. Dinâmica da Matéria e da Energia em Ecossistemas. Piracicaba: USP/ESALQ. Departamento. de Física e Meteorologia, 1993, $2^{a}$ edição, 1996. 505 p.

SANT'ANNA NETO, J. L. As chuvas no Estado de SP: contribuição ao estudo da variabilidade e tendência da pluviosidade na perspectiva da análise geográfica. São Paulo, 1995. 286p. Tese (Doutorado) - FFLCH/Departamento de Geografia, Universidade de São Paulo.

SANT'ANNA NETO, J. L. Variabilidade e tendência das chuvas no Oeste Paulista. Boletim Climatológico, v.1, n.1, p.44-56, 1996.

SCHRÖDER, R. Distribuição e curso anual das precipitações no Estado de São Paulo. Bragantia, v.15, n.18, p.193-247, 1956.

SCIAN, B.; DONNARI, M. Aplicacion del indice $Z$ de Palmer para la Comparacion de sequias en las regiones trigueras II, IV y $\mathrm{V}$ sur de Argentina. In: $7^{\mathrm{a}}$ REUNION ARGENTINA Y $1^{\text {a }}$ LATINO-AMERICANA DE AGROMETEOROLOGÍA, Buenos Aires, 1997. Actas. Buenos Aires: Facultad de Agronomía - UBA, 1997.

TARIFA, J. R. Sucessão de tipos de tempo e variação do balanço hídrico no extremo oeste paulista. São Paulo: USP/IGEO, 1973. 71 p. (Série Teses e Monografias, 8). 
THORNTHWAITE, C. W. An Approach toward a rational classification of climate. Geogr. Rev., v.38, p.55-94, 1948.

THORNTHWAITE, C. W. ; MATHER, J. R. The water balance. Publications in Climatology. New Jersey: Drexel Institute of Technology, 104p. 1955.

TUBELIS, A.; NASCIMENTO, F. J. L. Meteorologia descritiva: fundamentos e aplicações brasileiras. São Paulo: Nobel, 1986. 374 p.

VAN BAVEL, C. H. M. A Drought Criterion and its application in evaluating incidence and hazard. Agronomy Journal, v. 45, p.167-172, 1953.

WEISS, N. A.; HASSETT, M. J. Introductory statistics. Arizona: Addison-Wesley Publishing Company, 1982. 651p.

WILHITE, D. A. Government response to drought in the United States: with particular reference to the Great Plains. J. Climate Appl. Meteor., v.22, p.40-50, 1983. 